\title{
Effects of heterogeneous reactions on tropospheric chemistry: a global simulation with the chemistry-climate model CHASER V4.0
}

\author{
Phuc T. M. Ha ${ }^{1}$, Ryoki Matsuda ${ }^{1}$, Yugo Kanaya ${ }^{2}$, Fumikazu Taketani ${ }^{2}$, and Kengo Sudo ${ }^{1,2}$ \\ ${ }^{1}$ Graduate School of Environmental Studies, Nagoya University, Nagoya, 464-8601, Japan \\ ${ }^{2}$ Research Institute for Global Change, JAMSTEC, Yokohama, 236-0001, Japan
}

Correspondence: Phuc T. M. Ha (hathiminh.phuc@gmail.com)

Received: 6 October 2020 - Discussion started: 5 November 2020

Revised: 18 May 2021 - Accepted: 24 May 2021 - Published: 24 June 2021

\begin{abstract}
This study uses a chemistry-climate model CHASER (MIROC) to explore the roles of heterogeneous reactions (HRs) in global tropospheric chemistry. Three distinct $\mathrm{HRs}$ of $\mathrm{N}_{2} \mathrm{O}_{5}, \mathrm{HO}_{2}$, and $\mathrm{RO}_{2}$ are considered for surfaces of aerosols and cloud particles. The model simulation is verified with EANET and EMEP stationary observations; R/V Mirai ship-based data; ATom1 aircraft measurements; satellite observations by OMI, ISCCP, and CALIPSO-GOCCP; and reanalysis data JRA55. The heterogeneous chemistry facilitates improvement of model performance with respect to observations for $\mathrm{NO}_{2}, \mathrm{OH}, \mathrm{CO}$, and $\mathrm{O}_{3}$, especially in the lower troposphere. The calculated effects of heterogeneous reactions cause marked changes in global abundances of $\mathrm{O}_{3}(-2.96 \%), \mathrm{NO}_{x}(-2.19 \%), \mathrm{CO}$ $(+3.28 \%)$, and global mean $\mathrm{CH}_{4}$ lifetime $(+5.91 \%)$. These global effects were contributed mostly by $\mathrm{N}_{2} \mathrm{O}_{5}$ uptake onto aerosols in the middle troposphere. At the surface, $\mathrm{HO}_{2}$ uptake gives the largest contributions, with a particularly significant effect in the North Pacific region $\left(-24 \% \mathrm{O}_{3},+68 \%\right.$ $\mathrm{NO}_{x},+8 \% \mathrm{CO}$, and $\left.-70 \% \mathrm{OH}\right)$, mainly attributable to its uptake onto clouds. The $\mathrm{RO}_{2}$ reaction has a small contribution, but its global mean negative effects on $\mathrm{O}_{3}$ and $\mathrm{CO}$ are not negligible. In general, the uptakes onto ice crystals and cloud droplets that occur mainly by $\mathrm{HO}_{2}$ and $\mathrm{RO}_{2}$ radicals cause smaller global effects than the aerosol-uptake effects by $\mathrm{N}_{2} \mathrm{O}_{5}$ radicals $\left(+1.34 \% \mathrm{CH}_{4}\right.$ lifetime, $+1.71 \% \mathrm{NO}_{x}$, $-0.56 \% \mathrm{O}_{3},+0.63 \% \mathrm{CO}$ abundances). Nonlinear responses of tropospheric $\mathrm{O}_{3}, \mathrm{NO}_{x}$, and $\mathrm{OH}$ to the $\mathrm{N}_{2} \mathrm{O}_{5}$ and $\mathrm{HO}_{2}$ uptakes are found in the same modeling framework of this study $(R>0.93)$. Although all HRs showed negative tendencies for $\mathrm{OH}$ and $\mathrm{O}_{3}$ levels, the effects of $\mathrm{HR}\left(\mathrm{HO}_{2}\right)$ on the tropospheric abundance of $\mathrm{O}_{3}$ showed a small increment with an
\end{abstract}

increasing loss rate. However, this positive tendency turns to reduction at higher rates ( $>5$ times). Our results demonstrate that the HRs affect not only polluted areas but also remote areas such as the mid-latitude sea boundary layer and upper troposphere. Furthermore, $\mathrm{HR}\left(\mathrm{HO}_{2}\right)$ can bring challenges to pollution reduction efforts because it causes opposite effects between $\mathrm{NO}_{x}$ (increase) and surface $\mathrm{O}_{3}$ (decrease).

\section{Introduction}

Heterogeneous reactions (HRs) on the surfaces of atmospheric aerosols and cloud droplets are regarded as playing crucial roles in atmospheric chemistry. They affect ozone $\left(\mathrm{O}_{3}\right)$ concentrations in various pathways via the cycle of odd hydrogen $\left(\mathrm{HO}_{x}\right)$ and nitrogen oxides $\left(\mathrm{NO}_{x}\right)$ (Jacob, 2000). Tropospheric ozone, an important greenhouse gas, causes damage to human health, crops, and ecosystem productivity (Monks et al., 2015). Although tropospheric $\mathrm{O}_{3}$ was recognized as a critical oxidant species, its global distribution has not been adequately captured to date because of the limited number of observations. Whereas many sites in the heavily polluted regions of eastern Asia show ozone increases since 2000 (Liu and Wang, 2020), many sites in other regions show decreases (Gaudel et al., 2018). Moreover, $\mathrm{O}_{3}$ responds to changes of multiple pollutants such as $\mathrm{NO}_{x}$ and volatile organic compounds (VOCs) in different ways, which challenge the local pollutant control policy. For instance, since the Chinese government released the Air Pollution Prevention and Control Action Plan in 2010 (Zheng et al., 2018), the targets of $\mathrm{SO}_{2}, \mathrm{NO}_{x}$, and particulate matter (PM) decreased drastically, but urban ozone pollution has been worsening (Liu 
and Wang, 2020). Indeed, the $\mathrm{O}_{3}$ responses are controlled by several mechanisms, including heterogeneous effects of $\mathrm{HO}_{2}$ and $\mathrm{N}_{2} \mathrm{O}_{5}$ onto aerosols (Kanaya et al., 2009; Li et al., 2019; Liu and Wang, 2020; Taketani et al., 2012).

Stationary observations and laboratory experiments are important for enhancing the understanding of the tropospheric chemistry of $\mathrm{O}_{3}$ and other essential components $\left(\mathrm{NO}_{x}, \mathrm{HO}_{x}\right)$. However, direct observation of vertical $\mathrm{O}_{3}$ distribution, including upper tropospheric $\mathrm{O}_{3}$, was not available before 1970. It has been deployed only at limited sites across the globe. Global atmospheric modeling is a useful method to reanalyze or forecast the past and future changes in $\mathrm{O}_{3}$ and their effects on human health and the climate. To serve this task, atmospheric models use both laboratory and observational data to help achieve accurate simulations of $\mathrm{O}_{3}$ and its precursors $\left(\mathrm{HO}_{x}, \mathrm{NO}_{x}\right.$, hydrocarbons). To date, many modeling studies have suggested that heterogeneous chemistry be included in a standard model for tropospheric chemistry (Jacob, 2000; Macintyre and Evans, 2010, 2011; de Reus et al., 2005).

One fundamentally important $\mathrm{HR}$ in the troposphere is the uptake of $\mathrm{N}_{2} \mathrm{O}_{5}$ onto aqueous aerosols, known as a removal pathway for $\mathrm{NO}_{x}$ at night (Platt et al., 1984). Actually, $\mathrm{NO}_{x}$ plays crucially important roles in the troposphere because it controls the cycle of $\mathrm{HO}_{x}$ and the production rate of tropospheric $\mathrm{O}_{3}$ (Logan et al., 1981; Riemer et al., 2003). The morning photochemistry can be affected by $\mathrm{NO}_{3}$ and $\mathrm{N}_{2} \mathrm{O}_{5}$, which are important nocturnal oxidants. Since the early 1980s, the role of urban $\mathrm{NO}_{x}$ chemistry in Los Angeles pollution (National Research Council, 1991) has been acknowledged, but the proclamation of nighttime radicals remained sparse. It was only recognized in the past decade that $\mathrm{N}_{2} \mathrm{O}_{5}$ radical chemistry could have a much more perceptible effect stemming from reasons including a refined understanding of heterogeneous processes occurring at night (Brown and Stutz, 2012). The HR of $\mathrm{N}_{2} \mathrm{O}_{5}$ was revealed under different meteorological conditions in the US, Europe, and China (photosmog, high relative humidity (RH), or seasonal variation) for particles of various types: ice, aqueous aerosols with organic-coating, urban aerosols, dust, and soot (Apodaca et al., 2008; Lowe et al., 2015; Qu et al., 2019; Riemer et al., 2003, 2009; Wang et al., 2018, 2017; Xia et al., 2019). The uptake of $\mathrm{N}_{2} \mathrm{O}_{5}$ can markedly enhance nitrate concentration in nocturnal chemistry or $\mathrm{PM}_{2.5}$ explosive growth events in summer, decrease $\mathrm{NO}_{x}$, and either increase or decrease $\mathrm{O}_{3}$ concentrations in different $\mathrm{NO}_{x}$ conditions (Dentener and Crutzen, 1993; Qu et al., 2019; Riemer et al., 2003; Wang et al., 2017). Even during daytime, $\mathrm{N}_{2} \mathrm{O}_{5}$ in the marine boundary layers can enhance the $\mathrm{NO}_{x}$ to $\mathrm{HNO}_{3}$ conversion, and chemical destruction of $\mathrm{O}_{3}$ (Osthoff et al., 2006). A 10-20 ppbv reduction of $\mathrm{O}_{3}$ because of $\mathrm{N}_{2} \mathrm{O}_{5}$ uptake in the polluted regions of China has also been reported (Li et al., 2018). At mid- to high latitudes, $\mathrm{N}_{2} \mathrm{O}_{5}$ uptakes on sulfate aerosols could engender $80 \%$ and $10 \% \mathrm{NO}_{x}$ reduction, respectively, in winter and summer, leading to an ap- proximate $10 \%$ reduction of $\mathrm{O}_{3}$ in both seasons ( $\mathrm{Li}$ et al., 2018).

Another vital process taking place on particles is the HRs of peroxy radicals $\left(\mathrm{HO}_{2}\right.$ and $\left.\mathrm{RO}_{2}\right)$. Peroxy radicals are the primary chain carriers driving $\mathrm{O}_{3}$ production in the troposphere. Moreover, it can drive the hydrocarbon and $\mathrm{NO}_{x}$ concentrations, which are important for nocturnal radical chemistry (Geyer et al., 2003; Richard, 2000; Salisbury et al., 2001). In the past, the $\mathrm{HR}\left(\mathrm{HO}_{2}\right)$ effects have been well considered in the laboratory (Macintyre and Evans, 2011) and field observations (Kanaya et al., 2001, 2002a, b, 2003, 2007; Taketani et al., 2012), but many technical problems (e.g., detecting $\mathrm{HO}_{2}$ ) have created difficulties that challenge its reported importance in the troposphere, as asserted from recent studies (Liao and Seinfeld, 2005; Martin et al., 2003; Tie et al., 2001). More recently, global modeling reports have described that the inclusion of $\mathrm{HO}_{2}$ uptake can affect atmospheric constituents strongly by the increment in tropospheric abundances for carbon monoxide $(\mathrm{CO})$ and other trace gases because of reduced oxidation capacity (Lin et al., 2012; Macintyre and Evans, 2011). The $\mathrm{HO}_{x}$ loss on aerosols can reduce $\mathrm{O}_{3}$ concentrations by up to $33 \%$ in remote areas and up to $10 \%$ in a smog episode (Saathoff et al., 2001; Taketani et al., 2012). The $\mathrm{HO}_{x}$ loss on sea salt, sulfate, and organic carbon in various environments can decrease $\mathrm{HO}_{2}$ levels by $6 \%-13 \%, 10 \%-40 \%$, and $40 \%-70 \%$, respectively (Martin et al., 2003; Taketani et al., 2008, 2009; Tie et al., 2001). For $\mathrm{RO}_{2}$ with a typical representative of $\mathrm{CH}_{3} \mathrm{CO} . \mathrm{O}_{2}$ (peroxyacetyl radical, PA), it plays a big role in the longrange transport of pollution (VOC, $\mathrm{NO}_{x}$ ) (Richard, 2000; Villalta et al., 1996). It can bring $\mathrm{NO}_{x}$ from polluted domains as peroxyacyl nitrates (PAN) to remote regions in the ocean and higher altitudes (Qin et al., 2018; Richard, 2000). The concentrations of $\mathrm{HO}_{2}$ and $\mathrm{RO}_{2}$ at nighttime in the marine boundary layer were measured and confirmed (Geyer et al., 2003; Salisbury et al., 2001). Moreover, some evidence suggests uptake of $\mathrm{HO}_{2}$ and PA on clouds, aqueous aerosols, and other surfaces in high-humidity conditions, although the mechanism is uncertain (Geyer et al., 2003; Jacob, 2000; Kanaya et al., 2002b; Liao and Seinfeld, 2005; Lin et al., 2012; Richard, 2000; Salisbury et al., 2001). The predominance of peroxy uptake to clouds results from the ubiquitous existence and larger SAD maxima of cloud droplets in the atmosphere. Indeed, aqueous-phase chemistry might represent an important sink for $\mathrm{O}_{3}$ (Lelieveld and Crutzen, 1990). In addition, PA loss on aqueous particles can mediate the loss of PAN $\left(\mathrm{CH}_{3} \mathrm{CO} . \mathrm{O}_{2} \mathrm{NO}\right)$ in fog (Villalta et al., 1996). Some modeling studies indicate that $\mathrm{HO}_{x}$ loss (including $\mathrm{HO}_{2}$ loss) on aqueous aerosols reduces $\mathrm{OH}$ by $2 \%$, increases $\mathrm{CO}$ by $7 \%$ and increases $\mathrm{O}_{3}$ by $0.5 \%$ in the annual mean global burden (Huijnen et al., 2014). However, in a coastal environment in the Northern Hemisphere it increases $\mathrm{OH}$ by $15 \%$ and reduces $\mathrm{HO}_{2}$ by $30 \%$ (Sommariva et al., 2006; Thornton et al., 2008). 
Although the contributions of each uptake category to tropospheric chemistry differ and must be considered both separately and as a whole, few studies have provided a global overview of heterogeneous chemistry the comprehensively examines the uptakes of $\mathrm{N}_{2} \mathrm{O}_{5}, \mathrm{HO}_{2}$, and $\mathrm{RO}_{2}$ on widely various particles. For instance, uptakes of both $\mathrm{N}_{2} \mathrm{O}_{5}$ and $\mathrm{HO}_{2}$ tend to reduce $\mathrm{O}_{3}$ in particular environments ( $\mathrm{Li}$ et al., 2018; Saathoff et al., 2001; Taketani et al., 2012), but the $\mathrm{HO}_{2}$ loss on clouds can increase the tropospheric $\mathrm{O}_{3}$ burden (Huijnen et al., 2014). The latter trend is not widely suggested yet because the cloud chemistry is still neglected in many $\mathrm{O}_{3}$ models (Stadtler et al., 2018; Thornton et al., 2008). The predominant effects of $\mathrm{HO}_{2}$ uptake on aerosols compared to the effect by $\mathrm{N}_{2} \mathrm{O}_{5}$ were reported during the summer smog condition (Saathoff et al., 2001) but with lack of confirmation on a global scale. Moreover, the heterogeneous effects of $\mathrm{RO}_{2}$ have been investigated only insufficiently (Jacob, 2000). In this study, we examine these uncertainties using the global model CHASER to perceive the respective and total effects of the $\mathrm{HRs}$ of $\mathrm{N}_{2} \mathrm{O}_{5}, \mathrm{HO}_{2}$, and $\mathrm{RO}_{2}$ on the tropospheric chemistry. For the interface of HRs in the atmosphere, we tentatively consider surfaces of cloud particles and those of aerosols and discuss details of its effects in this study. In the following text, the research method, including model description and configuration, is described in Sect. 2. In Sect. 3.1, our model is verified with available observations including ground stations and ship, aircraft, and satellite measurements, particularly addressing the roles of the HRs. The global effects of $\mathrm{N}_{2} \mathrm{O}_{5}, \mathrm{HO}_{2}$, and $\mathrm{RO}_{2}$ uptake are discussed in Sect. 3.2 to elucidate cloud particles and aerosol effects. Section 3.3 will discuss sensitivities of tropospheric chemistry to the magnitudes of HRs. Section 4 presents a summary and concluding remarks.

\section{Method}

\subsection{Global chemistry model}

The global chemistry model used for this study is CHASER (MIROC-ESM) (Sudo et al., 2002; Sudo and Akimoto, 2007; Watanabe et al., 2011), which considers detailed photochemistry in the troposphere and stratosphere. The chemistry component of the model, based on CHASER-V4.0, calculates the concentrations of 92 chemical species and 262 chemical reactions (58 photolytic, 183 kinetic, and 21 heterogeneous reactions including reactions on polar stratospheric clouds); more details on CHASER can be found in an earlier report of the literature (Morgenstern et al., 2017). Its tropospheric chemistry considers the fundamental chemical cycle of $\mathrm{O}_{x}-\mathrm{NO}_{x}-\mathrm{HO}_{x}-\mathrm{CH}_{4}-\mathrm{CO}$, along with oxidation of nonmethane volatile organic compounds (NMVOCs). Its stratospheric chemistry simulates chlorine and bromine-containing compounds, CFCs, HFCs, carbonyl sulfide (OCS), $\mathrm{NO}_{2}$, and the formation of polar stratospheric clouds (PSCs) and het- erogeneous reactions on PSC surfaces. In the framework of MIROC-Chem, CHASER is coupled with the MIROCAGCM atmospheric general circulation model (version 4; Watanabe et al., 2011). The meteorological fields simulated by MIROC-AGCM were nudged toward the 6-hourly NCEP FNL data (https://rda.ucar.edu/datasets/ds083.2/, last access: 30 October 2018). For this study, the spatial resolution of the model was set as T42 (about $2.8^{\circ} \times 2.8^{\circ}$ grid spacing) in horizontal and L36 (surface to approx. $50 \mathrm{~km}$ ) in vertical. Anthropogenic emissions for $\mathrm{O}_{3}$ and aerosol precursors like $\mathrm{NO}_{x}, \mathrm{CO}, \mathrm{VOCs}$, and $\mathrm{SO}_{2}$ are specified using the HTAPII inventory (Janssens-Maenhout et al., 2015), with biomass burning emissions derived from the MACC reanalysis system (Inness et al., 2013).

In the model, the aerosol concentrations for black carbon (BC) / organic carbon (OC), sea salt, and soil dust are handled by the SPRINTAR module, which is also based on the CCSR/NIES AGCM (Takemura et al., 2000). The bulk thermodynamics for aerosols are applied, including $\mathrm{SO}_{4}^{2-}$ chemistry $\left(\mathrm{SO}_{2}\right.$ oxidation with $\mathrm{OH}, \mathrm{O}_{3} / \mathrm{H}_{2} \mathrm{O}_{2}$, which is cloud-pH dependent) $\mathrm{SO}_{4}^{2-}-\mathrm{NO}_{3}^{-}-\mathrm{NH}_{4}^{+}$and $\mathrm{SO}_{4}^{2-}$-dust interaction.

\subsection{Heterogeneous reactions in the chemistry-climate model (CHASER)}

The CHASER-V4 model considers HRs in both the troposphere and stratosphere. In this work, we particularly examine HRs in the troposphere. In the current version of CHASER, tropospheric HRs are considered for $\mathrm{N}_{2} \mathrm{O}_{5}, \mathrm{HO}_{2}$, and $\mathrm{RO}_{2}$, using uptake coefficients for the distinct surfaces of aerosols (sulfate, sea salt, dust, and organic carbons) and cloud particles (liquid/ice) as listed in Table 2. Although some other views incorporate the catalysis of transition metal ions (TMIs) $\mathrm{Cu}(\mathrm{I}) / \mathrm{Cu}$ (II) and $\mathrm{Fe}(\mathrm{II}) / \mathrm{Fe}(\mathrm{III})$ for the $\mathrm{HO}_{2}$ conversion on aqueous aerosols (Li et al., 2018; Mao et al., 2013; Taketani et al., 2012), this mechanism remains uncertain (Jacob, 2000). The TMI mechanism might lead to either $\mathrm{H}_{2} \mathrm{O}_{2}$ (Jacob, 2000) or $\mathrm{H}_{2} \mathrm{O}$ products (Mao et al., 2013). However, this may not cause any significant difference, since recycling $\mathrm{HO}_{2}$ from $\mathrm{H}_{2} \mathrm{O}_{2}$ is ineffective ( $\mathrm{Li}$ et al., 2018). For this study, the uptake of $\mathrm{HO}_{2}$ is affirmed with $\mathrm{H}_{2} \mathrm{O}_{2}$ as the product (Loukhovitskaya et al., 2009; Taketani et al., 2009), as it is generally used in many atmospheric models such that this is not counted as a terminal sink for $\mathrm{HO}_{2}$ (Jacob, 2000; Lelieveld and Crutzen, 1990; Morita et al., 2004; Thornton et al., 2008). The $\mathrm{RO}_{2}$ uptakes are assumed with inert products, as suggested by Jacob (2000). The heterogeneous pseudofirst-order loss rate $\beta$ for the species $i$ is given using the theory of Schwartz (Dentener and Crutzen, 1993; Jacob, 2000; Schwartz, 1986), in which it is simply treated with the mass transfer limitations operating two conductances representing free molecular and continuum regimes for tropospheric clouds and aerosols, in addition to using reactive uptake coefficient $(\gamma)$ instead of the mass accommodation coefficient 
as follows:

$\beta_{i}=\sum_{j}\left(\frac{4}{v_{i} \gamma_{i j}}+\frac{R_{j}}{D_{i j}}\right)^{-1} A_{j}$,

where $v_{i}$ stands for the mean molecular speed $\left(\mathrm{cm} \mathrm{s}^{-1}\right)$ of species $i, D_{i j}$ is the gaseous mass transfer (diffusion) coefficient $\left(\mathrm{cm}^{2} \mathrm{~s}^{-1}\right)$ of species $i$ for particle type $j$, and $A_{j}$ expresses the surface area density $\left(\mathrm{cm}^{2} \mathrm{~cm}^{-3}\right)$ for particle type $j$. In the model, the particle size and effective radius $R_{j}$ for aerosols are calculated as a function of RH (Takemura et al., 2000). The aerosol concentrations are based on SPRINTAR for BC/OC, sea salt, and dust (Takemura et al., 2000). The surface area density (SAD) for aerosols $\left(A_{j}\right)$ is estimated using lognormal distributions of particle size $\left(\mathrm{SF}_{j}\right)$ with mode radii variable with the $\mathrm{RH}$ (Sudo et al., 2002) as follows

$A_{j, \mathrm{ae}}=C_{N} \cdot 4 \pi R_{j}^{2} \cdot \mathrm{SF}_{j}$,

where $C_{N}$ represents number density $\left(\mathrm{cm}^{-3}\right)$ and $R_{j}$ signifies the effective radii $(\mathrm{cm})$ of particle type $j$. To calculate SAD for cloud particles, the liquid water content (LWC) and ice water content (IWC) in the AGCM are converted using the cloud droplet distribution of Battan and Reitan (1957) and the relation between IWC and the surface area density for ice clouds (Lawrence and Crutzen, 1998; McFarquhar and Heymsfield, 1996).

$$
\begin{array}{r}
A_{\mathrm{c}}=10^{-4} \cdot \mathrm{IWC}^{0.9} \\
A_{j, \text { ice }}=3 \cdot A_{\mathrm{c}}
\end{array}
$$

In these equations, $A_{\mathrm{c}}$ represents the cross-section area for ice crystals $\left(\mathrm{cm}^{2} \mathrm{~cm}^{-3}\right)$. For liquid clouds, the following holds:

$A_{j, \mathrm{liq}}=\mathrm{LWC} \times 10^{-6} \cdot \frac{3}{R_{j}}$.

The uptake coefficient parameter $(\gamma)$ is defined as the net probability that a molecule $X$ undergoing a gas-kinetic collision with a surface is actually taken up onto the surface. Although several recent model studies that consider dependency of $\gamma$ on RH and/or T, the majority of the earlier studies use constant $\gamma$ values that only vary with aerosol particle compositions (Chen et al., 2018; Evans and Jacob, 2005; Macintyre and Evans, 2010, 2011). For one study, $\gamma_{\mathrm{HO}_{2}}$ for the uptake onto aqueous aerosols is considered with $\mathrm{pH}$ dependence (Thornton et al., 2008). However, another study demonstrated that the uptake is large, irrespective of the solubility in cloud water or $\mathrm{pH}$ (Morita et al., 2004). Therefore, we instead choose $\gamma_{\mathrm{HO}_{2}}$ as fixed values depending on the type of particle. Indeed, from Eq. (1) it is apparent that uptake coefficients should be unimportant for uptake onto large particles such as cloud droplets. In this study, $\gamma$ for cloud particles of liquid and ice phases are given based on suggestions from earlier reports (Dentener and Crutzen,
1993; Jacob, 2000). One study (Dentener and Crutzen, 1993) used a constant $\gamma \mathrm{N}_{2} \mathrm{O}_{5}$ of 0.1 for uptake on sea salt, sulfate, and cloud particles. They also revealed that a smaller $\gamma \mathrm{N}_{2} \mathrm{O}_{5}$ of 0.01 , which had been reported as laboratory measurements, is insensitive to effects on tropospheric oxidant components. Results of another study (Jacob, 2000) indicated constants $\gamma_{\mathrm{N}_{2} \mathrm{O}_{5}}=0.1$ and $\gamma_{\mathrm{HO}_{2}}=0.2$ for uptakes on both liquid clouds and aerosols, the latter aiming to involve $\mathrm{HO}_{2}$ scavenging by clouds without accounting for details of aqueous-phase chemistry. For ice crystals, Jacob (2000) suggested $\gamma_{\mathrm{HO}_{2}}=0.025$ based on a report by Cooper and $\mathrm{Ab}$ batt (1996). Jacob (2000) recommended using $\gamma_{\mathrm{RO}_{2}}=0.1$ for hydroxy- $\mathrm{RO}_{2}$ group produced by oxidation of unsaturated hydrocarbons and $\gamma_{\mathrm{RO}_{2}}=4 \times 10^{-3}$ for PA. The $\gamma$ values for aerosols are assumed to be fundamentally the same as those for liquid cloud particles in this study. It is noteworthy that the $\gamma$ values for cloud particles are given tentatively in this study and are adjusted based on evaluation of the resulting species concentrations of $\mathrm{O}_{3}, \mathrm{NO}_{y}$, and $\mathrm{OH}$ with the observations.

\subsection{Experiment setup}

In this study, simulations of two types were conducted to isolate the distinct effects of each HR for the surface types considered in the model (Tables 3 and S1). Whereas a control simulation standard (STD) run considers all HRs, cases with no HRs (noHR) cases intentionally ignore one or all of the HRs to calculate effects of individual HRs. The sensitivity runs turned off the separate HRs onto clouds (liquid and ice), and aerosols were also added to exploit the separate aerosol-heterogeneous and cloud-heterogeneous effects, as suggested in many earlier studies (Apodaca et al., 2008; Jacob, 2000; Lelieveld and Crutzen, 1990, 1991; Morita et al., 2004). All simulations were run in the 2009-2017 timeframe, with 2009 being treated as a spin-up year. The HR effects are determined as the differences between noHR cases and an STD simulation as in Eq. (5):

$\operatorname{Impact}(i)_{j}=\frac{\left(\operatorname{STD}_{i}-\operatorname{noHR}(j)_{i}\right)}{\operatorname{noHR}(j)_{i}} \cdot 100(\%)$,

where $\mathrm{STD}_{i}$ stands for the concentration of investigated atmospheric component $i$ in the STD run and $\operatorname{noHR}(j)_{i}$ denotes the concentration of component $i$ in the sensitivity run in which the HRs of/onto $j$ was ignored ( $j$ could be $\mathrm{N}_{2} \mathrm{O}_{5}$, $\mathrm{HO}_{2}, \mathrm{RO}_{2}$, clouds, aerosols).

An additional sensitivity test was run to examine the sensitivity of the troposphere's responses with the amplified HRs magnitudes (Table S1). These simulations only apply for $\mathrm{HR}\left(\mathrm{N}_{2} \mathrm{O}_{5}\right)$ and $\mathrm{HR}\left(\mathrm{HO}_{2}\right)$ to verify some uncertainties that have been argued among earlier studies (Chen et al., 2018; Evans and Jacob, 2005; Macintyre and Evans, 2010, 2011). 
Table 1. Computation packages in the chemistry-climate model CHASER.

\begin{tabular}{|c|c|}
\hline Base model & MIROC4.5 AGCM \\
\hline Spatial resolution & $\begin{array}{l}\text { Horizontal, T42 }\left(2.8^{\circ} \times 2.8^{\circ}\right) \text {; vertical, } 36 \text { layers (surfaces ap- } \\
\text { prox. } 50 \mathrm{~km})\end{array}$ \\
\hline Meteorology $(u, v, T)$ & Nudged to the NCEP2 FNL reanalysis \\
\hline Emission (anthropogenic, natural) & $\begin{array}{l}\text { Industry traffic, vegetation, ocean, } \\
\text { Biomass burning specified by MACC reanalysis }\end{array}$ \\
\hline Aerosol & $\begin{array}{l}\mathrm{BC} / \mathrm{OC} \text {, sea-salt, and dust } \\
\mathrm{BC} \text { aging with } \mathrm{SO}_{x} / \text { secondary organic aerosol (SOA) production }\end{array}$ \\
\hline Chemical process & $\begin{array}{l}94 \text { chemical species, } 263 \text { chemical reactions (gas phase, liquid phase, } \\
\text { non-uniform) } \\
\mathrm{O}_{x}-\mathrm{NO}_{x}-\mathrm{HO}_{x}-\mathrm{CH}_{4}-\mathrm{CO} \text { chemistry with VOCs } \\
\mathrm{SO}_{2} \text {, dimethyl sulfide (DMS) oxidation (sulfate aerosol simulation) } \\
\mathrm{SO}_{4}-\mathrm{NO}_{3}-\mathrm{NH}_{4} \text { system and nitrate formation } \\
\text { Formation of } \mathrm{SOA} \\
\mathrm{BC} \text { aging } \\
(+) \text { Heterogeneous reactions: } 8 \text { reactions of } \mathrm{N}_{2} \mathrm{O}_{5}, \mathrm{HO}_{2}, \mathrm{RO}_{2} \text {; constant } \\
\text { uptake coefficients }(\gamma) \text { on types of aerosols (ice, liquid, sulfate, sea salt, } \\
\text { dust, OC) }\end{array}$ \\
\hline
\end{tabular}

Table 2. Heterogeneous reactions in CHASER.

\begin{tabular}{llrrrrrr}
\hline No & Reactions & $\gamma_{\text {ice }}$ & $\gamma_{\text {liq }}$ & $\gamma_{\text {sulf }}$ & $\gamma_{\text {salt }}$ & $\gamma_{\text {dust }}$ & $\gamma_{\text {oc }}$ \\
\hline$(\mathrm{R} 1)$ & $\mathrm{HO}_{2} \rightarrow 0.5 \mathrm{H}_{2} \mathrm{O}_{2}+0.5 \mathrm{O}_{2}$ & 0.02 & 0.1 & 0.1 & 0.1 & 0.1 & 0.1 \\
$(\mathrm{R} 2)$ & $\mathrm{N}_{2} \mathrm{O}_{5} \rightarrow 2 \mathrm{HNO}_{3}$ & 0.01 & 0.08 & 0.1 & 0.1 & 0.1 & 0.1 \\
\hline $\mathrm{RO}_{2} \rightarrow$ products & & & & & & \\
\hline$(\mathrm{R} 3)$ & $\mathrm{HOC}_{2} \mathrm{H}_{4} \mathrm{O}_{2} \rightarrow$ product & 0.02 & 0.2 & 0.2 & 0.2 & 0.2 & 0.2 \\
$(\mathrm{R} 4)$ & $\mathrm{HOC}_{3} \mathrm{H}_{6} \mathrm{O}_{2} \rightarrow$ product & 0.02 & 0.2 & 0.2 & 0.2 & 0.2 & 0.2 \\
$(\mathrm{R} 5)$ & $\mathrm{ISO}_{2} \rightarrow$ product & 0.01 & 0.1 & 0.1 & 0.1 & 0.1 & 0.1 \\
$(\mathrm{R} 6)$ & $\mathrm{MACRO}_{2} \rightarrow$ product & 0.01 & 0.1 & 0.1 & 0.1 & 0.1 & 0.1 \\
$(\mathrm{R} 7)$ & $\mathrm{CH}_{3} \mathrm{COO}_{2} \rightarrow$ product & 0 & 0.001 & 0.004 & 0.004 & 0.004 & 0.004 \\
\hline
\end{tabular}

References and the details of these adjustments are given in the main text. The $\mathrm{RO}_{2}$ uptakes are assumed with inert products, as suggested by Jacob (2000). $\mathrm{ISO}_{2}$ is denoted for peroxy radicals from $\mathrm{C}_{5} \mathrm{H}_{8}+\mathrm{OH}$, and $\mathrm{MACRO}_{2}$ stands for peroxy radicals from methacrolein $\left(\mathrm{CH}_{2}=\mathrm{C}\left(\mathrm{CH}_{3}\right) \mathrm{CHO}\right)$.

\subsection{Observation data for model evaluation}

Model simulations with and without HRs are evaluated distinctively with stationary, ship-based, aircraft-based, and satellite-based measurements. The observational information, locations of the surface sites, and ship or aircraft tracks for the observations used for this study are summarized in Table 4 and Fig. 1.

EANET is well known as the Acid Deposition Monitoring Network in eastern Asia. The monthly data from 45 stations over 13 countries during 2010-2016 were used to verify surface concentrations of aerosols (sulfate, nitrate) and trace gases $\left(\mathrm{HNO}_{3}, \mathrm{NO}_{x}, \mathrm{O}_{3}\right)$ in eastern Asia. We also used data of the European Monitoring and Evaluation Programme (EMEP), which compiles observations over 245 European stations.
Additionally, we exploited ship-based observational data from R/V Mirai cruise (http://www.godac.jamstec.go.jp/ darwin/e, last access: 30 June 2020) undertaken by the Japan Agency for Marine-Earth Science and Technology (JAMSTEC). This study used data for surface $\mathrm{CO}$ and $\mathrm{O}_{3}$ concentrations in summer 2015-2017 along the JapanAlaska and Japan-Indonesia-Australia routes (Kanaya et al., 2019). The model data were compiled in hourly time steps and were interpolated corresponding with the Mirai time step and coordinates. For verification of the vertical tropospheric profiles, we used Atmospheric Tomography (ATom1) aircraft measurements (https://espo.nasa.gov/atom/content/ ATom, last access: 30 June 2020) for $\mathrm{NO}_{2}, \mathrm{OH}, \mathrm{CO}$, and $\mathrm{O}_{3}$.

The simulated tropospheric ozone was also evaluated using the tropospheric column $\mathrm{O}_{3}$ (TCO) derived from the OMI satellite data (https://daac.gsfc.nasa.gov/, 
Table 3. Main sensitivity simulations for HRs in this work.

\begin{tabular}{|c|c|c|c|c|c|c|}
\hline No. & Simulation ID & $\mathrm{HR}: \mathrm{N}_{2} \mathrm{O}_{5}$ & HR: $\mathrm{HO}_{2}$ & HR: $\mathrm{RO}_{2}$ & HRs on clouds & HRs on aerosols \\
\hline 1 & STD & $x$ & $x$ & $x$ & & \\
\hline 2 & noHR & & & & & \\
\hline 3 & noHR_n2o5 & & $x$ & $x$ & & \\
\hline 4 & noHR_ho2 & $x$ & & $x$ & & \\
\hline 5 & noHR_ro2 & $x$ & $x$ & & & \\
\hline 6 & noHR(Cld) & & & & & $x$ \\
\hline 7 & $\operatorname{noHR}(\mathrm{Ae})$ & & & & $x$ & \\
\hline
\end{tabular}

last access: 25 February 2020). For distribution of the cloud fraction, satellite data from International Satellite Cloud Climatology Project (ISCCP, https://isccp.giss. nasa.gov/, last access: 12 June 2020), GCM-Oriented CALIPSO Cloud Products (CALIPSO-GOCCP, https:// eosweb.larc.nasa.gov/project/calipso/calipso_table, last access: 12 June 2020), and Japanese 55-year reanalysis (JRA55 - https://doi.org/10.5065/D6HH6H41, Japan Meteorological Agency/Japan, 2013) were used.

Model bias and normalized root-mean-squared error (NRMSE) for each species were calculated as shown below, where $n$ is the number of available data (number of stations $\times$ time step).

bias $=\frac{\sum_{1}^{n} \text { Model }- \text { observation }}{n}$
NRMSE $=\frac{\sqrt{\frac{\sum_{1}^{n}(\text { Model-observation })^{2}}{n}}}{\overline{\text { Observation }}}$

\section{Results and discussion}

\subsection{Model verifications}

\subsubsection{Cloud verification}

For this study, we tentatively consider HRs on the cloud particle surface. Given the great uncertainties related to the reaction coefficient $(\gamma)$ (Macintyre and Evans, 2010, 2011), the cloud distributions must be examined adequately in the model to the greatest extent possible. The model-calculated cloud distributions were verified using satellite observation data ISCCP D2, CALIPSO-GOCCP, and reanalysis data JRA55.

For the entire troposphere, the calculated cloud fraction was generally underestimated against the satellite observations and reanalysis data (Fig. 2, the first row). In the North Pacific region in JJA (Fig. 2, the second row), when the cloud fraction peaked in the region, the model was able to reproduce the satellite observations (ISCCP and CALIPSO). How- ever, for the lower troposphere over the region, the cloud fraction calculated using CHASER in JJA appears to be overestimated (Fig. 2, the fourth row), suggesting that the resulting HR effects would also be exaggerated to some extent.

\subsubsection{Verification with stationary observations}

Verifications with EANET and EMEP stationary observations were conducted to assess the model performance on land domains of eastern Asia and Europe, particularly addressing the roles of the heterogeneous reactions considered for this study.

The mass concentrations of particulate matter $\left(\mathrm{PM}_{2.5}\right)$; sulfate $\left(\mathrm{SO}_{4}^{2-}\right)$; nitrate $\left(\mathrm{NO}_{3}^{-}\right)$; and gaseous $\mathrm{HNO}_{3}, \mathrm{NO}_{x}$, $\mathrm{O}_{3}$, and CO (CO only for EMEP) of 2010-2016 were evaluated (see Figs. S1 to S8 for monthly concentrations and Fig. S9 for correlations). In general, the model can moderately reproduce the $\mathrm{PM}_{2.5}, \mathrm{SO}_{4}^{2-}$, and $\mathrm{NO}_{3}^{-}$aerosol concentrations at these locations $(R=0.3-0.7$, Table 5), although $\mathrm{PM}_{2.5}$ was underestimated, sulfate was overestimated slightly. Nitrate was underestimated for EANET and overestimated for EMEP. It is noteworthy that the model performance for EMEP stations was better than that for EANET. The $\mathrm{PM}_{2.5}$ concentration was better estimated with the inclusion of $\mathrm{N}_{2} \mathrm{O}_{5}$ and $\mathrm{HO}_{2}$ uptakes (bias reduction in Table 5). Figure $3 \mathrm{a}-\mathrm{g}$ present the median values of $\mathrm{NO}_{x}, \mathrm{O}_{3}$, and $\mathrm{CO}$ for grouped stations in the Chinese and South Korean regions (stations in China: Jinyunshan; stations in South Korea: Kanghwa, Imsil, Cheju), remote stations with low $\mathrm{NO}_{x}$ levels of EANET, and all EMEP stations. Figure $3 \mathrm{~h}-\mathrm{n}$ show changes in $\mathrm{NO}_{x}, \mathrm{O}_{3}$, and $\mathrm{CO}$ for these stations. The model's positive bias for $\mathrm{NO}_{3}^{-}$at Kanghwa as a remote area is different from the model underestimates at other EANET stations (e.g., Bangkok, Hanoi, and Hongwen in Fig. S1). These high negative biases for $\mathrm{NO}_{3}^{-}$can be associated with undervaluation for $\mathrm{NO}_{x}$ and can thereby lessen the effects of $\mathrm{N}_{2} \mathrm{O}_{5}$ uptake.

Nitric acid in both regions was overestimated. The correlations, biases, and normalized root-mean-square error (NRMSE) of the model for $\mathrm{SO}_{4}^{2-}, \mathrm{NO}_{3}^{-}$, and $\mathrm{HNO}_{3}$ are in the ranges reported in a multi-model study by Bian et al. (2017) (Table 6). 

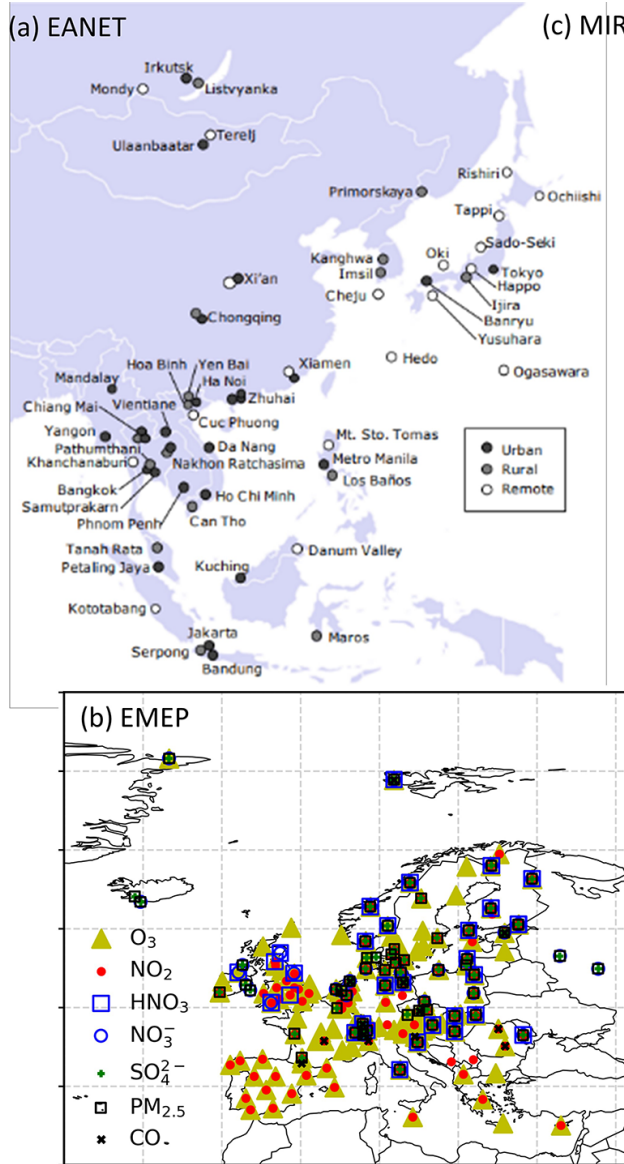

c) MIRAI Tracks $1,4,5,6$

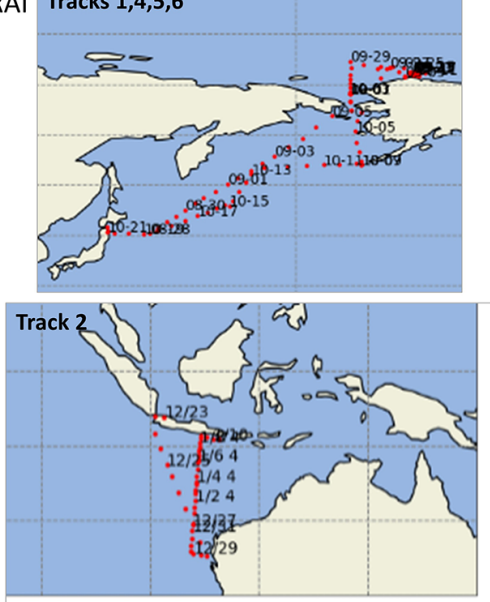

(d) ATom1

Flight

no. Date

1 2016-8-1

2 2016-8-3

3 2016-8-6

4 2016-8-8

5 2016-8-12

6 2016-8-15

7 2016-8-17

8 2016-8-20

9 2016-8-22

10 2016-8-23

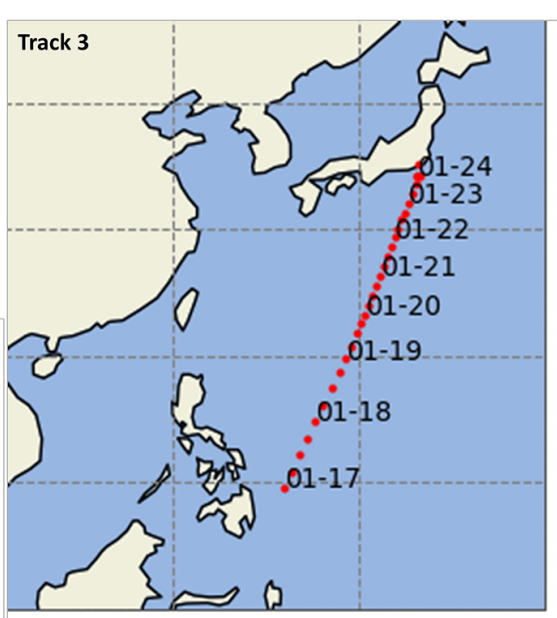

ATom1's pressures

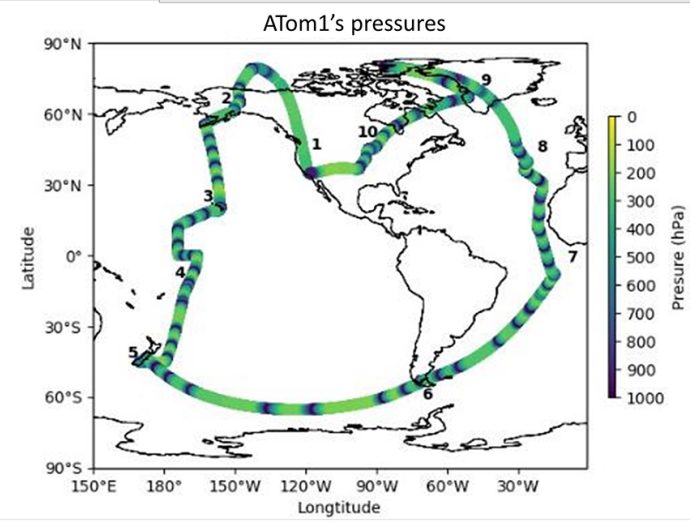

Figure 1. Locations of EANET stations (a), EMEP stations (b), Mirai cruises (c), and ATom1 flights (d). The source for panel (a) is https://monitoring.eanet.asia/document/overview.pdf (last access: 12 June 2020).

Table 4. Datasets used for verification in this study.

\begin{tabular}{|c|c|c|c|c|}
\hline Verified species & Regions & Data & Time series & Time step \\
\hline Sulfate, nitrate, $\mathrm{NO}_{x}, \mathrm{O}_{3}, \mathrm{HNO}_{3}$ & Eastern Asia & EANET & $2010-2016$ & Daily to 2-weekly \\
\hline Sulfate, nitrate, $\mathrm{NO}_{x}, \mathrm{O}_{3}, \mathrm{CO}$ & Europe & EMEP & $2010-2016$ & Hourly \\
\hline \multirow[t]{2}{*}{$\mathrm{CO}, \mathrm{O}_{3}$} & $\begin{array}{l}\text { Surface of the Pacific } \\
\text { Ocean (Australia- } \\
\text { Indonesia-Japan- } \\
\text { Alaska) }\end{array}$ & Mirai & Aug, Sep 2015 & $30 \mathrm{~min}$ \\
\hline & & & $\begin{array}{l}\text { Jan, Aug, Sep } 2016 \\
\text { Jul, Aug, Sep } 2017\end{array}$ & \\
\hline $\mathrm{NO}_{2}, \mathrm{OH}, \mathrm{CO}, \mathrm{O}_{3}$ & $\begin{array}{l}\text { Various altitudes above } \\
\text { the Pacific and Atlantic } \\
\text { oceans }\end{array}$ & ATom1 & Aug 2016 & $30 \mathrm{~min}$ \\
\hline TCO & $60^{\circ} \mathrm{S}-60^{\circ} \mathrm{N}$ (satellite) & OMI & 2010-2016 & Daily \\
\hline Cloud fraction & $\begin{array}{l}\text { Global (satellite) } \\
\text { Global (satellite) } \\
\text { Global (reanalysis) }\end{array}$ & $\begin{array}{l}\text { ISCCP } \\
\text { CALIPSO-GOCCP } \\
\text { JRA55 }\end{array}$ & $\begin{array}{l}2000-2009 \\
2007-2017 \\
2000-2015\end{array}$ & $\begin{array}{l}\text { Monthly } \\
\text { Monthly } \\
\text { 6-hourly }\end{array}$ \\
\hline
\end{tabular}



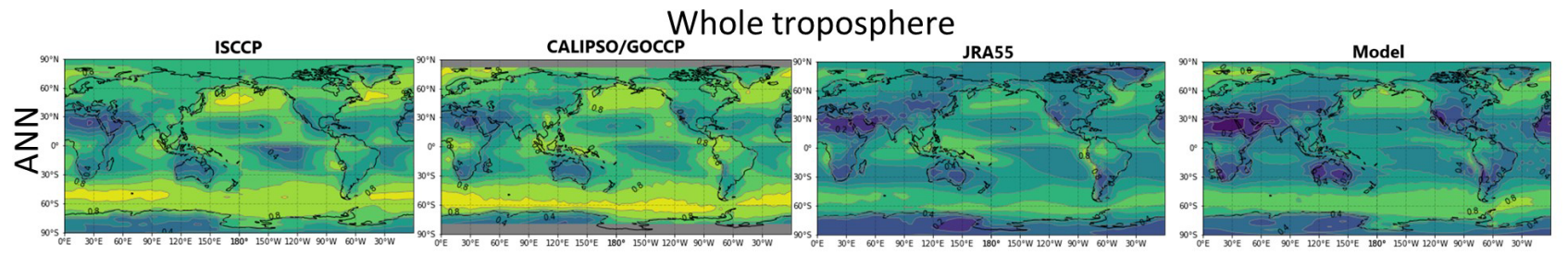

Cloud fraction
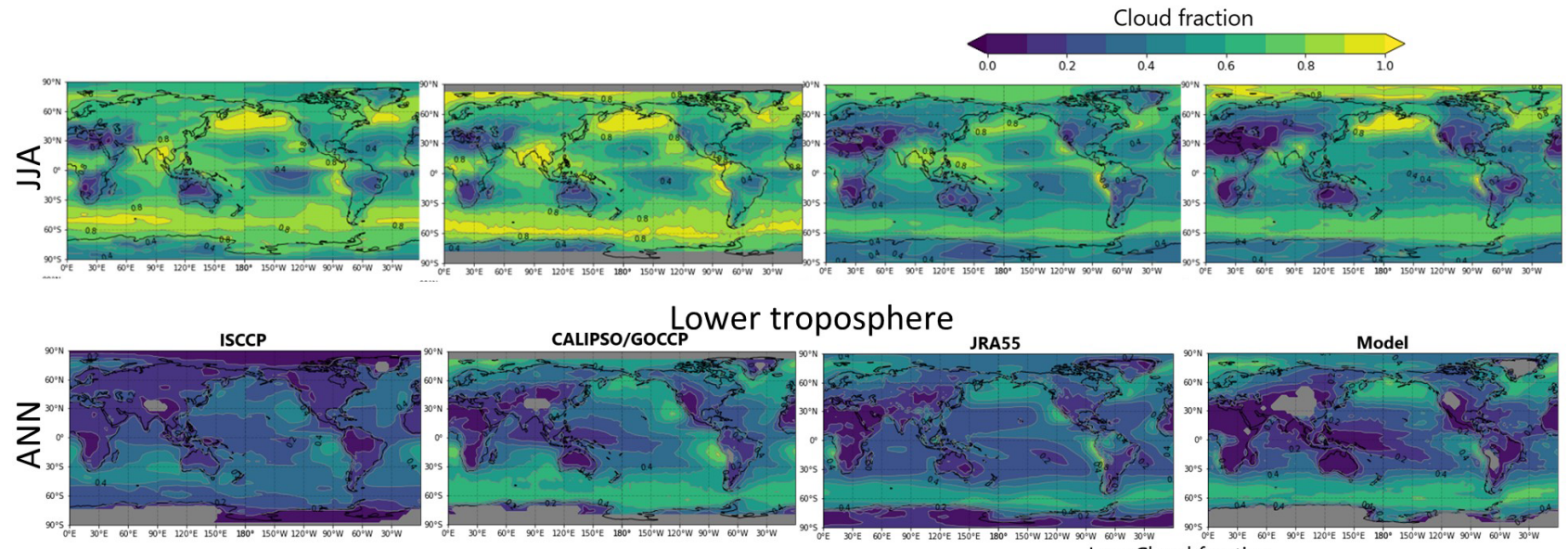

Low Cloud fraction
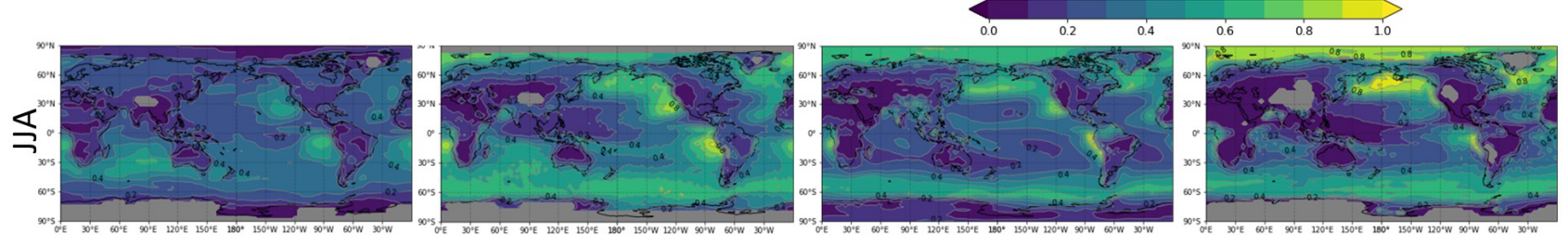

Figure 2. Comparisons for cloud fraction in the whole troposphere (first and second rows) and lower troposphere (third and fourth rows). ANN denotes annual mean, and JJA denotes June + July + August mean. The first column is for ISCCP (2000-2009), the second column is for CALIPSO/GOCCP (2007-2017), and third and fourth columns are for JRA55 and CHASER (2000-2015), respectively. Color bars are the same for all panels. In ISCCP and CALIPSO data, the pressure boundary layer of the low troposphere is $>680 \mathrm{hPa}$. In JRA55, the low troposphere was defined as $850-1100 \mathrm{hPa}$ of pressure.

The $\mathrm{NO}_{x}$ concentration for eastern Asia and Europe was underestimated, with significant bias for polluted Asian locations (Bangkok, Metro Manila, Nai Muaeng, Samutprakarn, Si Phum, Ulaanbaatar, not shown). In Fig. $3 \mathrm{a}$ and c, simulated $\mathrm{NO}_{x}$ levels still underestimated the observed values for Chinese and European regions, at which the observed $\mathrm{NO}_{x}$ could reach 16 and $7 \mathrm{ppb}$, respectively. For the low$\mathrm{NO}_{x}$ EANET region, excluding the abovementioned sites (Fig. 3b), simulated $\mathrm{NO}_{x}$ levels turned to overestimate the observed levels in January, February, September, and October. The increasing effects of $\mathrm{NO}_{x}$ attributable to heterogeneous reactions, although minor, mitigated these underestimations (Fig. 3a-c). Although $\mathrm{NO}_{x}$ was partly reduced via uptake of $\mathrm{N}_{2} \mathrm{O}_{5}$, the $\mathrm{NO}_{x}$ level was mostly increased because of $\mathrm{HO}_{2}$ and $\mathrm{RO}_{2}$ uptakes (Fig. 3h-j).

In this comparison, the low correlations of the model with EANET and EMEP sites for $\mathrm{HNO}_{3}$ and $\mathrm{NO}_{x}$ are still a problem. The high biases for nitrogen species could be ascribed to the low horizontal resolution in this study $\left(\sim 2.8^{\circ}\right)$. Higher resolutions could improve the model reproduction for sur- face $\mathrm{NO}_{x}$ as previously investigated by Sekiya et al. (2018). Moreover, the low reproducibility of the model for $\mathrm{NO}_{x}$ is probably caused by lacking mechanisms that reduce $\mathrm{HNO}_{3}$ and enhance $\mathrm{NO}_{x}$ in our model. One possible mechanism is the heterogeneous reaction of $\mathrm{HNO}_{3}$ on soot surfaces (Reaction R8) (Akimoto et al., 2019, and references therein): $\mathrm{HNO}_{3}+$ soot $\rightarrow \mathrm{NO}+\mathrm{NO}_{2}$ (Reaction R8).

The additional Reaction (R4) followed by $\mathrm{NO}_{2}$ uptakes onto soot (Jacob, 2000), $\mathrm{NO}_{2}+$ particles $\rightarrow 0.5 \mathrm{HONO}+0.5$ $\mathrm{HNO}_{3}$ (Reaction R9), can be expected to increase NO and decrease $\mathrm{O}_{3}$ via the consequent titration reaction. These changes could reduce the model overestimates for $\mathrm{HNO}_{3}$ and $\mathrm{O}_{3}$ and the model underestimates for $\mathrm{NO}_{x}$ with EANET and EMEP stations. Further tests for this issue shall be discussed in a future report.

CO for EMEP was partly underestimated by the model, especially during January-March (Fig. 3g). This underestimate was mitigated by increasing effects because of HRs of $\mathrm{N}_{2} \mathrm{O}_{5}$ and $\mathrm{HO}_{2}$. The uptakes of $\mathrm{RO}_{2}$, in contrast, minorly reduced $\mathrm{CO}$ levels (Fig. 3n) so that the model bias was wors- 
ened slightly. For $\mathrm{O}_{3}$, whereas the model tends to overestimate this tracer for both regions (Fig. 3d-f), $\mathrm{O}_{3}$ reduction effects of all HRs (Fig. 3k-m) alleviated the model overestimates from April to December, although advanced reduction is still needed. In January-March, the model tended to underestimate $\mathrm{O}_{3}$ levels (Fig. 3d-f), which was exaggerated by reduction effects for $\mathrm{O}_{3}$. In general, the STD simulation with coupled HRs partly improved the agreement related to the particulate and gaseous species, showing less bias than that of simulations without HRs (Table 5).

\subsubsection{Verification with ship-based measurements}

The model simulations were also verified with $\mathrm{O}_{3}$ and $\mathrm{CO}$ observations from the Research Vessel (R/V) Mirai for the Pacific Ocean region. This study specifically examines data from the four cruises of R/V Mirai for the Japan-Alaska region $\left(40-75^{\circ} \mathrm{N}, 140^{\circ} \mathrm{E}-150^{\circ} \mathrm{W}\right)$ in summer, designated as MR15-03 leg 1 and leg 2 (28 August-21 October 2015, labeled as Track 1 in this study), MR16-06 (22 August-3 October 2016 as Track 4), MR1704 leg 1 (11 July-2 August 2017 as Track 5), and MR1705C (24 August-29 September 2017 as Track 6). Two other cruises during DJF for the IndonesiaAustralia region $\left(5-25^{\circ} \mathrm{S}, 105-115^{\circ} \mathrm{E}\right)$ and Indonesia-Japan region $\left(10-35^{\circ} \mathrm{N}, 129-140^{\circ} \mathrm{E}\right)$ are also explored in this study, respectively designated as MR15-05 leg 1 (23 December 2015-10 January 2016 as Track 2) and MR15-05 leg 2 (17-24 January 2016 as Track 3). All measuring data for CO and $\mathrm{O}_{3}$ from the six cruises are respectively plotted in Fig. 4a and $b$ as grey dots. The ship-based data used in this study was partly reported (T1-4) in the work of Kanaya et al. (2019), including the extraordinary peak of CO on 26 September 2016 exceeded 500 ppbv (off the scale in Fig. 4a-T4) associated with heavy fires in Russia (Kanaya et al., 2019). Data for the North Pacific region $\left(40-60^{\circ} \mathrm{N}\right)$ are addressed in light-blue shades in Fig. 4 (T1, T4-6) for analysis in Sect. 3.2.

Table 7 shows correlation coefficients (plotted in Fig. S10), indicating that the CHASER simulations for CO and $\mathrm{O}_{3}$ are in good agreement with Mirai observations ( $R=$ approx. 0.6). However, the model still shows some discrepancies for both $\mathrm{CO}$ and $\mathrm{O}_{3}$ concentrations. In general, the estimated $\mathrm{CO}$ and $\mathrm{O}_{3}$ are both reduced for $\mathrm{T} 1$ and $\mathrm{T} 4-6$ as compared to observations, whereas they are superior for the data located in $20^{\circ} \mathrm{S}-20^{\circ} \mathrm{N}$ during $\mathrm{T} 2-3$. Overestimations for $\mathrm{CO}$ and $\mathrm{O}_{3}$ occurring in the region with considerably low levels of these species might be attributed to the lack of halogen chemistry in the model, as also discussed for the nearby region in a past report (Kanaya et al., 2019). Underestimates for $\mathrm{O}_{3}$ levels up to $70 \mathrm{ppbv}$ in the higher latitudes (Fig. 4b: $\mathrm{T} 1, \mathrm{~T} 4-6)$ are ascribable to the insufficient downward mixing process of stratosphere $\mathrm{O}_{3}$ in the model (Kanaya et al., 2019). Except for the CO's peak on 26 September 2016 mentioned above, the mild reductions for $\mathrm{CO}(<30 \mathrm{ppbv})$ in the model during T1 and T4-6 as compared to the observations could be attributed to the insufficient emission from territories, in-

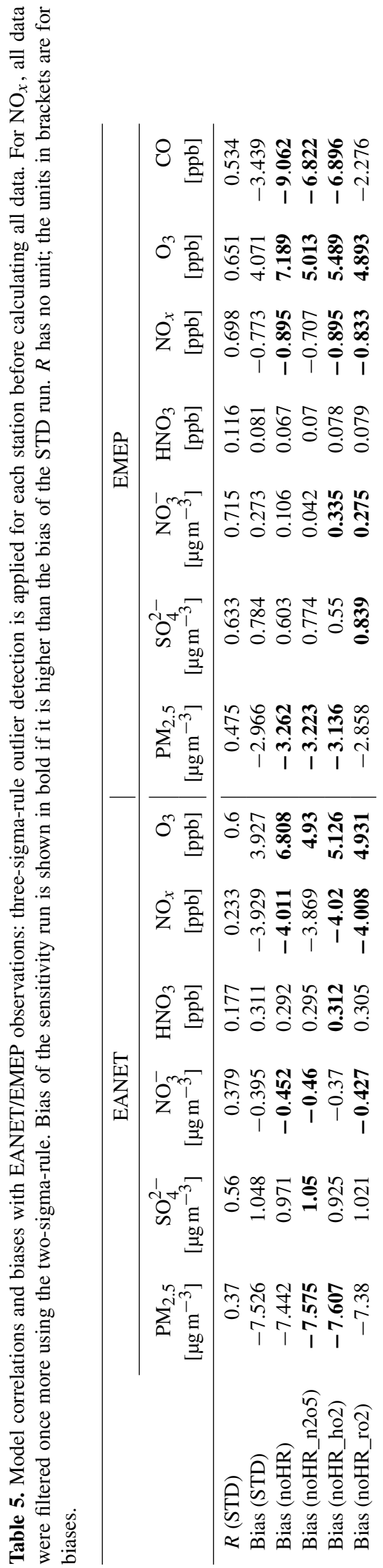

Geosci. Model Dev., 14, 3813-3841, 2021 

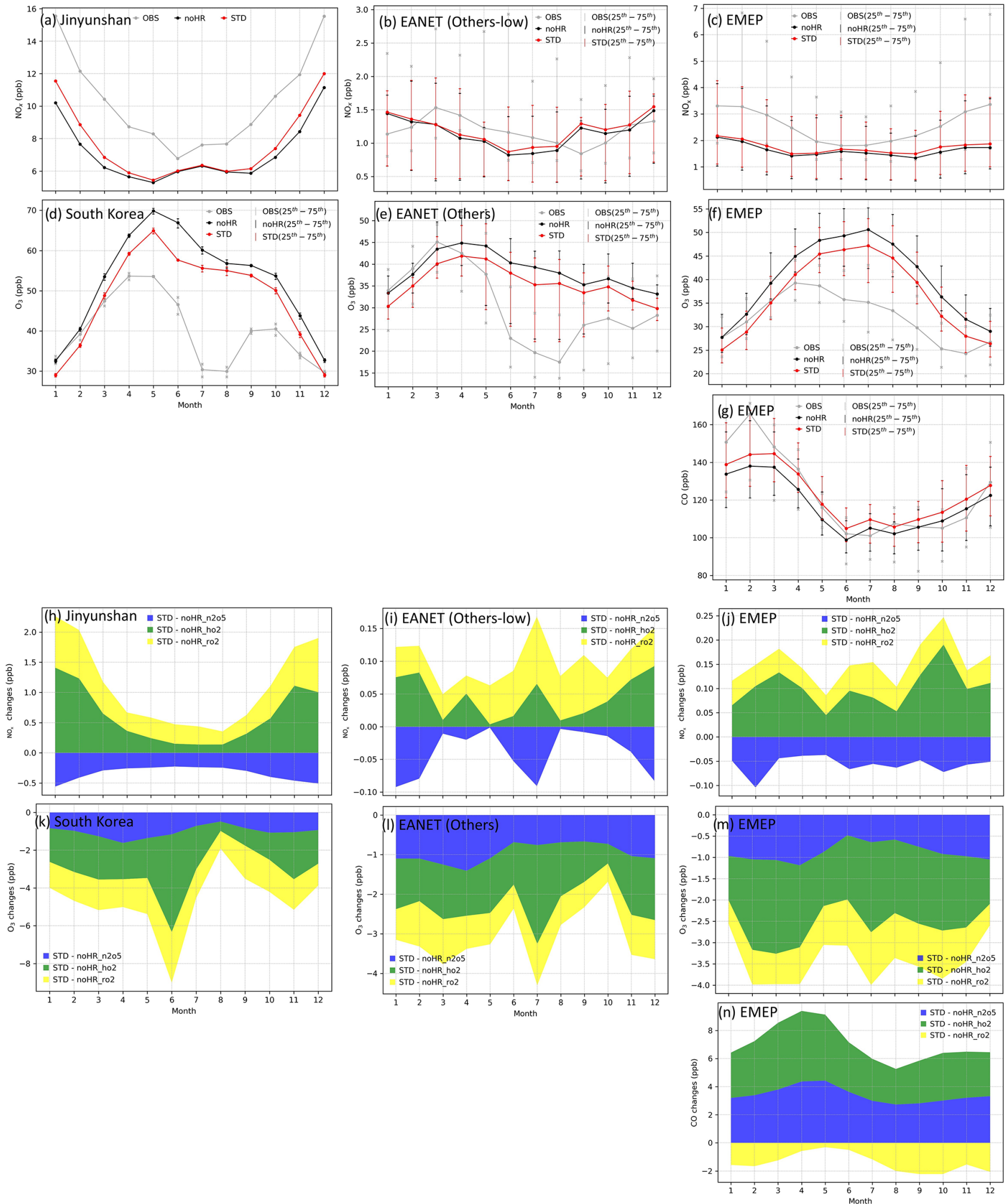

Figure 3. Monthly averaged concentrations at EANET and EMEP from 2010-2016 (a-g) and corresponding $\mathrm{HR}_{\text {effects }}(\mathbf{h}-\mathbf{n})$ for $\mathrm{NO}_{x}$ : (a, h) Jinyunshan (China), (b, i) other low-NO ${ }_{x}$ EANET stations, and (c, j) EMEP stations; for $\mathrm{O}_{3}$ : (d, k) Korean stations, (e, l) other EANET stations, and (f, m) EMEP stations; for CO: $(\mathbf{g}, \mathbf{n})$ EMEP stations. In (a)-(g), grey lines are observations (OBS), red lines are the STD simulation, and black lines are the noHR simulation. All lines showed the median of monthly mean concentrations for each group of stations, except (a). In (b)-(g), vertical thin lines with markers show the 25th-75th percentiles of monthly mean concentration at the particular group of stations. In (h)-(n), blue fields are changes caused by $\mathrm{HR}\left(\mathrm{N}_{2} \mathrm{O}_{5}\right)$, green fields are changes in $\mathrm{HR}\left(\mathrm{HO}_{2}\right)$, and yellow fields are changes caused by $\mathrm{HR}\left(\mathrm{RO}_{2}\right)$. 
Table 6. Comparisons between EANET and EMEP observations with atmospheric models. Outlier detection follows that in Table 5. The model result is shown in bold if it is better than or agreed with Bian's report. $R$ has no unit; units in brackets are for biases and NRMSE.

\begin{tabular}{llll}
\hline EANET & $\mathrm{SO}_{4}\left[\mu \mathrm{g} \mathrm{m}^{-3}\right]$ & $\mathrm{NO}_{3}\left[\mu \mathrm{g} \mathrm{m}^{-3}\right]$ & $\mathrm{HNO}_{3}[\mathrm{ppb}]$ \\
\hline This study & $R=\mathbf{0 . 5 6}$ & $R=\mathbf{0 . 3 7 9}$ & $R=\mathbf{0 . 1 7 7}$ \\
& bias $=\mathbf{1 . 0 4 8}$ & bias $=\mathbf{- 0 . 3 9 5}$ & bias $=\mathbf{0 . 3 1 1}$ \\
& $\mathrm{NRMSE}=\mathbf{0 . 9 5 4}$ & $\mathrm{NRMSE}=\mathbf{1 . 5 8}$ & $\mathrm{NRMSE}=\mathbf{2 . 4 9 1}$ \\
Bian et al. (2017) & $R=0.449-0.640$ & $R=0.226-0.448$ & $R=0.098-0.370$ \\
& bias $=0.358-1.353$ & bias $=0.338-1.920$ & bias $=0.347-3.596$ \\
& $\mathrm{NRMSE}=0.840-0.968$ & $\mathrm{NRMSE}=1.494-2.080$ & $\mathrm{NRMSE}=0.980-2.880$ \\
\hline \multirow{2}{*}{ EMEP } & $\mathrm{SO}_{4}\left[\mu \mathrm{g} \mathrm{m}^{-3}\right]$ & $\mathrm{NO}_{3}\left[\mu \mathrm{g} \mathrm{m}^{-3}\right]$ & $\mathrm{HNO}_{3}\left[\mu \mathrm{g} \mathrm{m}^{-3}\right]$ \\
\hline \multirow{2}{*}{ This study } & $R=\mathbf{0 . 6 3 3}$ & $R=\mathbf{0 . 7 1 5}$ & $R=0.116$ \\
& bias $=\mathbf{0 . 7 8 4}$ & bias $=\mathbf{0 . 2 7 3}$ & bias $=\mathbf{0 . 8 8 6}$ \\
\multirow{3}{*}{ Bian et al. (2017) } & $\mathrm{NRMSE}=0.961$ & $\mathrm{NRMSE}=\mathbf{0 . 9 1}$ & $\mathrm{NRMSE}=3.33$ \\
& $R=0.230-0.463$ & $R=0.393-0.585$ & $R=0.157-0.502$ \\
& bias $=0.452-1.699$ & bias $=0.539-1.421$ & bias $=0.570-3.836$ \\
& $\mathrm{NRMSE}=0.514-0.818$ & $\mathrm{NRMSE}=0.745-1.031$ & $\mathrm{NRMSE}=0.908-2.542$
\end{tabular}

ternational shipping, and aviation, as we used the HTAP-II emission inventory. These reductions for $\mathrm{CO}$ in Kanaya's work are minor, e.g., for T1 (MR15-03 leg 1 and 2 in their work), due to reanalysis data with finer horizontal resolution $\left(1.1^{\circ}\right)$ utilized for the $\mathrm{CO}$ emission rate (Kanaya et al., 2019).

The negative biases in the noHR simulations for $\mathrm{CO}$ are lower in the STD run for all cruises, as they are for the North Pacific region (second versus third/fourth/fifth data rows for $\mathrm{CO}$, Table 7). The CO-increasing effects by $\mathrm{N}_{2} \mathrm{O}_{5}$ and $\mathrm{HO}_{2}$ uptakes (Fig. 4c) are consistent with the comparison for EMEP. This is also true for CO-reduction effects because of $\mathrm{HR}\left(\mathrm{RO}_{2}\right)$. Whereas the effects by $\mathrm{N}_{2} \mathrm{O}_{5}$ and $\mathrm{HO}_{2}$ reduce the model bias, the CO-reducing effects by $\mathrm{HR}\left(\mathrm{RO}_{2}\right)$ exaggerated the $\mathrm{CO}$ bias (second versus sixth data rows for $\mathrm{CO}$ in Table 7), which is already apparent for comparison with EMEP (last column, Table 5).

For $\mathrm{O}_{3}$ level, the model underestimates (Table 7) are in the opposite direction to the $\mathrm{O}_{3}$ overestimates for EANET and EMEP stations (Table 5). The lower panels presented in Fig. 4b show marked $\mathrm{O}_{3}$ reduction with all HRs (gaps between red and black lines), mostly contributed from the $\mathrm{HO}_{2}$ uptake onto cloud particles (Fig. 4d: green and hatched fields). This marked reduction of the $\mathrm{O}_{3}$ level is evident at some points during the cruises, especially in the North Pacific region (the shaded areas) and for T5. Unlike comparisons for land domain data (Table 5), $\mathrm{O}_{3}$ reduction because of HRs worsens the model underestimates during the Mirai cruises. It is noteworthy that one cannot necessarily confirm whether the STD run simulates these species better than the noHR does because tropospheric $\mathrm{CO}$ and $\mathrm{O}_{3}$ levels are controlled by a complicated chemical mechanism and an interplay of emission, transport, deposition, and local mixing in the boundary layers. As discussed later in Sect. 3.2, the surface aerosols concentration in the western Pacific Ocean is mostly dominated by liquid clouds (exceed- ing $50000 \mu \mathrm{m}^{2} \mathrm{~cm}^{-3}$ during JJA) and sulfate aerosols (approximately $75 \mu^{2} \mathrm{~cm}^{-3}$ in JJA). The model improvements in reproducing $\mathrm{CO}$ by adding $\mathrm{N}_{2} \mathrm{O}_{5}$ and $\mathrm{HO}_{2}$ uptake indicate that the appropriate mechanisms of these processes onto cloud droplets and sulfate aerosols are well established in the model. For $\mathrm{HR}\left(\mathrm{RO}_{2}\right)$, which induces the smallest and opposite effects on $\mathrm{CO}$ compared with the effects of $\mathrm{N}_{2} \mathrm{O}_{5}$ and $\mathrm{HO}_{2}$ uptakes, it can be stated in general for the total $\mathrm{HR}$ effects that including all three HRs partially improves the model during Mirai cruises.

\subsubsection{Verification using aircraft measurements}

To verify the model performance in the free troposphere, we used ATom1 aircraft measurements in August 2016 (for $\mathrm{NO}_{2}$, $\mathrm{OH}, \mathrm{CO}$, and $\mathrm{O}_{3}$ ). Table 8 lists the model's correlation coefficients and biases of each sensitivity run against ATom 1 . Figure 5 shows observed and simulated concentrations of $\mathrm{CO}$ and $\mathrm{O}_{3}$ during flight no. 2 in the North Pacific (NP) region. Figure 6 exhibits vertical biases of the model and computed HR effects caused by each HR for all ATom 1 flights and NP region. The spatial and temporal concentrations are available in Fig. S11. Correlations are shown in Fig. S12.

In general, the model simulations for $\mathrm{NO}_{2}, \mathrm{OH}, \mathrm{CO}$, and $\mathrm{O}_{3}$ adequately agree with aircraft measurements with $R>$ 0.5 (Fig. S12). However, $\mathrm{NO}_{2}$ and $\mathrm{CO}$ still tend to be underestimated by the model, which is consistent with comparisons for EANET/EMEP and Mirai observations. In Fig. 5, the CO-increasing effects, mostly due to the uptake of $\mathrm{N}_{2} \mathrm{O}_{5}$ and $\mathrm{HO}_{2}$ (Fig. 6o), mitigated the negative bias of the model. This CO bias reduction was visible for all flight altitudes, the lower troposphere, and the North Pacific region (Table 8; Fig. 6d and h). Both $\mathrm{N}_{2} \mathrm{O}_{5}$ and $\mathrm{HO}_{2}$ uptakes show improvements for $\mathrm{CO}$ reproduction of the model. However, $\mathrm{RO}_{2}$ uptake seems to worsen the model's $\mathrm{CO}$ bias due to its reducing 
Table 7. Model correlations and biases for Mirai. No outlier filtration is applied. The bias of the sensitivity run is shown in bold if it is higher than the bias of STD run. $R$ has no unit; the units in brackets are for biases.

\begin{tabular}{lrrrr}
\hline & $\mathrm{CO}$ [ppbv] & $\mathrm{O}_{3}$ [ppbv] & $\mathrm{CO}\left(40-60^{\circ} \mathrm{N}\right)[\mathrm{ppbv}]$ & $\mathrm{O}_{3}\left(40-60^{\circ} \mathrm{N}\right)[\mathrm{ppbv}]$ \\
\hline$R$ (STD) & 0.689 & 0.617 & 0.58 & 0.665 \\
Bias (STD) & -4.988 & -4.996 & -11.668 & -3.493 \\
Bias (noHR) & $\mathbf{- 1 0 . 3 2 4}$ & -2.388 & $\mathbf{- 1 7 . 6 2 5}$ & 1.211 \\
Bias (noHR_n2o5) & $\mathbf{- 8 . 1 2 7}$ & -4.362 & $\mathbf{- 1 4 . 8 0 4}$ & -2.738 \\
Bias (noHR_ho2) & $\mathbf{- 9 . 0 3 6}$ & -3.358 & $\mathbf{- 1 6 . 3 5 8}$ & -0.226 \\
Bias (noHR_ro2) & -3.433 & -4.431 & -10.035 & -2.526 \\
Bias (noHR(cld)) & $\mathbf{- 6 . 8 2 1}$ & -3.199 & $\mathbf{- 1 4 . 0 0 5}$ & 0.025 \\
\hline
\end{tabular}

effect for $\mathrm{CO}$ (Fig. 6o and s), which is consistent with the $\mathrm{Mi}$ rai comparison.

For the $\mathrm{O}_{3}$ level, the model generally overestimates $\mathrm{O}_{3}$ when calculating for all altitudes or lower troposphere, which is similar to the EANET/EMEP observations. In the North Pacific region with $P>600 \mathrm{hPa}\left(40-60^{\circ} \mathrm{N}, 198-210^{\circ} \mathrm{W}\right)$, the model bias for $\mathrm{O}_{3}$ in STD run turns to underestimate (second data row and second column from the right, Table 8), which might be similar with Mirai data verification for the western North Pacific $\left(143^{\circ} \mathrm{E}-193^{\circ} \mathrm{W}\right)$. However, the underlayers $(>700 \mathrm{hPa}$ ) again show overestimation (second data row - last column, Table 8). As Mirai and ATom1 data show, the underestimates for $\mathrm{O}_{3}$ exist at the marine boundary layer in the western North Pacific and extend to the upper troposphere $(<700 \mathrm{hPa})$ of the east side, which might be ascribed to the insufficient downward mixing process of stratosphere $\mathrm{O}_{3}$ in the model as discussed previously.

The HR effects on $\mathrm{O}_{3}$ are generally negative effects (Fig. 6m), although they are small and barely recognizable in Fig. 5, which mitigates the model bias in the noHR run. This model improvement is consistent for all flight altitudes, the low troposphere, and the North Pacific region (second versus third data rows in Table 8). Both $\mathrm{HR}\left(\mathrm{N}_{2} \mathrm{O}_{5}\right)$ and $\mathrm{HR}\left(\mathrm{RO}_{2}\right)$ typically contribute to this improvement (Fig. $6 \mathrm{~m}$ and q). In contrast, $\mathrm{HR}\left(\mathrm{HO}_{2}\right)$ seems to only reduce the model bias in a thin layer: from the ground up to $800 \mathrm{hPa}$ for all flights and $700 \mathrm{hPa}$ for the North Pacific region (Fig. 6m and q). At the bottommost layers in this region, the model's overestimates for $\mathrm{O}_{3}$ are reduced by the negative effects of $\mathrm{HO}_{2}$ uptake (Fig. $6 \mathrm{f}$ and q). The extension of model bias because of $\mathrm{HO}_{2}$ uptake above $800 \mathrm{hPa}$ is attributable to its increasing effect on $\mathrm{O}_{3}$ level (Fig. 6m). We recognize that this $\mathrm{O}_{3}$ increase effect above $800 \mathrm{hPa}$ is opposite to the effects for EANET/EMEP and Mirai comparisons, which is discussed in Sect. 3.2 for $\mathrm{HO}_{2}$ uptake effects.

The vertical means of model biases and changes for all four species $\left(\mathrm{NO}_{2}, \mathrm{OH}, \mathrm{CO}, \mathrm{O}_{3}\right)$ are presented in Fig. 6 . In general, the STD run reduces model biases for all four species, with better performance for broader regions (all flights) than for the smaller region (North Pacific). In the North Pacific region, the negative bias for $\mathrm{O}_{3}$ is observed only for the 500-900 hPa layers (Fig. 6f). The model bias is apparently extended in this region. However, the inclusion of $\mathrm{HR}\left(\mathrm{HO}_{2}\right)$ leading to $\mathrm{O}_{3}$ increment (Fig. 6f) reduces $\mathrm{O}_{3}$ bias in this region, which might indicate that the $\mathrm{O}_{3}$ increase effect by $\mathrm{HR}\left(\mathrm{HO}_{2}\right)$ is verified, particularly in $500-900 \mathrm{hPa}$ layers during ATom1.

We also verify the total uptake of $\mathrm{N}_{2} \mathrm{O}_{5}, \mathrm{HO}_{2}$, and $\mathrm{RO}_{2}$ onto ice and liquid clouds using data obtained from ATom1 flights within the free troposphere. As Table 8 shows, the inclusion of HRs onto clouds reduces the model biases for $\mathrm{CO}$ and $\mathrm{O}_{3}$ in all calculations. In Fig. 61-s, because the HRs(cloud) effects occupy the major part of total HRs effects for $\mathrm{NO}_{2}, \mathrm{O}_{3}$, and $\mathrm{OH}$, especially for NP region and low troposphere ( $>800 \mathrm{hPa}$ ), cloud uptakes could also contribute to the overall reduction in model bias against ATom1. For $\mathrm{O}_{3}$, HRs(cloud) mostly induce negative effects (Fig. $6 \mathrm{~m}$ and q). At the layer of $600-800 \mathrm{hPa}$ in the NP region, this $\mathrm{O}_{3}$ reduction due to $\mathrm{HR}\left(\mathrm{RO}_{2}\right)$ onto clouds (Fig. 6q: yellow and hatched patterns) might account for the model worsening in $\mathrm{O}_{3}$ levels as described above. This result might prove that cloud overestimation for the North Pacific, as revealed at the beginning of this section, affects the model bias in this region.

\subsubsection{Verification with OMI satellite observation for TCO}

We also tested STD and noHR simulations using the tropospheric column ozone (TCO) derived from the OMI satellite instrument (Figs. S13 and 7). In a large area of the Northern Hemisphere, the inclusion of HRs (STD run) generally improved the consistency with the OMI TCO, as seen in Fig. 7b, d, f with less overestimation than Fig. 7a, c, e, particularly enhancing the winter minima (first and second panels in Fig. S13). This improvement in DJF is attributed mostly to the reductive effects of $\mathrm{HR}\left(\mathrm{N}_{2} \mathrm{O}_{5}\right)$ and $\mathrm{HR}\left(\mathrm{RO}_{2}\right)$ in the lower $(800 \mathrm{hPa})$ and middle troposphere $(500 \mathrm{hPa})$, respectively (see Fig. 10 for vertical profiles of $\mathrm{HR}\left(\mathrm{N}_{2} \mathrm{O}_{5}\right)$ on $\mathrm{O}_{3}$ and Fig. 13 for vertical profiles of $\left.\mathrm{HR}\left(\mathrm{RO}_{2}\right)\right)$. In the North Pacific, HRs appeared to exaggerate $\mathrm{O}_{3}$ underestimates, especially for latitudes higher than $40^{\circ} \mathrm{N}$ (Fig. 7) during the first half of the year (third panel, Fig. S13). However, such a discrepancy, which was also observed from comparison for 

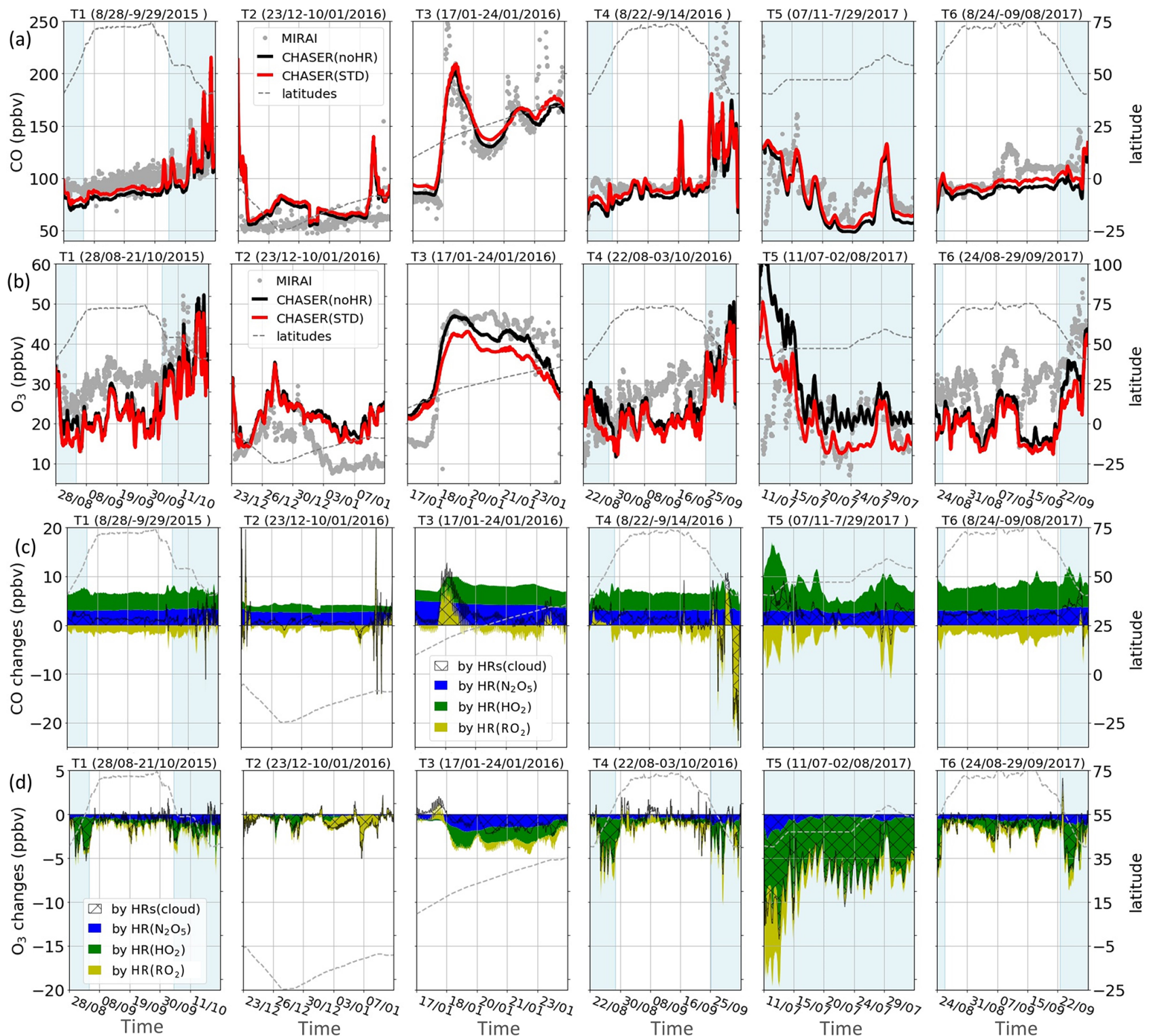

Figure 4. Observed and simulated concentrations for $\mathrm{CO}$ (a) and $\mathrm{O}_{3}$ (b) and their changes caused by each HR (c, d) during Mirai cruises. The left axis shows concentrations. Dashed lines show latitudes of cruises scaled with the right axis. The horizontal axis shows cruise travel times. Light-blue areas show data in the North Pacific region (140-240 ${ }^{\circ}$ E, 40-60 $\left.\mathrm{N}\right)$. In (a) and (b), grey dots are for observations, red lines are for STD simulations, and black lines are for noHR simulations. In (c) and (d), blue fields are for changes in $\mathrm{HR}\left(\mathrm{N}_{2} \mathrm{O}_{5}\right)$, green fields for changes in $\mathrm{HR}\left(\mathrm{HO}_{2}\right)$, yellow fields for changes in $\mathrm{HR}\left(\mathrm{RO}_{2}\right)$, and hatched fields for changes in HRs (cloud). Note that in (d) all three fields are stacked but in (c) only blue and green fields are stacked for better illustration of negative and positive changes.

R/V Mirai observations (Fig. 4), might result from other factors such as deposition or vertical mixing rather than by HRs.

\subsection{HR effects}

This section presents a discussion of the global effects of HRs calculated using CHASER with their spatial distributions in the troposphere using standard (STD) and sensitivity simulations (noHR_n2o5, noHR_ho2, noHRs_ro2, noHR) for the meteorological year of 2011. Aside from the main simulations described in Table 3, additional runs that separately turned off the uptakes onto clouds or aerosols for each HR are also conducted to exploit the contributions of effects to the troposphere.

\subsubsection{Distribution of clouds and aerosols surface area density (SAD)}

To obtain the parameters for uptake to clouds and aerosols, SAD estimations are used together with cloud fraction and 
Table 8. Model correlations and biases with ATom1: three-sigma-rule was applied for $\mathrm{CO}$ and $\mathrm{O}_{3}$. NP denotes North Pacific region (140$240^{\circ} \mathrm{E}, 40-60^{\circ} \mathrm{N}$ ). The bias of the sensitivity run is presented in bold when it is higher than the bias of STD run. $R$ has no unit; the units in brackets are for biases.

\begin{tabular}{lrrrrrrrr}
\hline & $\mathrm{CO}$ & $\mathrm{O}_{3}$ & $\begin{array}{r}\mathrm{CO} \\
(>600 \mathrm{hPa}) \\
{[\mathrm{ppb}]}\end{array}$ & $\begin{array}{r}\mathrm{O}_{3} \\
(>600 \mathrm{hPa}) \\
{[\mathrm{ppb}]}\end{array}$ & $\begin{array}{r}\mathrm{O}_{3} \\
(>800 \mathrm{hPa}) \\
{[\mathrm{ppb}]}\end{array}$ & $\begin{array}{r}\mathrm{CO} \\
(\mathrm{NP},>600 \mathrm{hPa}) \\
{[\mathrm{ppb}]}\end{array}$ & $\begin{array}{r}\mathrm{O}_{3} \\
(\mathrm{NP},>600 \mathrm{hPa}) \\
{[\mathrm{ppb}]}\end{array}$ & $\begin{array}{r}\mathrm{O}_{3} \\
(\mathrm{NP},>700 \mathrm{hPa}) \\
{[\mathrm{ppb}]}\end{array}$ \\
\hline$R$ (STD) & 0.642 & 0.742 & 0.805 & 0.679 & 0.659 & 0.918 & 0.755 & 0.844 \\
Bias (STD) & -4.462 & 15.337 & -9.42 & 2.162 & 1.257 & -16.548 & -0.239 & 2.022 \\
Bias (noHR) & $\mathbf{- 8 . 5 8 1}$ & $\mathbf{1 7 . 3 4 5}$ & $\mathbf{- 1 3 . 5 8 9}$ & $\mathbf{3 . 2 6 6}$ & $\mathbf{2 . 3 6 5}$ & $\mathbf{- 2 1 . 0 2 5}$ & $\mathbf{0 . 9 0 2}$ & $\mathbf{2 . 8 8 4}$ \\
Bias (noHR_n205) & $\mathbf{- 7 . 5 8 3}$ & $\mathbf{1 6 . 6 9 7}$ & $\mathbf{- 1 2 . 4 7 7}$ & $\mathbf{2 . 9 2 5}$ & $\mathbf{1 . 8 2 9}$ & $\mathbf{- 1 9 . 4 4}$ & $\mathbf{0 . 3 2}$ & $\mathbf{2 . 4 4}$ \\
Bias (noHR_ho2) & $\mathbf{- 6 . 1 0 1}$ & 15.127 & $\mathbf{- 1 1 . 2 7 8}$ & 2.095 & $\mathbf{1 . 3 1 2}$ & $\mathbf{- 1 8 . 2 4 7}$ & 0.035 & $\mathbf{2 . 5 2 6}$ \\
Bias (noHR_ro2) & $\mathbf{- 3 . 3 5 9}$ & $\mathbf{1 6 . 4 1 2}$ & -8.241 & $\mathbf{2 . 5 5}$ & $\mathbf{1 . 5 3 7}$ & -15.741 & $\mathbf{0 . 5 7 4}$ & $\mathbf{2 . 1 6 3}$ \\
Bias (noHR(cld)) & $\mathbf{- 4 . 9 7 8}$ & $\mathbf{1 6 . 1 4 1}$ & $\mathbf{- 1 0 . 0 2 3}$ & $\mathbf{2 . 4 0 3}$ & $\mathbf{1 . 5 9 6}$ & $\mathbf{- 1 7 . 1 9 9}$ & $\mathbf{0 . 7 2 5}$ & $\mathbf{2 . 9 0 4}$ \\
\hline
\end{tabular}
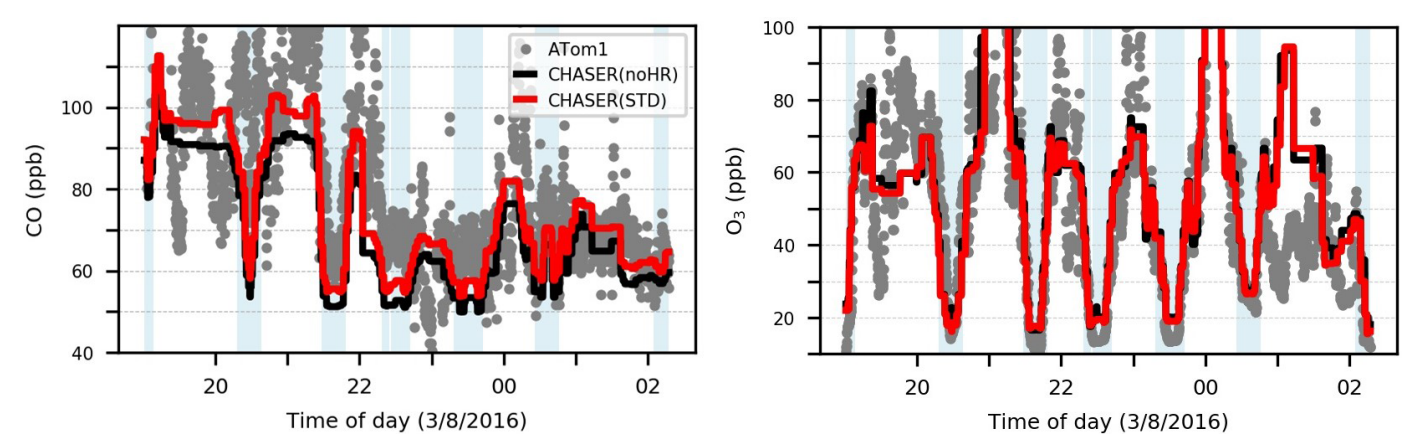

Figure 5. Observations and simulations for $\mathrm{CO}$ and $\mathrm{O}_{3}$ during ATom 1 flight $2\left(198-210^{\circ} \mathrm{E}, 20-62^{\circ} \mathrm{N}\right)$. Blue shaded areas show data for $P>600 \mathrm{hPa}$.

aerosols concentration. Hereinafter, we discuss SAD distributions for total aerosol, ice clouds, and cloud droplets, which are estimated for the model using Eqs. (2), (3), and (4), respectively.

In Fig. 8, total surface area concentrations of liquid clouds and aerosols are both much lower aloft than at the surface (as counted on the dry and wet depositions). The liquid cloud SAD results are 2 orders of magnitude larger than ice cloud SAD and total aerosol SAD. The ice cloud SAD, distributed at the middle and upper troposphere, is enhanced for $\mathrm{N} / \mathrm{S}$ middle latitudes in wintertime. Liquid cloud SAD concentrates mainly at the surface with distributions extending to $500 \mathrm{hPa}$ and maximized at approx. $800 \mathrm{hPa}$ over the midlatitude storm tracks and in tropical convective systems, especially at $60^{\circ} \mathrm{N}$ in JJA. Total aerosol SAD was derived mainly from pollution sources at $40^{\circ} \mathrm{N}$ during both seasons, with higher concentrations apparent for DJF and a greater spatial spread observed for JJA. Sulfate aerosols are becoming the dominant source of aerosol surface area in the model above $600 \mathrm{hPa}$ (approx. $20 \mu^{2} \mathrm{~cm}^{-3}$ ) in addition to organic carbons and soil dust (both are approx. $10 \mu \mathrm{m}^{2} \mathrm{~cm}^{-3}$ in JJA) for the Northern Hemisphere.

In Fig. S14, showing the SAD distribution at the surface, the SAD for liquid clouds is dominant in JJA, reaching approx. $50000 \mathrm{\mu m}^{2} \mathrm{~cm}^{-3}$ for mid-latitude and high-latitude ocean regions. Liquid clouds make the greatest contribution to the SAD at the surface. Our model performance for aerosol SAD shows agreement with that presented in an earlier report (Thornton et al., 2008). Sulfate aerosols are prevalent in the northern mid-latitudes near industrial bases; maximize at the surface in DJF for the Chinese region (exceeding $1000 \mu \mathrm{m}^{2} \mathrm{~cm}^{-3}$ ), NE U.S. (approx. $500 \mu \mathrm{m}^{2} \mathrm{~cm}^{-3}$ ), and western Europe; and transport to the North Pacific region in JJA (approx. $250 \mu \mathrm{m}^{2} \mathrm{~cm}^{-3}$ ). Soil dust aerosol SAD dominate in the regions of the Sahara and Gobi deserts, reaching annual average values exceeding $100 \mu \mathrm{m}^{2} \mathrm{~cm}^{-3}$. Organic carbon (OC) is a dominant source of aerosol SAD over biomass burning regions in China (up to $1000 \mu \mathrm{m}^{2} \mathrm{~cm}^{-3}$ in DJF), South Africa (up to $800 \mu \mathrm{m}^{2} \mathrm{~cm}^{-3}$ in JJA), western Europe, and South America. The black carbon (BC) surface area can reach values exceeding $600 \mu \mathrm{m}^{2} \mathrm{~cm}^{-3}$ in DJF for the region of China or other significant industrial areas (India, which reaches $75 \mu \mathrm{m}^{2} \mathrm{~cm}^{-3}$, NE U.S., and Europe) or over tropical forests, primarily in Africa. Sea salt aerosols are most important in high-latitude oceans during winter. However, the maximum contributions only reach $2 \mu \mathrm{m}^{2} \mathrm{~cm}^{-3}$ in our model, which is greatly underestimated compared to Thornton's work $\left(75 \mu^{2} \mathrm{~cm}^{-3}\right)$ (Thornton et al., 2008). In brief, SAD for aerosols of all types contributes the most during DJF, whereas during JJA, the SAD for liquid clouds and sulfate aerosols are dominant, particularly for the northern highlatitude and mid-latitude oceans. The total aerosol SAD in 

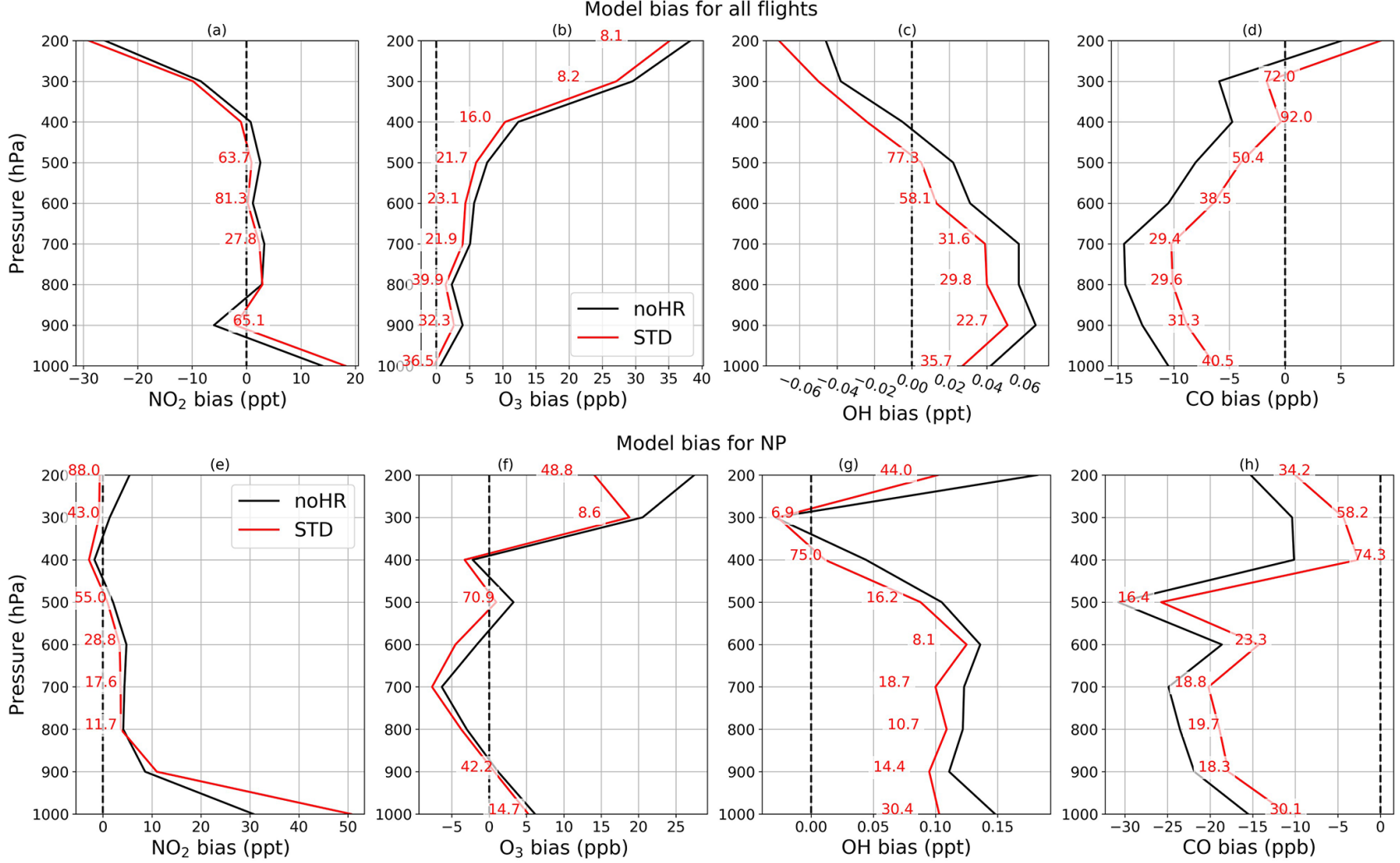

$\mathrm{OH}$ bias (ppt)

CO bias $(p p b)$

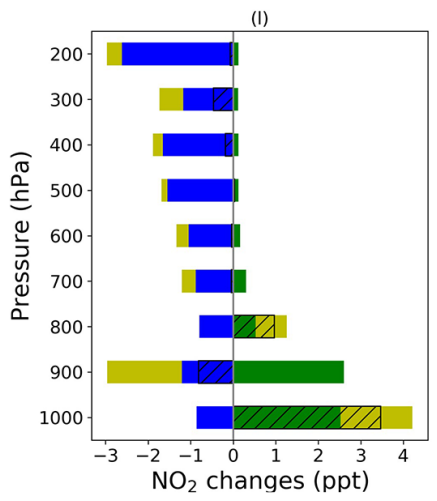

Vertical
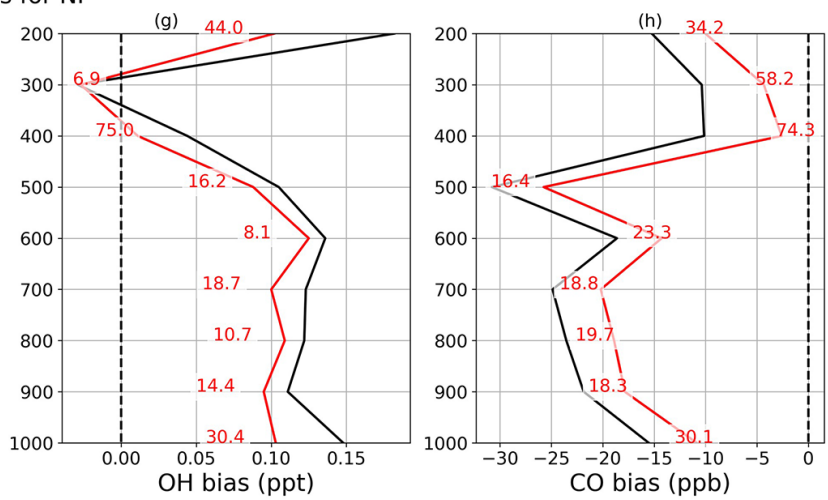

Vertical changes for all flights
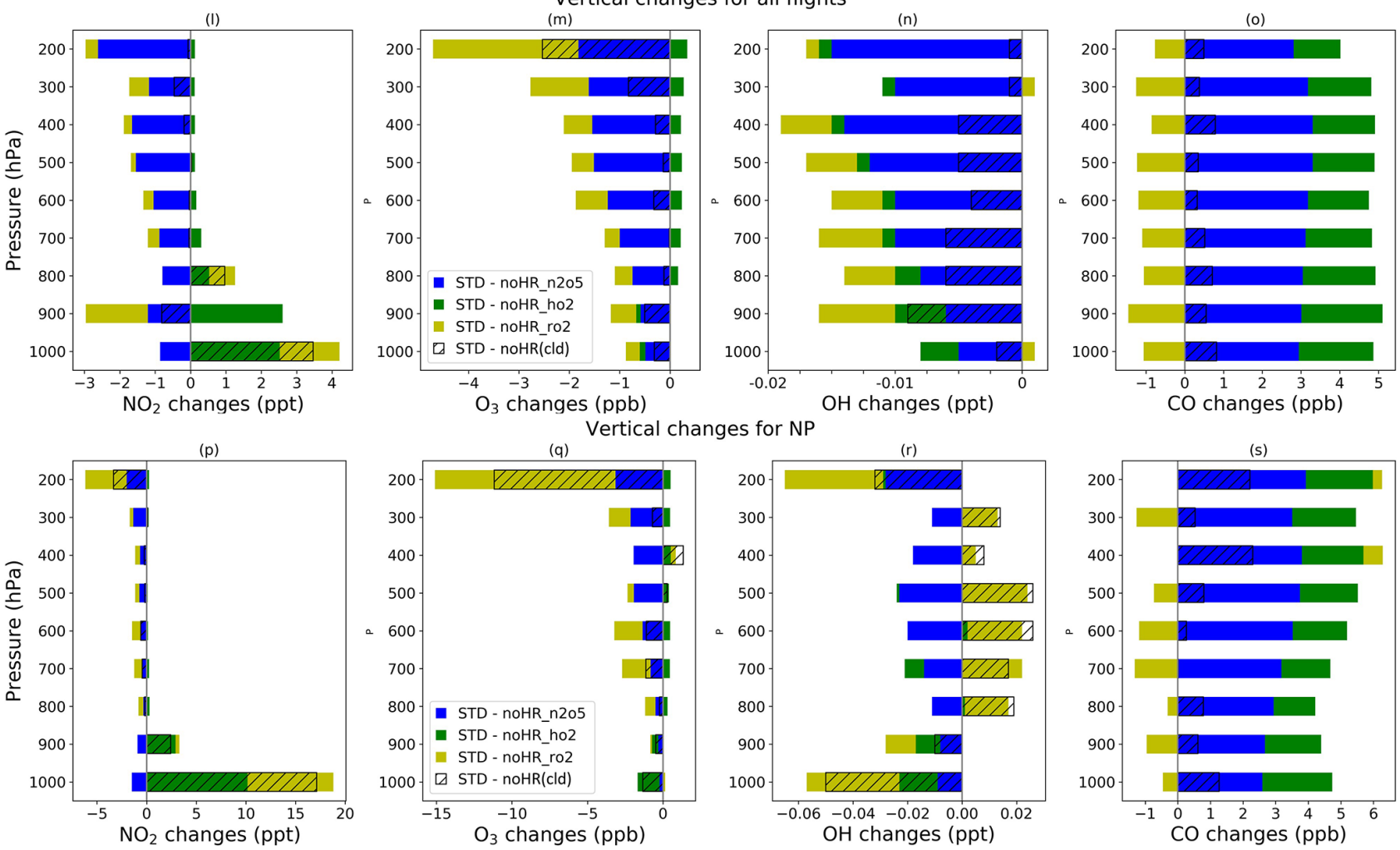

Figure 6. Vertical bias against ATom $1(\mathbf{a}-\mathbf{h})$ and vertical HR effects (1-s). Data for each pressure level $P$ are calculated within the range of $P \pm 50 \mathrm{hPa}$, with the applied three-sigma-rule for outlier detection. All rows show calculations for all flight domains the and the North Pacific region. The horizontal axis shows model bias and absolute changes with units written in each panel. The vertical axis shows pressure (hPa). The red numbers in (a)-(h) represent relative reductions (\%) of the STD run's bias compared to that of the noHR run. 
(a) TCO CHASER (nOHR) - TCO OMI : 2015 ANN

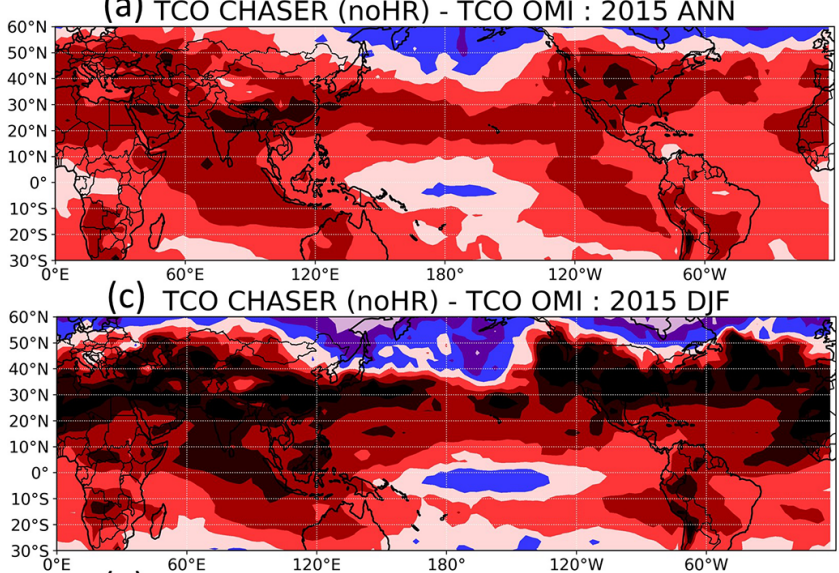

(e) TCO CHASER (nOHR) - TCO OMI : 2015 JJA

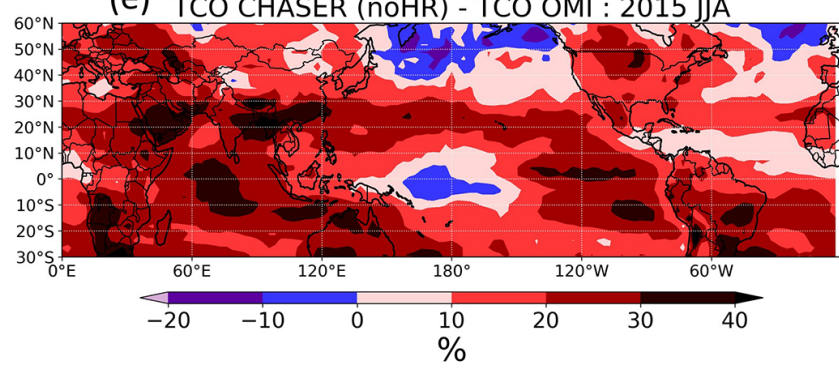

(b) TCO CHASER (STD) - TCO OMI : 2015 ANN

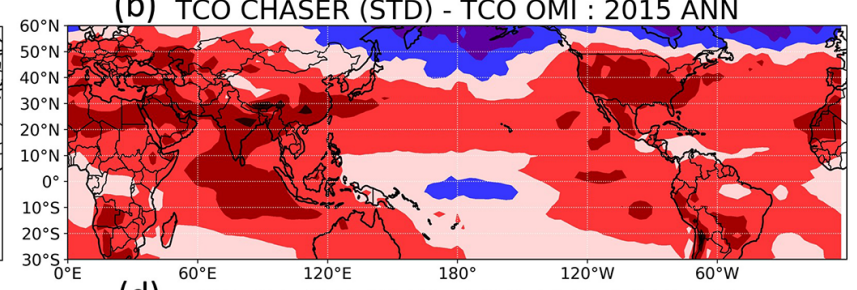

(d) TCO CHASER (STD) - TCO OMI : 2015 DJF

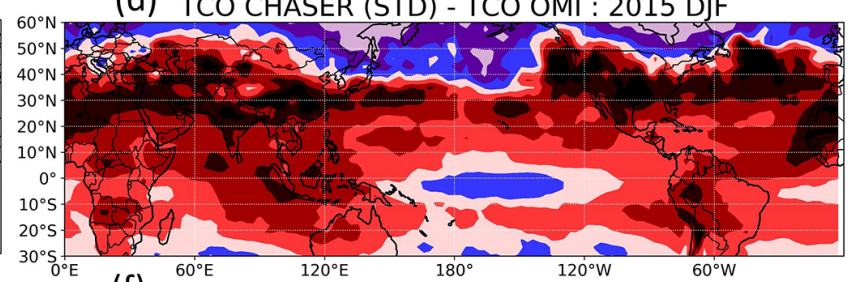

(f) ${ }^{60^{\circ} \mathrm{E}} 120^{\circ} \mathrm{E}$ TCO CHASER (STD) - TCO OMI : $2015 \mathrm{JJA}$

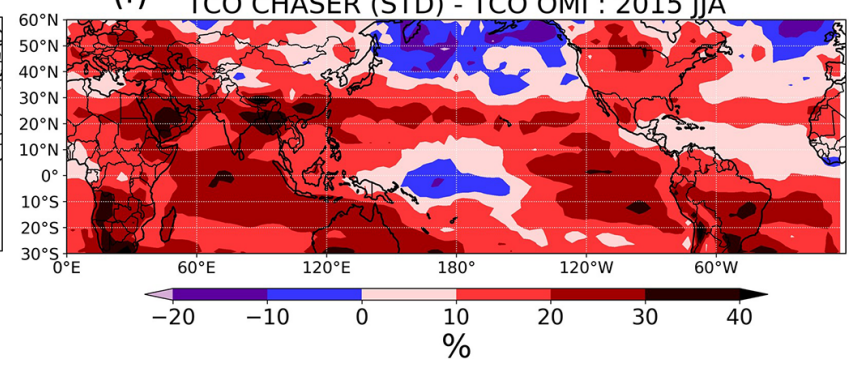

Figure 7. Differences in tropospheric column ozone (TCO) in CHASER's noHR (a, c, e) and STD (b, d, f) runs from OMI: ANN is annual; DJF is December, January, February; and JJA is June, July, and August.

this region is approx. $75 \mu \mathrm{m}^{2} \mathrm{~cm}^{-3}$, which is consistent with the estimation by Thornton et al. (2008).

\subsubsection{Effects of $\mathrm{N}_{2} \mathrm{O}_{5}$ heterogeneous reaction $\left(\mathrm{HR}\left(\mathrm{N}_{2} \mathrm{O}_{5}\right)\right)$}

The inclusion of $\mathrm{HR}\left(\mathrm{N}_{2} \mathrm{O}_{5}\right)$ in the model increases global methane lifetime by $+4.48 \%$ and changes $\mathrm{NO}_{x}, \mathrm{O}_{3}$, and CO abundances by $-5.51 \%,-2.12 \%$, and $+3.42 \%$, respectively (Table 9).

In Fig. 9a-h, the changes in $\mathrm{OH}, \mathrm{NO}_{x}, \mathrm{O}_{3}$, and $\mathrm{CO}$ are most significant in the middle troposphere $(400-600 \mathrm{hPa})$. These changes are attributed mostly to uptakes of $\mathrm{N}_{2} \mathrm{O}_{5}$ onto aerosols, rather than onto clouds. Marked negative effects on $\mathrm{NO}_{x}$ concentration are apparent for DJF in the middle troposphere $(600-700 \mathrm{hPa})$ of the $60^{\circ} \mathrm{N}$ and the Arctic region $(>-20 \%$ at $700 \mathrm{hPa}$ ) (Fig. 9c). The effects are probably associated with high concentrations of sulfate aerosols, organic carbons, or soil dusts in the middle troposphere (see the paragraph above) and are also related to a long chemical lifetime of $\mathrm{NO}_{y}$ in the middle and upper troposphere in winter. When it comes to JJA, these negative effects become significant at higher altitudes around $30^{\circ} \mathrm{N} / \mathrm{S}(>-10 \%$ at $400 \mathrm{hPa})$. At the surface (Fig. 9i-p), $\mathrm{HR}\left(\mathrm{N}_{2} \mathrm{O}_{5}\right)$ causes negative effects on $\mathrm{NO}_{x}, \mathrm{O}_{3}$, and $\mathrm{OH}$ concentrations (up to about $-24 \%,-5 \%$ and $-8 \%$ respectively) and positive effects on $\mathrm{CO}$ concen- tration (up to about $+4 \%$ ), which are also mainly attributable to the $\mathrm{N}_{2} \mathrm{O}_{5}$ uptake on aerosols.

In Fig. 10, the latitude-longitude (lat-long) means of $\mathrm{HR}\left(\mathrm{N}_{2} \mathrm{O}_{5}\right)$ effects are calculated for each pressure range (pressure ranges are defined as in Fig. 6). The global $\mathrm{NO}_{x}$ decrease is up to $-9 \%$ at $300-400 \mathrm{hPa}$. This decrease causes correspondent reductions in $\mathrm{O}_{3}$ and $\mathrm{OH}$, which are calculated as about $-3 \%$ and $-7 \%$ at $400-600 \mathrm{hPa}$, respectively, for lat-long mean $\mathrm{O}_{3}$ and $\mathrm{OH}$. About $4 \%$ lat-long mean $\mathrm{CO}$ increment throughout the entire troposphere responds to decreased $\mathrm{OH}$.

The small effects of $\mathrm{HR}\left(\mathrm{N}_{2} \mathrm{O}_{5}\right)$ on $\mathrm{O}_{3}$ in the lower troposphere are consistent with findings from an earlier study (Riemer et al., 2003). Reductions in $\mathrm{O}_{3}$ and $\mathrm{NO}_{x}$ concentrations also agree well with the collective knowledge summarized in work reported by Brown and Stutz (2012). Despite a considerable $\mathrm{HR}\left(\mathrm{N}_{2} \mathrm{O}_{5}\right)$ effect calculated in the middle troposphere, its effect in the whole troposphere is apparently not as great as reported to date. Another study assessed $\mathrm{HR}\left(\mathrm{N}_{2} \mathrm{O}_{5}\right)$ effects on annual burdens of $\mathrm{NO}_{x}, \mathrm{O}_{3}$, and $\mathrm{OH}$ as $-11 \%,-5 \%$, and $-7 \%$, respectively, when using a similar $\gamma_{\mathrm{N}_{2} \mathrm{O}_{5}}$ value (0.1) (Macintyre and Evans, 2010). Although the effects of magnitude estimated in our work (Table 9) are almost half those of this earlier study (probably because of differences in $\mathrm{NO}_{x}$ emissions, estimation of $\mathrm{SAD}$, and chemical mechanism), the effect tendencies are similar. A strong increase of ozone attributed to $\mathrm{N}_{2} \mathrm{O}_{5}$ uptake under high- $\mathrm{NO}_{x}$ 


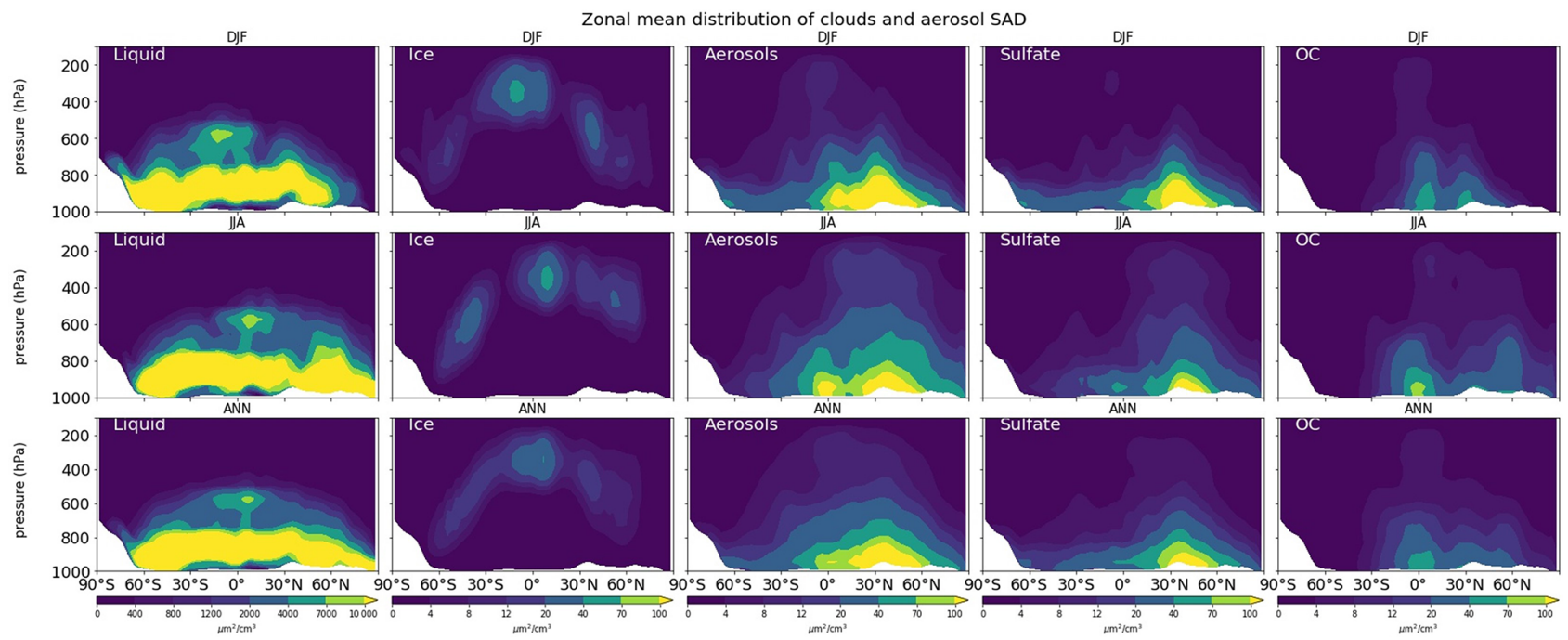

Figure 8. Zonal, seasonal mean (upper and middle), and annual mean (lower) distribution of cloud droplet surface aerosol density (SAD), cloud ice $\mathrm{SAD}$, total aerosol SAD, sulfate aerosol SAD, and organic carbon SAD (from left to right).
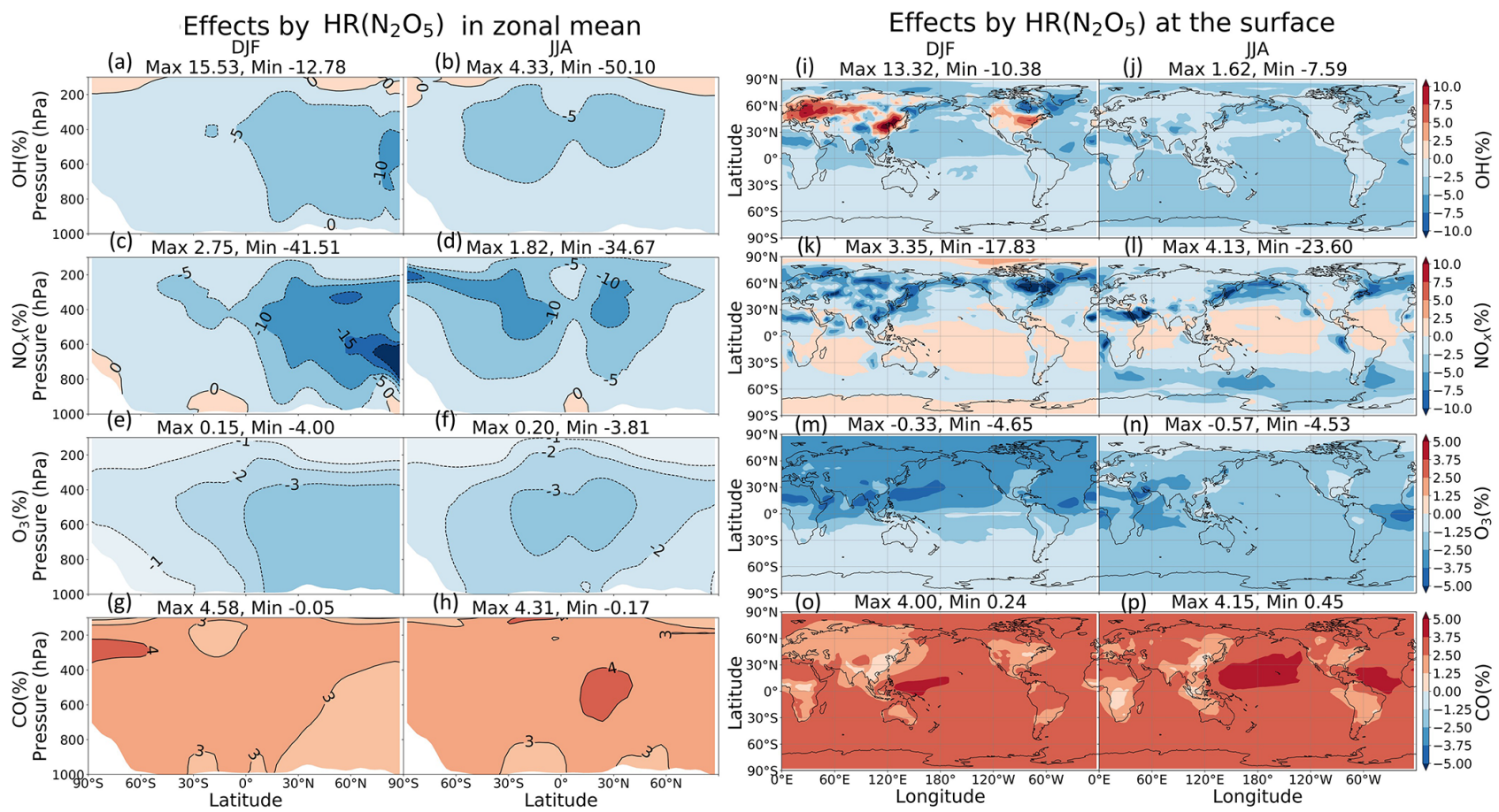

Figure 9. Effects by $\mathrm{N}_{2} \mathrm{O}_{5}$ uptake onto both clouds and aerosols in zonal mean (a-h) and at the surface (i-p). Note that the color scale for (a)-(h) is different from that for (i)-(p).

conditions calculated using box models was reported from an earlier study (Riemer et al., 2003), but this is only slightly apparent in our global model. Our results revealed that the $\mathrm{HR}\left(\mathrm{N}_{2} \mathrm{O}_{5}\right)$ effect might help clean up $\mathrm{NO}_{x}$ pollutant. However, it increases the concentration of other pollutants (such as $\mathrm{CO}$ ) because of the effects of reducing oxidizing agents in the atmosphere.

\subsubsection{Effects of $\mathrm{HO}_{2}$ heterogeneous reaction $\left(\mathrm{HR}\left(\mathrm{HO}_{2}\right)\right)$}

Regarding the effects of $\mathrm{HR}\left(\mathrm{HO}_{2}\right)$, the tropospheric methane lifetime increases by approx. $1.51 \%$. Abundances in $\mathrm{NO}_{x}$, $\mathrm{O}_{3}$, and $\mathrm{CO}$ change, respectively, by $+3.26 \%,+0.05 \%$, and $+1.95 \%$ (Table 9). In the entire troposphere, the influences of $\mathrm{HR}\left(\mathrm{HO}_{2}\right)$ are not as large as that of $\mathrm{HR}\left(\mathrm{N}_{2} \mathrm{O}_{5}\right)$. 

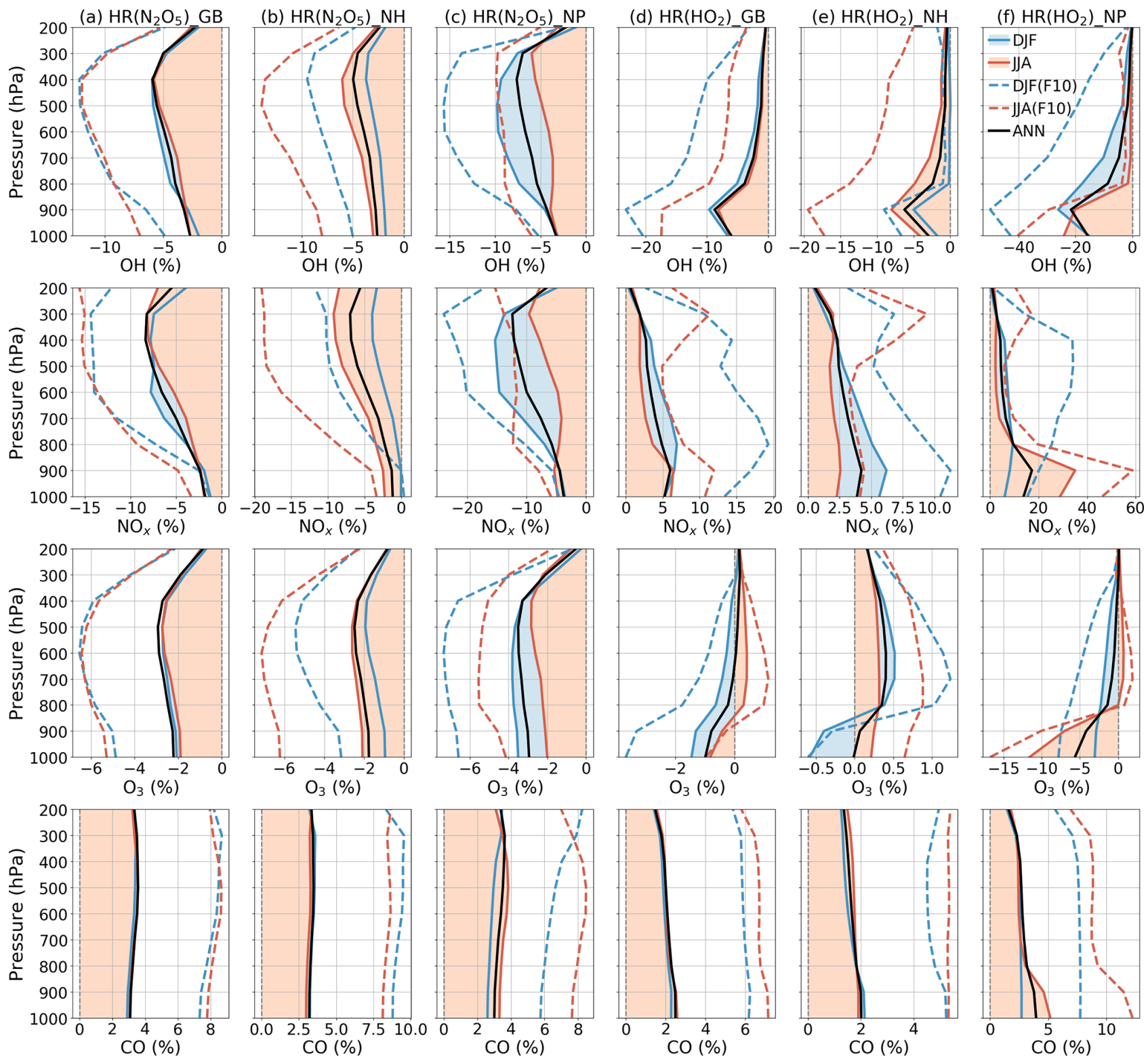

Figure 10. Averaged effects of $\mathrm{N}_{2} \mathrm{O}_{5}(\mathbf{a}-\mathbf{c})$ and $\mathrm{HO}_{2}$ uptakes (d-f) for each air pressure range. Calculations are for global data (a, d), Northern Hemisphere data (b, e), and North Pacific region data (c, f). Dashed lines show effects of the FCTHR_10 run (Sect. 3.3). The legend is in panel (f) for December-January-February (DJF), June-July-August (JJA), and annual (ANN) data.

As Fig. 11a-f shows, the zonal-mean effects of $\mathrm{HR}\left(\mathrm{HO}_{2}\right)$ on $\mathrm{NO}_{x}, \mathrm{OH}$, and $\mathrm{O}_{3}$ are more widespread in DJF but are more concentrated at the surface in JJA because of the high level of $\mathrm{HO}_{2}$. The most substantial effects by $\mathrm{HR}\left(\mathrm{HO}_{2}\right)$ are calculated in JJA at the surface of North Pacific (140$\left.240^{\circ} \mathrm{E}, 40-60^{\circ} \mathrm{N}\right)$ by as much as about $+69 \%\left(\mathrm{NO}_{x}\right),+7 \%$ $(\mathrm{CO}),-70 \%(\mathrm{OH})$, and $-21 \%\left(\mathrm{O}_{3}\right)$, which are more significant than those of $\mathrm{HR}\left(\mathrm{N}_{2} \mathrm{O}_{5}\right)$ at the surface. In the lower troposphere, $\mathrm{HR}\left(\mathrm{HO}_{2}\right)$ suppresses the $\mathrm{NO}$ oxidation (Reaction $\mathrm{R} 10)$ and thus preserves a high $\mathrm{NO} / \mathrm{NO}_{x}$ ratio and gen- erally restricts $\mathrm{OH}$ and $\mathrm{O}_{3}$ formations.

$\mathrm{HO}_{2}+\mathrm{NO} \rightarrow \mathrm{OH}+\mathrm{NO}_{2}$

These effects are primarily attributable to $\mathrm{HR}\left(\mathrm{HO}_{2}\right)$ in clouds rather than to aerosols (which is opposite to $\mathrm{N}_{2} \mathrm{O}_{5}$ uptake). These $\mathrm{OH}$ and $\mathrm{O}_{3}$ reduction effects go along with past studies in which approx. 50\% $\mathrm{OH}$ and approx. $10 \% \mathrm{O}_{3}$ of reductions are calculated for the low troposphere of northern mid-latitude region ascribed to aqueous-phase $\mathrm{HO}_{x}$ sink in clouds (Lelieveld and Crutzen, 1990, 1991). The efficient scavenge of $\mathrm{HO}_{2}$ radical by cloud droplets might associate with acid-base dissociation $\mathrm{HO}_{2} / \mathrm{O}_{2}^{-}$and electron transfer of 
$\mathrm{O}_{2}^{-}$to $\mathrm{HO}_{2}$ to produce $\mathrm{H}_{2} \mathrm{O}_{2}$ (Jacob, 2000). Furthermore, cloud droplets $\mathrm{SAD}$ in our model are 2 orders of magnitude higher than total aerosol SAD (Fig. 8), which also contributes to the preference of the aqueous-phase $\mathrm{HO}_{2}$ sink. Our large calculated effects for the North Pacific region are new findings from other models, which have considered only aqueous aerosols (Stadtler et al., 2018; Thornton et al., 2008) because cloud particles are dominant at remote marine areas in addition to sulfate and aqueous sea salt particles (discussed at the beginning of Sect. 3.2). The $\mathrm{HO}_{2}$ uptake onto aerosols is minor; it is observed only in DJF in the Arctic region and polluted areas (China and US), with apparent changes of up to $+17 \%$ for $\mathrm{NO}_{x},-40 \%$ for $\mathrm{OH}$, and $-14 \%$ for $\mathrm{O}_{3}$ at the local surface (Fig. 11i, k, m). The aerosol negative effect of $\mathrm{HR}\left(\mathrm{HO}_{2}\right)$ on surface $\mathrm{O}_{3}$ concentration is significant in the Chinese area, which might be in line with other studies of the Chinese $\mathrm{O}_{3}$ trend (Kanaya et al., 2009; Li et al., 2019; Liu and Wang, 2020; Taketani et al., 2012), which suggests that the observed recent $\mathrm{O}_{3}$ increases can be attributed in part to reduced $\mathrm{HO}_{2}$ uptake under aerosol (PM) decreases brought about by the new Chinese air pollution policy.

In Fig. 10, vertical profiles show that the lat-long averaged effect of $\mathrm{HR}\left(\mathrm{HO}_{2}\right)$ on $\mathrm{OH}$ is $-9 \%$ in the lower troposphere. As a result, the lat-long mean $\mathrm{CO}$ level increases by $2 \%$ at the surface. Additionally, the daytime $\mathrm{NO}_{x}$ oxidation by $\mathrm{OH}$ is suppressed. Also, $\mathrm{NO}_{x}$ might be preserved in clouds (Dentener, 1993), which increases the lat-long averaged $\mathrm{NO}_{x}$ level by $+6 \%$ at $900 \mathrm{hPa}$. The lat-long mean $\mathrm{O}_{3}$ is reduced by $-1 \%$ at the surface, but it is increased at higher altitudes (about $+0.2 \%$ at $300 \mathrm{hPa}$ ). The reduction of $\mathrm{O}_{3}$ is associated with $\mathrm{HO}_{2}$ depletion in clouds and aqueous aerosols as described above, coupled with the $\mathrm{NO}_{x}$ preservation in clouds, which enhances the $\mathrm{NO} / \mathrm{NO}_{x}$ ratio. The preserved $\mathrm{NO}_{x}$ in clouds might remain available for $\mathrm{O}_{3}$ production after the cloud evaporates (Dentener, 1993), along with the low SAD for both liquid clouds and aerosols at higher altitudes (Fig. 8), thereby increasing $\mathrm{O}_{3}$ in places other than the aqueous phase. The $\mathrm{O}_{3}$ increment might be trivial in DJF but enhanced in JJA. As a result, the Northern Hemisphere mean $\mathrm{O}_{3}$ in JJA exhibits only positive effects. In contrast, for the North Pacific region in JJA, due to its large cloud fraction, an $\mathrm{O}_{3}$ reduction effect is apparent in this region. The effects in JJA for this region show changes of $-25 \% \mathrm{OH},+35 \%$ $\mathrm{NO}_{x},-12 \% \mathrm{O}_{3}$, and $+5 \% \mathrm{CO}$ at $900-100 \mathrm{hPa}$ as the most remarkable $\mathrm{HR}\left(\mathrm{HO}_{2}\right)$ effects, as described above. In general, the regional mean effects of $\mathrm{HR}\left(\mathrm{HO}_{2}\right)$ in the North Pacific region are enhanced in JJA, but the mean global effects of $\mathrm{HR}\left(\mathrm{HO}_{2}\right)$ are slightly favored in DJF because of the additional effects of aerosols during this season.

Macintyre and Evans (2011) also found a similar contrast between the behaviors of $\mathrm{HR}\left(\mathrm{N}_{2} \mathrm{O}_{5}\right)$ and $\mathrm{HR}\left(\mathrm{HO}_{2}\right)$ : the uptake of $\mathrm{N}_{2} \mathrm{O}_{5}$ produces both regional and global effects on $\mathrm{O}_{3}$, whereas the uptake of $\mathrm{HO}_{2}$ affects $\mathrm{O}_{3}$ at regional scales more strongly than on a global scale (Macintyre and Evans, 2011). Such features are generally consistent with our results.

\subsubsection{Effects of $\mathrm{RO}_{2}$ heterogeneous reactions $\left(\mathrm{HR}\left(\mathrm{RO}_{2}\right)\right)$}

Effects of $\mathrm{HR}\left(\mathrm{RO}_{2}\right)$ increase the global mean methane lifetime by $+0.15 \%$ and change tropospheric abundances of $\mathrm{NO}_{x}(+0.52 \%), \mathrm{O}_{3}(-0.93 \%)$, and $\mathrm{CO}(-1.78 \%)$ (Table 9). In Fig. 12k-1, significant latitudinal contrasts exist in the $\mathrm{NO}_{x}$ changes: large $\mathrm{NO}_{x}$ increases at high latitudes and decreases at lower latitudes. These $\mathrm{NO}_{x}$ changes probably reflect the reduced formation of PANs, which decreases $\mathrm{NO}_{x}$ transport from source regions to remote areas and from the surface to the upper troposphere (Villalta et al., 1996). The model calculated especially large $\mathrm{NO}_{x}$ increases $(>50 \%)$ for high latitudes around the Arctic Ocean in JJA, indicating a reduction in the formation of PANs $\left(\mathrm{NO}_{2}+\mathrm{RO}_{2} \rightarrow\right.$ PANs), which is linked tightly to the enhanced biogenic emissions of VOCs such as isoprene and terpenes in summer. The PANreducing effect of $\mathrm{HR}\left(\mathrm{RO}_{2}\right)$, associated with the suppression of NO oxidation, as seen in the case of $\mathrm{HR}\left(\mathrm{HO}_{2}\right)$, causes a double increase for $\mathrm{NO}_{x}$ at the surface as compared to $\mathrm{HR}\left(\mathrm{HO}_{2}\right)(144 \%$ in Fig. 121 versus $66 \%$ in Fig. 111). The increases in $\mathrm{NO}_{x}$ in DJF at high latitudes offshore of southern oceans could also reflect reduced transport of $\mathrm{NO}_{x}$ under reduced PAN formation caused by $\mathrm{HR}\left(\mathrm{RO}_{2}\right)$ since these coastal areas are located downwind of the major biogenic volatile organic compounds (BVOC) sources of South America, South Africa, and Australia. Moreover, the areas with pronounced $\mathrm{NO}_{x}$ increases in Fig. 12k-1 are all associated with high-cloud SAD, as seen in Fig. S14 (left panels).

In the troposphere, the $\mathrm{NO}$ oxidation carried out by $\mathrm{RO}_{2}$ via Reaction (R11) produces another $\mathrm{HO}_{x}$ molecule (Reaction R12). Hence, the uptakes of $\mathrm{RO}_{2}$ onto particles are also expected to confine the $\mathrm{OH}$ and $\mathrm{O}_{3}$ formations, similar to what the uptake of $\mathrm{HO}_{2}$ does.

$\mathrm{RO}_{2}+\mathrm{NO} \rightarrow \mathrm{RO}+\mathrm{NO}_{2}$

$\mathrm{RO}+\mathrm{O}_{2} \rightarrow \mathrm{R}^{\prime} \mathrm{O}+\mathrm{HO}_{2}$

However, the different catalytic role of $\mathrm{NO}_{x}$ in the oxidizing mechanisms between polluted and remote regions results in different tendencies for $\mathrm{OH}$ and $\mathrm{O}_{3}$ (Jacob, 1999). Accordingly, $\mathrm{O}_{3}$ and $\mathrm{OH}$ molecules are produced through the oxidation of hydrocarbons in presence of high $\mathrm{NO}_{x}$, whereas $\mathrm{HO}_{x}$ molecules are consumed and no $\mathrm{O}_{3}$ is produced in the same process that occurred devoid of $\mathrm{NO}_{x}$. For that reason, less $\mathrm{RO}_{2}$ participating in the hydrocarbon oxidation only reduces $\mathrm{OH}$ and $\mathrm{O}_{3}$ levels in polluted regions, e.g., the Chinese region in DJF (Fig. 12i and m), while enhancing $\mathrm{OH}$ level and leaving no significant effect on $\mathrm{O}_{3}$ at remote regions, e.g., the NP region (Fig. 12i, j, m, n). The corresponding changes in $\mathrm{OH}$ concentration at the surface are in the range of about $-5 \%$ to $+20 \%$ in JJA (Fig. $12 \mathrm{j}$ ). $\mathrm{O}_{3}$ levels are slightly reduced throughout the troposphere, at most about $-5 \%$ at the surface of the Arctic region above Canada, due to $\mathrm{HR}\left(\mathrm{RO}_{2}\right)$, with only about a $3 \%$ increase, corresponding with the $\mathrm{NO}_{x}$ 

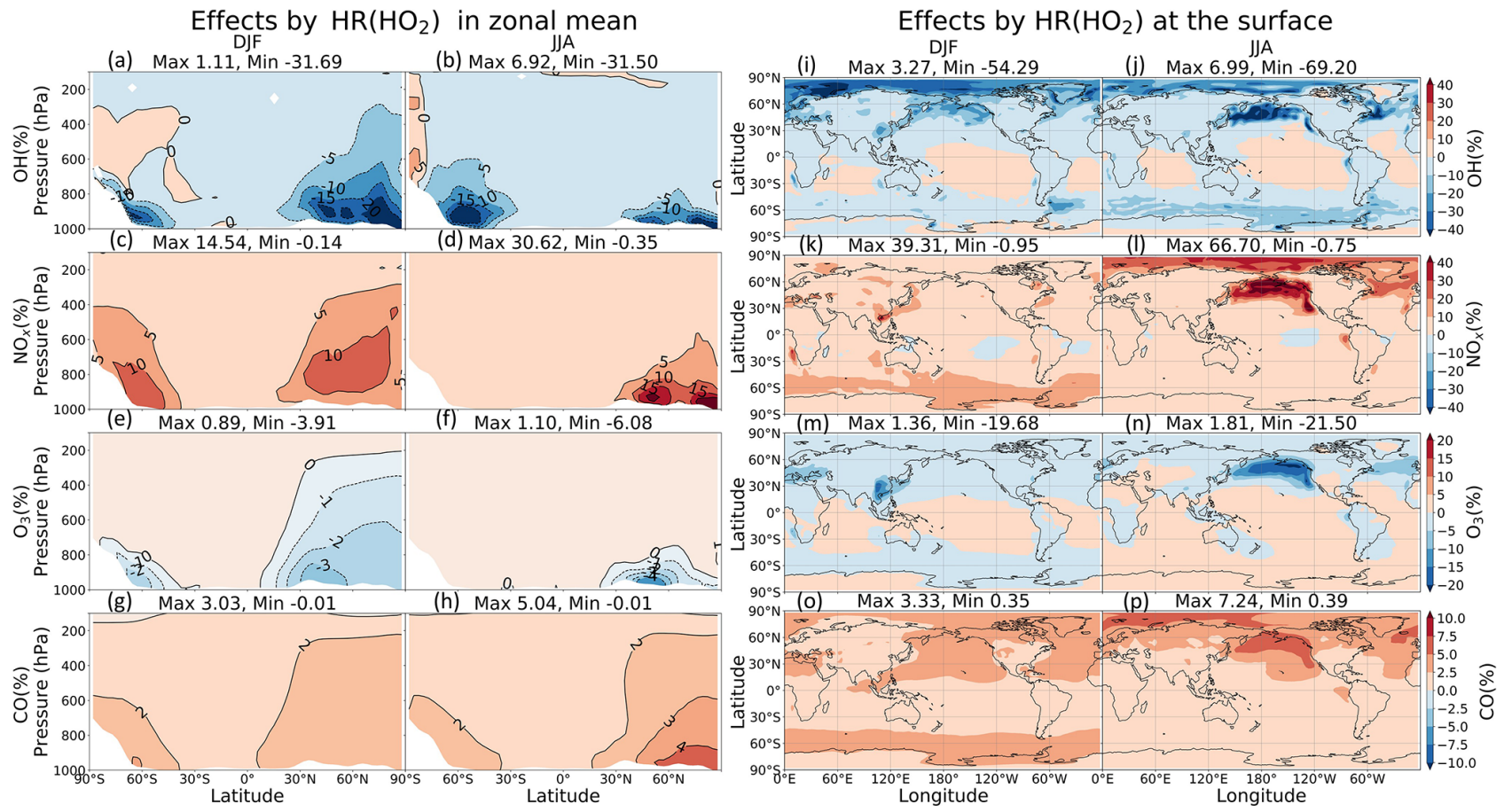

Figure 11. Effects of $\mathrm{HR}\left(\mathrm{HO}_{2}\right)$ on both clouds and aerosols in zonal mean (a-h) and at the surface layer (i-p). Note that the color scale for $(\mathbf{a}-\mathbf{h})$ is different from that for $(\mathbf{i}-\mathbf{p})$.
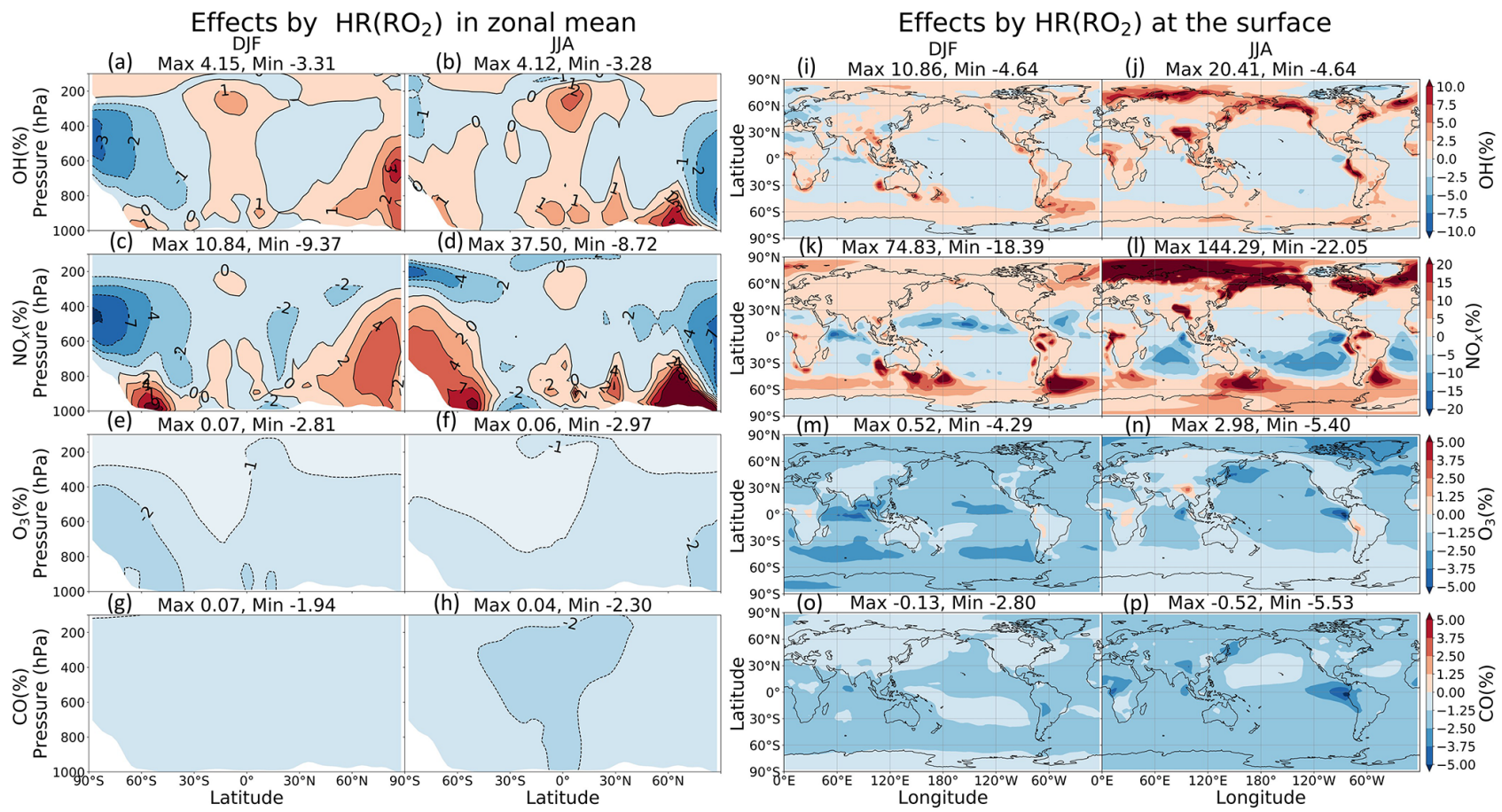

Figure 12. Effects of $\mathrm{HR}\left(\mathrm{RO}_{2}\right)$ on both clouds and aerosols in the zonal mean $(\mathbf{a}-\mathbf{h})$ and at the surface layer (i-p). Note that the color scale for (a)-(h) is different from that for (i) $-(\mathbf{p})$. 

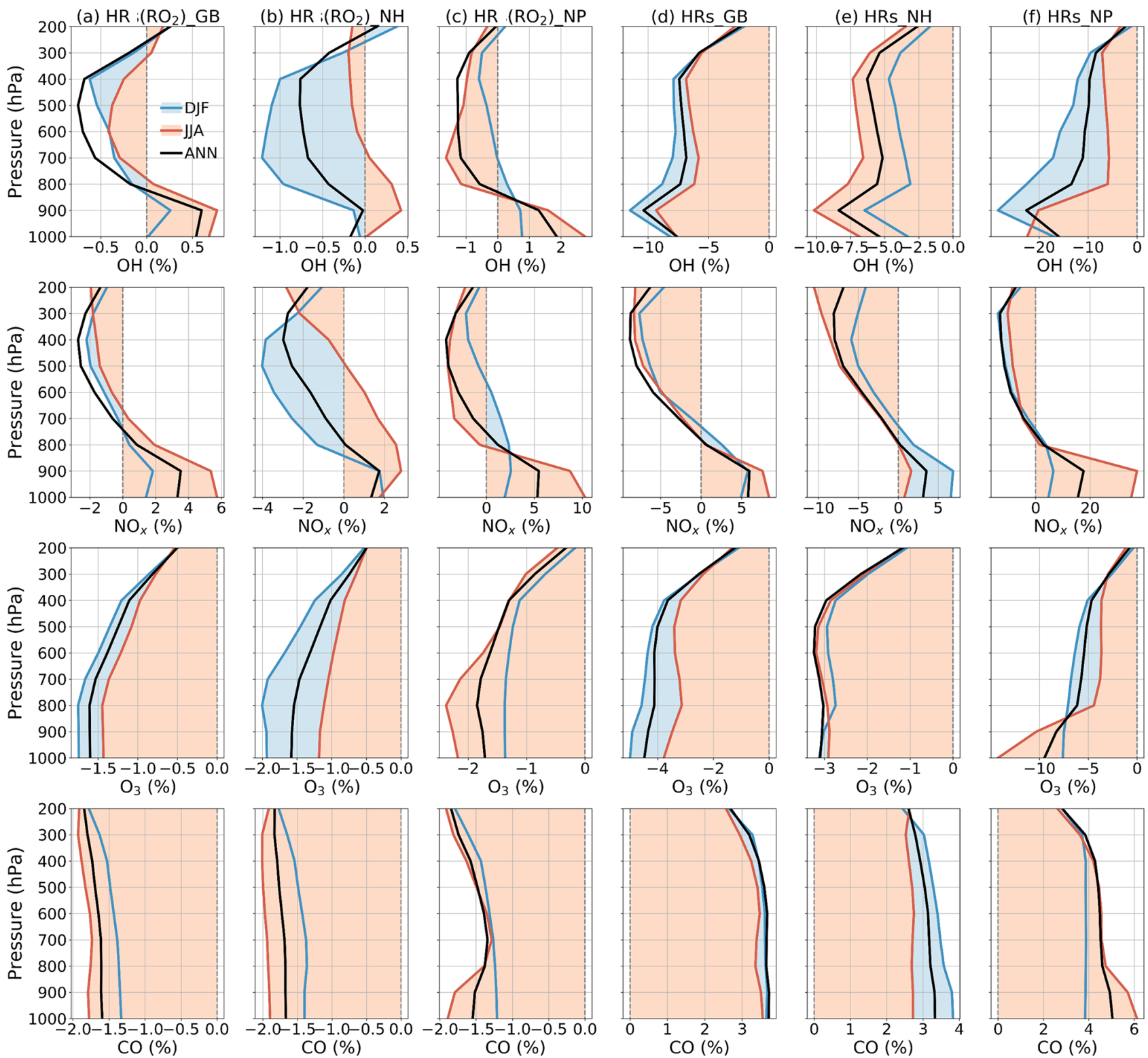

Figure 13. Averaged effects of $\mathrm{HR}\left(\mathrm{RO}_{2}\right)(\mathbf{a}-\mathbf{c})$ and all $\mathrm{HRs}(\mathbf{d}-\mathbf{f})$ on $\mathrm{OH}$ (first row), $\mathrm{NO}_{x}$ (second row), $\mathrm{O}_{3}$ (third row), and $\mathrm{CO}$ (fourth row) for each air pressure range. Calculations are for global (a,d), Northern Hemisphere (b, e), and North Pacific region (c, f). Legend is on the first panel for December-January-February (DJF), June-July-August (JJA), and annual (ANN).

increases at the tropical coasts (Fig. 12n). For CO, different from the increasing impacts by $\mathrm{HR}\left(\mathrm{N}_{2} \mathrm{O}_{5}\right)$ and $\mathrm{HR}\left(\mathrm{HO}_{2}\right)$ $(+3.42 \%$ and $+1.95 \%$, respectively), a reduction effect occurs through the free troposphere $(-1.78 \%)$. CO decrease might be due to reduced secondary $\mathrm{CO}$ production from $\mathrm{RO}_{2}$ oxidation $\left(\mathrm{RO}_{2} \rightarrow \mathrm{HCHO} / \mathrm{RCHO}\right.$ or $\left.\mathrm{ROOH} \rightarrow \mathrm{CO}\right)$ such as isoprene (Bates and Jacob, 2019) when functionalized $\mathrm{RO}_{2}$ species uptake onto aerosols and clouds particles instead.

The effects of $\mathrm{HR}\left(\mathrm{RO}_{2}\right)$ are primarily attributed to the heterogeneous reaction on clouds rather than on aerosols in terms of changes in $\mathrm{NO}_{x}$ and $\mathrm{CH}_{4}$ lifetime, although this cloud effect is far smaller than the cloud effect on the $\mathrm{HO}_{2}$ uptake. The areas with pronounced $\mathrm{NO}_{x}$ increases in Fig. 12b are all associated with high-cloud SAD, as seen in Fig. S14 (left panels). Although it is proper to expect the high solubility of $\mathrm{RO}_{2}$ (e.g., $\mathrm{CH}_{3} \mathrm{O}_{2}$ ) from its peroxy substituent (Betterton, 1992; Shepson et al., 1996), it is much less soluble than $\mathrm{HO}_{2}$ because of its lower polarity and thus lower Henry law constant (Jacob, 2000). Consequently, the possible accumulation of $\mathrm{CH}_{3} \mathrm{O}_{2}$ in the cloud is attributable to suppression of its gas-phase sink with $\mathrm{HO}_{2}$ (Jacob, 1986).

Figure 13a-c show lat-long means of $\mathrm{HR}\left(\mathrm{RO}_{2}\right)$ effects calculated for the respective pressure ranges: the lat-long values are constrained for the entire globe, the Northern 
(a) Annual effects by HRs in zonal mean
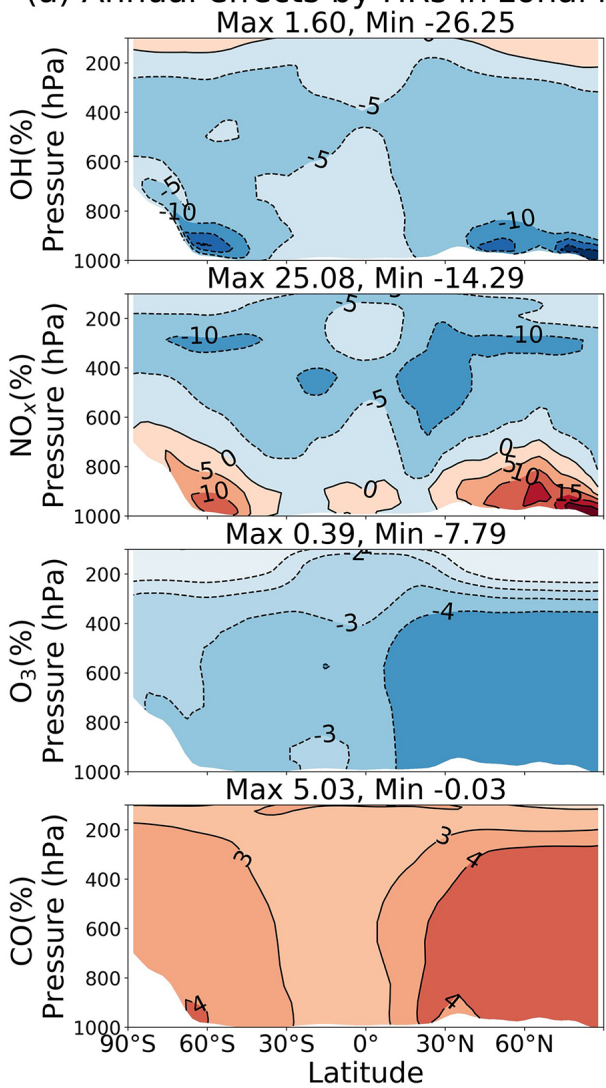

Figure 14. Annual zonal mean (a) and surface (b) total HR effects.

Hemisphere, and North Pacific region. For the entire globe, the contrast effects of $\mathrm{HR}\left(\mathrm{RO}_{2}\right)$ between the lower and higher troposphere on $\mathrm{NO}_{x}$ and $\mathrm{OH}$ are shown clearly $\left(+3.50 \% \mathrm{NO}_{x}\right.$ and $+0.55 \% \mathrm{OH}$ at $900 \mathrm{hPa}$, but $-2.50 \%$ $\mathrm{NO}_{x}$ and $-0.75 \% \mathrm{OH}$ at $400-500 \mathrm{hPa}$ annually). As a result, the annual mean $\mathrm{O}_{3}$ and $\mathrm{CO}$ levels decreased throughout the troposphere, reaching their lowest at $-1.60 \% \mathrm{O}_{3}$ and $-1.50 \% \mathrm{CO}$ at the surface. In JJA, the global effects by $\mathrm{HR}\left(\mathrm{RO}_{2}\right)$ are more concentrated in the lower troposphere, especially in the North Pacific $\left(+3 \% \mathrm{OH},+10 \% \mathrm{NO}_{x}\right.$, $-3 \% \mathrm{O}_{3},-2 \% \mathrm{CO}$ at $\left.900-1000 \mathrm{hPa}\right)$. In DJF, the $\mathrm{HR}\left(\mathrm{RO}_{2}\right)$ effects are observed mostly in the middle and higher troposphere, especially when considering the Northern Hemisphere $\left(-1.25 \% \mathrm{OH},-4 \% \mathrm{NO}_{x},-2 \% \mathrm{O}_{3}\right.$ at $\left.500-800 \mathrm{hPa}\right)$.

\subsubsection{Total effects of all HRs}

As discussed above, different heterogeneous reactions affect tropospheric chemistry differently. However, their effects can either augment or negate others in performing for the atmospheric chemistry. $\mathrm{HR}\left(\mathrm{N}_{2} \mathrm{O}_{5}\right)$ is the greatest contributor to reduction of tropospheric $\mathrm{OH}, \mathrm{O}_{3}$, and $\mathrm{NO}_{x}$ abundances and is more active in the middle troposphere. $\mathrm{HR}\left(\mathrm{HO}_{2}\right)$ reduces $\mathrm{OH}$ but increases the abundances of $\mathrm{O}_{3}$ and $\mathrm{NO}_{x}$ globally, (b) Annual effects by HRs at the surface
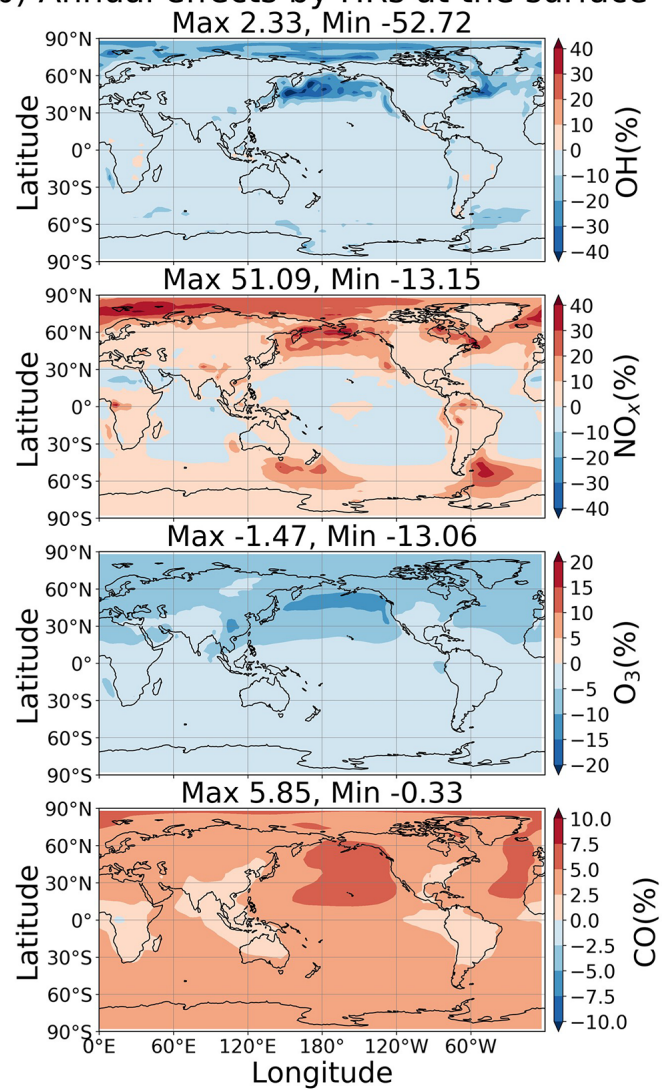

whereas it exposes a negative effect on $\mathrm{O}_{3}$ level at the surface of the North Pacific region. $\mathrm{HR}\left(\mathrm{RO}_{2}\right)$ similarly has a smaller distribution to the total heterogeneous effects, but its global mean negative effects for $\mathrm{O}_{3}$ are not negligible. The uptake of $\mathrm{N}_{2} \mathrm{O}_{5}$ mainly takes place for aerosols, whereas the uptakes of $\mathrm{HO}_{2}$ and $\mathrm{RO}_{2}$ occur more for liquid and ice clouds. Overall, the total effects of all HRs for the whole troposphere are $+5.91 \%$ for global mean $\mathrm{CH}_{4}$ lifetime, $-2.19 \%$ for $\mathrm{NO}_{x}$ (tropospheric abundance), $-2.96 \%$ for $\mathrm{O}_{3}$, and $+3.28 \%$ for CO (Table 9). At the surface, the annual effects ranged from about $-53 \%$ to $+2 \%$ for $\mathrm{OH},-13 \%$ to $+51 \%$ for $\mathrm{NO}_{x},-13 \%$ to $-2 \%$ for $\mathrm{O}_{3}$, and $-0.3 \%$ to $+6 \%$ for $\mathrm{CO}$ (Fig. 14).

As Fig. 13d-f show for the vertical profiles of HR effects, the change of $\mathrm{OH}$ largely concentrated in the lower troposphere $(-10 \% \mathrm{OH}$ at $900 \mathrm{hPa}$, calculated for the entire globe) is associated with the $\mathrm{HO}_{2}$ uptake. By contrast, the $\mathrm{NO}_{x}$ change is more intensive at higher altitudes $(-9 \%$ $\mathrm{NO}_{x}$ at $400 \mathrm{hPa}$, calculated for the entire globe), associated with $\mathrm{N}_{2} \mathrm{O}_{5}$ and $\mathrm{RO}_{2}$ uptake. The global mean HR effects on $\mathrm{O}_{3}$ and $\mathrm{CO}$ are vertically even, with the highest effects reaching $-4 \% \mathrm{O}_{3}$ and $+4 \% \mathrm{CO}$ at the surface. Globally, HR effects on atmospheric oxidants $\left(\mathrm{OH}\right.$ and $\left.\mathrm{O}_{3}\right)$ are enhanced in DJF because of the higher pollution in the Northern Hemi- 
Table 9. Tropospheric abundances changes by $\mathrm{HR}\left(\mathrm{N}_{2} \mathrm{O}_{5}\right), \mathrm{HR}\left(\mathrm{HO}_{2}\right), \mathrm{HR}\left(\mathrm{RO}_{2}\right)$, and all $\mathrm{HRs}$ for clouds and aerosols.

\begin{tabular}{|c|c|c|c|c|}
\hline & \multirow[t]{2}{*}{$\mathrm{CH}_{4}$ lifetime (year) } & \multicolumn{3}{|c|}{ Tropospheric abundances } \\
\hline & & $\mathrm{NO}_{x}(\mathrm{TgN})$ & $\mathrm{O}_{3}\left(\mathrm{TgO}_{3}\right)$ & $\mathrm{CO}(\mathrm{TgCO})$ \\
\hline STD & 9.44 & 0.115 & 402.29 & 337.12 \\
\hline noHR_n2o5 & 9.04 & 0.122 & 410.99 & 325.98 \\
\hline noHR_n2o5(Cld) & 9.41 & 0.116 & 402.81 & 336.43 \\
\hline noHR_n2o5(Ae) & 9.09 & 0.121 & 409.81 & 327.46 \\
\hline noHR_ho2 & 9.30 & 0.111 & 402.09 & 330.67 \\
\hline noHR_ho2(Cld) & 9.35 & 0.113 & 402.25 & 332.97 \\
\hline noHR_ho2(Ae) & 9.40 & 0.114 & 402.17 & 335.29 \\
\hline noHR_ro2 & 9.43 & 0.114 & 406.06 & 343.23 \\
\hline noHR_ro2(Cld) & 9.42 & 0.115 & 403.96 & 339.06 \\
\hline noHR_ro2(Ae) & 9.45 & 0.115 & 404.03 & 340.76 \\
\hline noHR & 8.91 & 0.118 & 414.55 & 326.43 \\
\hline $\operatorname{noHR}(\mathrm{Cld})$ & 9.32 & 0.113 & 404.55 & 335.03 \\
\hline $\operatorname{noHR}(\mathrm{Ae})$ & 9.06 & 0.119 & 411.38 & 329.20 \\
\hline STD - noHR_n2o5 & $+4.48 \%$ & $-5.51 \%$ & $-2.12 \%$ & $+3.42 \%$ \\
\hline STD - noHR_n2o5(Cld) & $+0.30 \%$ & $-0.43 \%$ & $-0.13 \%$ & $+0.21 \%$ \\
\hline STD - noHR_n2o5(Ae) & $+3.87 \%$ & $-4.56 \%$ & $-1.83 \%$ & $+2.95 \%$ \\
\hline STD - noHR_ho2 & $+1.51 \%$ & $+3.26 \%$ & $+0.05 \%$ & $+1.95 \%$ \\
\hline STD - noHR_ho2(Cld) & $+1.00 \%$ & $+1.87 \%$ & $+0.01 \%$ & $+1.25 \%$ \\
\hline STD - noHR_ho2(Ae) & $+0.41 \%$ & $+1.11 \%$ & $+0.03 \%$ & $+0.55 \%$ \\
\hline STD - noHR_ro2 & $+0.15 \%$ & $+0.52 \%$ & $-0.93 \%$ & $-1.78 \%$ \\
\hline STD - noHR_ro2(Cld) & $+0.23 \%$ & $+0.39 \%$ & $-0.41 \%$ & $-0.57 \%$ \\
\hline STD - noHR_ro2(Ae) & $-0.12 \%$ & $+0.09 \%$ & $-0.43 \%$ & $-1.07 \%$ \\
\hline STD - noHR & $+5.91 \%$ & $-2.19 \%$ & $-2.96 \%$ & $+3.28 \%$ \\
\hline STD - noHR(Cld) & $+1.34 \%$ & $+1.71 \%$ & $-0.56 \%$ & $+0.63 \%$ \\
\hline STD - noHR(Ae) & $+4.15 \%$ & $-3.44 \%$ & $-2.21 \%$ & $+2.41 \%$ \\
\hline
\end{tabular}

sphere. However, the largest HR effects are apparent for JJA at the surface of the North Pacific $\left(-25 \% \mathrm{OH},+38 \% \mathrm{NO}_{x}\right.$, $-14 \% \mathrm{O}_{3}$, and $+6 \% \mathrm{CO}$ as calculated for the $950-1000 \mathrm{hPa}$ layer). These effects are mostly ascribed to $\mathrm{HO}_{2}$ uptake onto clouds. This finding is also apparent from Fig. S15b: these effects reach $-66 \%$ for $\mathrm{OH},+206 \%$ for $\mathrm{NO}_{x},-23 \%$ for $\mathrm{O}_{3}$, and $+4.4 \%$ for $\mathrm{CO}$ at the surface. They were able to extend up to $400 \mathrm{hPa}$ in the atmosphere. These substantial effects are readily apparent for the large reduction of $\mathrm{O}_{3}$ level during Mirai observation (hatched field in Fig. 4d, T5). However, the major contribution of $\mathrm{HR}\left(\mathrm{HO}_{2}\right)$ to these effects is only partially verified by the ATom 1 measurements in this study (Fig.6q, hatched bars at 500-700 hPa). Because of model overestimates of cloud fraction in JJA for the North Pacific region, these effects of $\mathrm{HR}\left(\mathrm{HO}_{2}\right)$ should have existed at a smaller magnitude. For HR effects in the middle to upper troposphere, the $\mathrm{N}_{2} \mathrm{O}_{5}$ uptake on aerosols is dominant in these layers and intense in both DJF and JJA.

\subsection{Sensitivities of tropospheric chemistry respond to heterogeneous reactions}

From the discussion presented above, marked effects of HRs on global tropospheric chemistry are apparent. Here we examine how the tropospheric chemistry responds to the mag- nitude of HRs' loss rates. To do this, we introduced a factor $F$ for application to the first-order loss rate shown in Eq. (1) for artificially manipulating the HR magnitude.

$\beta_{i}=\sum_{j}\left(\frac{4}{v_{i} \gamma_{i j}}+\frac{R_{j}}{D_{i j}}\right)^{-1} A_{j} \times F$

For this sensitivity test, we only specifically examine $\mathrm{HR}\left(\mathrm{HO}_{2}\right)$ and $\mathrm{HR}\left(\mathrm{N}_{2} \mathrm{O}_{5}\right)$ and consider factors of $0-10$ for the STD run (Table S1). This test might help to show the effective oxidation sensitivity of the troposphere because future pollution and climate change might enhance the activities of these HRs.

For both effects, we performed nonlinear function fitting with their uptake loss rates, which yielded correlation coefficients higher than 0.93 (Fig. 15). Although both HRs showed negative tendencies for $\mathrm{OH}$ and $\mathrm{O}_{3}$ levels, the effect of $\mathrm{HR}\left(\mathrm{HO}_{2}\right)$ on the tropospheric abundance of $\mathrm{O}_{3}$ showed only a small increment with an increasing loss rate (maxima at around $F=3$ ) and turned to reduction at higher rates $(F>5)$. As discussed alongside $\mathrm{HR}\left(\mathrm{HO}_{2}\right)$ effects, the $\mathrm{O}_{3}$ level is expected to be primarily reduced only in JJA at the surface of the North Pacific region. At the same time, $\mathrm{O}_{3}$ will be increased gradually elsewhere because of the persistent $\mathrm{NO}_{x}$ increment. This behavior produces a positive global 

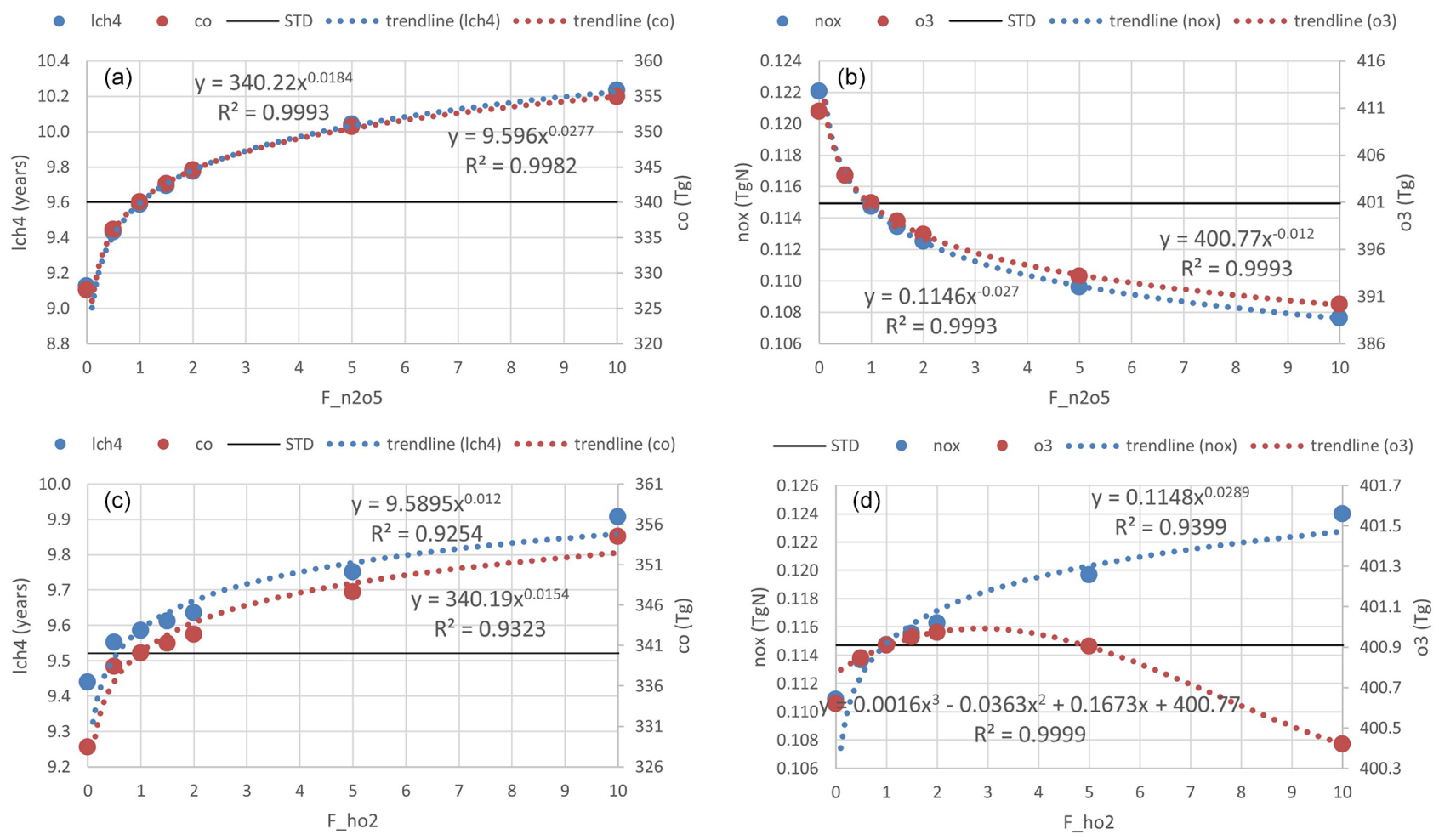

Figure 15. Trend lines for the sensitivity of $\mathrm{HR}\left(\mathrm{N}_{2} \mathrm{O}_{5}\right)(\mathbf{a}, \mathbf{b})$ and $\mathrm{HR}\left(\mathrm{HO}_{2}\right)$ effects $(\mathbf{c}, \mathbf{d})$, with uptake rates shown. Panels (a) and (c) show the $\mathrm{CH}_{4}$ lifetime (blue) and tropospheric abundance of $\mathrm{CO}$ (red). Panels (b) and (d) show tropospheric abundances of $\mathrm{NO}_{x}\left(\right.$ blue) and $\mathrm{O}_{3}$ (red).

mean effect. Figure 10 (dashed lines) shows that manipulation of the $\mathrm{HR}\left(\mathrm{HO}_{2}\right)$ loss rate that is 10 factors higher will effectively increase the negative $\mathrm{HR}\left(\mathrm{HO}_{2}\right)$ effects on $\mathrm{O}_{3}$ in DJF (dashed blue versus solid blue lines, third row, fourth column), which results in a higher tendency of negative values for global mean effects. This sensitivity in DJF might be attributable to the $\mathrm{HO}_{2}$ uptake to aerosols rather than to clouds during this polluted period, which is apparent through comparison of Figs. 11 and S16 for notable events. In DJF, by amplifying the $\mathrm{HO}_{2}$ uptake loss rate by a factor of 10 , the effects for the polluted Chinese area (because of $\mathrm{HO}_{2}$ uptake onto aerosols) significantly magnify from $-18 \%$ (Fig. 11m) to $-47 \%$ (third row, first column in Fig. S16b). In contrast, effects at the surface $\mathrm{O}_{3}$ level in JJA for the North Pacific region (because of $\mathrm{HO}_{2}$ uptake onto clouds) only enhance from $-21 \%$ (Fig. 11n) to $-29 \%$ (third row, second column in Fig. S16b).

When amplifying $\mathrm{HR}\left(\mathrm{N}_{2} \mathrm{O}_{5}\right)$ by a factor of 10 , the sensitivities of global effects show no seasonal variation. The $\mathrm{HR}\left(\mathrm{N}_{2} \mathrm{O}_{5}\right)$ effects are more sensitive in DJF for the North Pacific region, which link to the higher concentration of aerosol in this season. Otherwise, the $\mathrm{HR}\left(\mathrm{N}_{2} \mathrm{O}_{5}\right)$ effects for the generic Northern Hemisphere tend to be more sensitive in JJA as a result of pollutant transportation to the higher troposphere.
Consequently, we suggest that the sensitivity of tropospheric chemistry to $\mathrm{HR}\left(\mathrm{N}_{2} \mathrm{O}_{5}\right)$ and $\mathrm{HR}\left(\mathrm{HO}_{2}\right)$ might be attributable to loss activities of aerosols rather than to clouds. The sharply curved effect on $\mathrm{O}_{3}$ because of amplification of $\mathrm{HR}\left(\mathrm{HO}_{2}\right)$ makes sense in plans for ozone pollution control when increased pollution or climate change factors cause the rate of HRs to increase by 3-5 times or more in the future.

\section{Conclusion}

The "CHASER" chemistry-climate model was used to investigate global effects of $\mathrm{N}_{2} \mathrm{O}_{5}, \mathrm{HO}_{2}$, and $\mathrm{RO}_{2}$ uptake. Verification of the model with observations from inland and ocean domains showed adequate agreement for $\mathrm{PM}_{2.5}, \mathrm{SO}_{4}^{2-}$, and $\mathrm{NO}_{3}^{-}$particles and gaseous $\mathrm{HNO}_{3}, \mathrm{NO}_{x}, \mathrm{OH}, \mathrm{CO}$, and $\mathrm{O}_{3}$ concentrations. $R$, bias, and NRMSE values for $\mathrm{SO}_{4}^{2-}, \mathrm{NO}_{3}^{-}$, and $\mathrm{HNO}_{3}$ at EANET and EMEP stations are comparable with other models. Inclusion of HRs reduced model bias for $\mathrm{OH}, \mathrm{NO}_{2}, \mathrm{CO}$, and $\mathrm{O}_{3}$, especially in the low troposphere. However, verification with satellite and reanalysis data showed deterioration by HRs for TCO and an overestimate for cloud fraction in the North Pacific region.

The total effects of HRs are important for the tropospheric chemistry that might change $+5.91 \% \mathrm{CH}_{4}$ lifetime and $-2.19 \% \mathrm{NO}_{x},-2.96 \% \mathrm{O}_{3}$, and $+3.28 \% \mathrm{CO}$ abun- 
dances. Global effects are $-9 \% \mathrm{NO}_{x}$ at $400 \mathrm{hPa},-10 \% \mathrm{OH}$ at $900 \mathrm{hPa}$, and $-4 \% \mathrm{O}_{3}$ and $+4 \% \mathrm{CO}$ at the surface. Global HR effects tend to be enhanced in DJF because of greater amounts of pollution in the Northern Hemisphere.

Total HR effects are contributed mainly by $\mathrm{HR}\left(\mathrm{N}_{2} \mathrm{O}_{5}\right)$ onto aerosols in the middle troposphere. At the surface, $\mathrm{HR}\left(\mathrm{HO}_{2}\right)$ is more active and leaves a remarkable disturbance in JJA at the North Pacific region with changes of $-70 \%$ for $\mathrm{OH},-24 \%$ for $\mathrm{O}_{3},+68 \%$ for $\mathrm{NO}_{x}$, and $+8 \%$ for $\mathrm{CO}$. These effects were attributed to the uptake of $\mathrm{HO}_{2}$ on cloud particles, which were partially verified with ATom1 observations. $\mathrm{HR}\left(\mathrm{RO}_{2}\right)$, which also favors cloud particles, minorly contributes to the tropospheric chemistry, but it has enormous impacts on PAN and $\mathrm{NO}_{x}$ transportation $\left(+144 \% \mathrm{NO}_{x}\right.$ for the North Pacific and Atlantic regions in JJA) and the negative changes in $\mathrm{CO}(-1.78 \%)$, as compared to positive effects by $\mathrm{HR}\left(\mathrm{N}_{2} \mathrm{O}_{5}\right)$ and $\mathrm{HR}\left(\mathrm{HO}_{2}\right)$, that can not be neglected. However, the effect magnitude requires further investigation because of model overestimates for cloud fractions in this region.

The sensitivity of tropospheric chemistry to HR magnitude was determined as a nonlinear function. The increasing effect on the global $\mathrm{O}_{3}$ abundance from $\mathrm{HR}\left(\mathrm{HO}_{2}\right)$ will sharply change to a decreasing effect when the uptake rate is amplified by more than 3 times. This turning is ascribed to the uptake onto aerosols in DJF. In general, uptake to aerosols is more responsive to the heterogeneous loss rate than uptake to clouds.

Overall, the $\mathrm{N}_{2} \mathrm{O}_{5}$ and $\mathrm{HO}_{2}$ uptakes will sweep away atmospheric oxidants, thereby enhancing concentrations of pollutants. Our results reveal that although HRs are reported to be associated with polluted regions, the global effects of HRs reach further remote regions such as the marine boundary layer at mid-latitudes and the upper troposphere. For ground-based studies of polluted regions such as China, it should be considered that $\mathrm{HR}\left(\mathrm{HO}_{2}\right)$ and $\mathrm{HR}\left(\mathrm{RO}_{2}\right)$ were able to contribute to the $\mathrm{NO}_{x}$ increment in DJF and JJA, respectively. Moreover, the $\mathrm{HR}\left(\mathrm{HO}_{2}\right)$ effect might hinder efforts at reducing environmental pollution in urban areas because it increases $\mathrm{NO}_{x}$ but decreases $\mathrm{O}_{3}$ at the surface. Therefore, if this reaction is minimized because of a decrease in particulate matter, then the surface ozone level might increase.

Code availability. The source code for CHASER V4.0 and input data to reproduce results in this work can be obtained from the repository at https://doi.org/10.5281/zenodo.4153452 (Ha et al., 2020).

Data availability. The underlying data from R/V Mirai cruises for the period 2015-2017 are available from http://www.godac.jamstec. go.jp/darwin/e (last access: 30 June 2020). Due to a recent data security incident, the data owner (JAMSTEC) is suspending pub- lic access to this dataset. For any inquiries, please send email to yugo@jamstec.go.jp.

Supplement. The supplement related to this article is available online at: https://doi.org/10.5194/gmd-14-3813-2021-supplement.

Author contributions. PTMH performed all simulations (except simulations for the cloud fraction validation), interpreted the results, and wrote the manuscript. KS developed the model code, conceived of the presented idea, and supervised the findings of this work and the manuscript preparation. RM carried out the simulations and plots for the validation of cloud fraction. YK and FT provided the R/V Mirai ship data and contributed to the discussion of the work's findings.

Competing interests. The authors declare that they have no conflict of interest.

Disclaimer. Publisher's note: Copernicus Publications remains neutral with regard to jurisdictional claims in published maps and institutional affiliations.

Acknowledgements. We are grateful to the NASA scientists and staff for providing the ATom data (https://espo.nasa.gov/atom/ content/ATom, last access: 30 June 2020). The simulations were completed using the supercomputer (NEC SX-Ace and SX-Aurora TSUBASA) at NIES, Japan. The surface observational data for the model validation were taken from the monitoring networks EANET (https://www.eanet.asia/, last access: 25 February 2020) and EMEP (https://www.emep.int/, last access: 25 February 2020).

We also would like to thank the two anonymous reviewers for their helpful suggestions and advice on the earlier draft of the manuscript.

Financial support. This research was supported by the Global Environment Research Fund (grant nos. S-12 and S-20) of the Ministry of the Environment (MOE), Japan, and by JSPS KAKENHI (grant nos. JP20H04320, JP19H05669, and JP19H04235).

Review statement. This paper was edited by Gerd A. Folberth and reviewed by two anonymous referees.

\section{References}

Akimoto, H., Nagashima, T., Li, J., Fu, J. S., Ji, D., Tan, J., and Wang, Z.: Comparison of surface ozone simulation among selected regional models in MICS-Asia III - effects of chemistry and vertical transport for the causes of difference, Atmos. Chem. Phys., 19, 603-615, https://doi.org/10.5194/acp-19-6032019, 2019. 
Apodaca, R. L., Huff, D. M., and Simpson, W. R.: The role of ice in $\mathrm{N}_{2} \mathrm{O}_{5}$ heterogeneous hydrolysis at high latitudes, Atmos. Chem. Phys., 8, 7451-7463, https://doi.org/10.5194/acp-8-7451-2008, 2008.

Bates, K. H. and Jacob, D. J.: A new model mechanism for atmospheric oxidation of isoprene: global effects on oxidants, nitrogen oxides, organic products, and secondary organic aerosol, Atmos. Chem. Phys., 19, 9613-9640, https://doi.org/10.5194/acp19-9613-2019, 2019.

Battan, L. J. and Reitan, C. H.: Droplet size measurements in convective clouds, in Artificial simulation of Rain, Pergamon Press, New York, 184-191, 1957.

Betterton, E. A.: Henry's Law constants of soluble and moderately soluble organic gases: effects on aqueous-phase chemistry, in: Gaseous pollutants: Characterization and cycling, Wiley, 24, 150, 1992.

Bian, H., Chin, M., Hauglustaine, D. A., Schulz, M., Myhre, G., Bauer, S. E., Lund, M. T., Karydis, V. A., Kucsera, T. L., Pan, X., Pozzer, A., Skeie, R. B., Steenrod, S. D., Sudo, K., Tsigaridis, K., Tsimpidi, A. P., and Tsyro, S. G.: Investigation of global particulate nitrate from the AeroCom phase III experiment, Atmos. Chem. Phys., 17, 12911-12940, https://doi.org/10.5194/acp-1712911-2017, 2017.

Brown, S. S. and Stutz, J.: Nighttime radical observations and chemistry, Chem. Soc. Rev., 41, 6405-6447, 2012.

Chen, Y., Wolke, R., Ran, L., Birmili, W., Spindler, G., Schröder, W., Su, H., Cheng, Y., Tegen, I., and Wiedensohler, A.: A parameterization of the heterogeneous hydrolysis of N2O5 for mass-based aerosol models: improvement of particulate nitrate prediction, Atmos. Chem. Phys., 18, 673-689, https://doi.org/10.5194/acp-18-673-2018, 2018.

Cooper, P. L. and Abbatt, J. P. D.: Heterogeneous interactions of $\mathrm{OH}$ and $\mathrm{HO}_{2}$ radicals with surfaces characteristic of atmospheric particulate matter, J. Phys. Chem., 100, 2249-2254, 1996.

Dentener, F. J.: Heterogeneous chemistry in the troposphere, $\mathrm{PhD}$ Thesis, U. of Utrecht, the Netherlands, 1993.

Dentener, F. J. and Crutzen, P. J.: Reaction of $\mathrm{N}_{2} \mathrm{O}_{5}$ on tropospheric aerosols: Impact on the global distributions of $\mathrm{NO}_{x}, \mathrm{O}_{3}$, and $\mathrm{OH}$, J. Geophys. Res.-Atmos., 98, 7149-7163, 1993.

de Reus, M., Fischer, H., Sander, R., Gros, V., Kormann, R., Salisbury, G., Van Dingenen, R., Williams, J., Zöllner, M., and Lelieveld, J.: Observations and model calculations of trace gas scavenging in a dense Saharan dust plume during MINATROC, Atmos. Chem. Phys., 5, 1787-1803, https://doi.org/10.5194/acp5-1787-2005, 2005.

Evans, M. J. and Jacob, D. J.: Impact of new laboratory studies of $\mathrm{N}_{2} \mathrm{O}_{5}$ hydrolysis on global model budgets of tropospheric nitrogen oxides, ozone, and OH, Geophys. Res. Lett., 32, 1-4, 2005.

Gaudel, A., Cooper, O. R., Ancellet, G., Barret, B., Boynard, A., Burrows, J. P., Clerbaux, C., Coheur, P.-F., Cuesta, J., Cuevas, E., Doniki, S., Dufour, G., Ebojie, F., Foret, G., Garcia, O., Granados-Muñoz, M. J., Hannigan, J. W., Hase, F., Hassler, B., Huang, G., Hurtmans, D., Jaffe, D., Jones, N., Kalabokas, P., Kerridge, B., Kulawik, S., Latter, B., Leblanc, T., Le Flochmoën, E., Lin, W., Liu, J., Liu, X., Mahieu, E., McClure-Begley, A., Neu, J. L., Osman, M., Palm, M., Petetin, H., Petropavlovskikh, I., Querel, R., Rahpoe, N., Rozanov, A., Schultz, M. G., Schwab, J., Siddans, R., Smale, D., Steinbacher, M., Tanimoto, H., Tarasick, D. W., Thouret, V., Thompson, A. M., Trickl, T., Weath- erhead, E., Wespes, C., Worden, H. M., Vigouroux, C., Xu, X., Zeng, G., and Ziemke, J.: Tropospheric Ozone Assessment Report: Present-day distribution and trends of tropospheric ozone relevant to climate and global atmospheric chemistry model evaluation, Elem. Sci. Anth., 6, 1-58, 2018.

Geyer, A., Bächmann, K., Hofzumahaus, A., Holland, F., Konrad, S., Klüpfel, T., Pätz, H.-W., Perner, D., Mihelcic, D., Schäfer, H.J., Volz-Thomas, A., and Platt, U.: Nighttime formation of peroxy and hydroxyl radicals during the BERLIOZ campaign: Observations and modeling studies, J. Geophys. Res.-Atmos., 108, $1-16,2003$.

Ha, T. M. P., Taketani, F., Kanaya, Y., Matsuda, R., and Sudo, K.: Effects of heterogeneous reactions on global tropospheric chemistry (Version CHASER-V4.0) [Code], Zenodo, https://doi.org/10.5281/zenodo.4153452, 2020.

Huijnen, V., Williams, J. E., and Flemming, J.: Modeling global impacts of heterogeneous loss of $\mathrm{HO} 2$ on cloud droplets, ice particles and aerosols, Atmos. Chem. Phys. Discuss., 14, 8575-8632, https://doi.org/10.5194/acpd-14-8575-2014, 2014.

Inness, A., Baier, F., Benedetti, A., Bouarar, I., Chabrillat, S., Clark, H., Clerbaux, C., Coheur, P., Engelen, R. J., Errera, Q., Flemming, J., George, M., Granier, C., Hadji-Lazaro, J., Huijnen, V., Hurtmans, D., Jones, L., Kaiser, J. W., Kapsomenakis, J., Lefever, K., Leitão, J., Razinger, M., Richter, A., Schultz, M. G., Simmons, A. J., Suttie, M., Stein, O., Thépaut, J.-N., Thouret, V., Vrekoussis, M., Zerefos, C., and the MACC team: The MACC reanalysis: an $8 \mathrm{yr}$ data set of atmospheric composition, Atmos. Chem. Phys., 13, 4073-4109, https://doi.org/10.5194/acp13-4073-2013, 2013.

Jacob, D. J.: Chemistry of $\mathrm{OH}$ in remote clouds and its role in the production of formic acid and peroxymonosulfate, J. Geophys. Res., 91, 9807-9826, 1986.

Jacob, D. J.: Introduction to Atmospheric Chemistry, Princeton University Press, USA, 1999.

Jacob, D. J.: Heterogeneous chemistry and tropospheric ozone, Atmos. Environ., 34, 2131-2159, 2000.

Janssens-Maenhout, G., Crippa, M., Guizzardi, D., Dentener, F., Muntean, M., Pouliot, G., Keating, T., Zhang, Q., Kurokawa, J., Wankmüller, R., Denier van der Gon, H., Kuenen, J. J. P., Klimont, Z., Frost, G., Darras, S., Koffi, B., and Li, M.: HTAP_v2.2: a mosaic of regional and global emission grid maps for 2008 and 2010 to study hemispheric transport of air pollution, Atmos. Chem. Phys., 15, 11411-11432, https://doi.org/10.5194/acp-15-11411-2015, 2015.

Japan Meteorological Agency/Japan: JRA-55: Japanese 55-year Reanalysis, Daily 3-Hourly and 6-Hourly Data. Research Data Archive at the National Center for Atmospheric Research, Computational and Information Systems Laboratory, https://doi.org/10.5065/D6HH6H41 (last access: 12 June 2020), 2013, updated monthly.

Kanaya, Y., Sadanaga, Y., Hirokawa, J. U. N., Kajii, Y., and Akimoto, H.: Development of a Ground-Based LIF Instrument for Measuring $\mathrm{HO}_{x}$ Radicals: Instrumentation and Calibrations, J. Atmos. Chem., 38, 73-110, 2001.

Kanaya, Y., Nakamura, K., Kato, S., Matsumoto, J., Tanimoto, H., and Akimoto, $\mathrm{H}$.: Nighttime variations in $\mathrm{HO}_{2}$ radical mixing ratios at Rishiri Island observed with elevated monoterpene mixing ratios, Atmos. Environ., 36, 4929-4940, 2002a. 
Kanaya, Y., Yokouchi, Y., Matsumoto, J., Nakamura, K., Kato, S., Tanimoto, H., Furutani, H., Toyota, K., and Akimoto, H.: Implications of iodine chemistry for daytime $\mathrm{HO}_{2}$ levels at Rishiri Island, Geophys. Res. Lett., 29, 1-4, 2002 b.

Kanaya, Y., Kajii, Y., and Akimoto, H.: Solar actinic flux and photolysis frequency determinations byradiometers and a radiative transfer model at Rishiri Island: Comparisons, cloud effects, and detection of an aerosol plumefrom Russian forest fires, Atmos. Environ., 37, 2463-2475, 2003.

Kanaya, Y., Cao, R., Kato, S., Miyakawa, Y., Kajii, Y., Tanimoto, H., Yokouchi, Y., Mochida, M., Kawamura, K., and Akimoto, H.: Chemistry of $\mathrm{OH}$ and $\mathrm{HO}_{2}$ radicals observed at Rishiri Island, Japan, in September 2003: Missing daytime sink of $\mathrm{HO}_{2}$ and positive nighttime correlations with monoterpenes, J. Geophys. Res., 112, D11308, https://doi.org/10.1029/2006JD007987, 2007.

Kanaya, Y., Pochanart, P., Liu, Y., Li, J., Tanimoto, H., Kato, S., Suthawaree, J., Inomata, S., Taketani, F., Okuzawa, K., Kawamura, K., Akimoto, H., and Wang, Z. F.: Rates and regimes of photochemical ozone production over Central East China in June 2006: a box model analysis using comprehensive measurements of ozone precursors, Atmos. Chem. Phys., 9, 7711-7723, https://doi.org/10.5194/acp-9-7711-2009, 2009.

Kanaya, Y., Miyazaki, K., Taketani, F., Miyakawa, T., Takashima, H., Komazaki, Y., Pan, X., Kato, S., Sudo, K., Sekiya, T., Inoue, J., Sato, K., and Oshima, K.: Ozone and carbon monoxide observations over open oceans on R/V Mirai from $67^{\circ} \mathrm{S}$ to $75^{\circ} \mathrm{N}$ during 2012 to 2017: testing global chemical reanalysis in terms of Arctic processes, low ozone levels at low latitudes, and pollution transport, Atmos. Chem. Phys., 19, 7233-7254, https://doi.org/10.5194/acp-19-7233-2019, 2019.

Lawrence, M. G. and Crutzen, P. J.: The impact of cloud particle gravitational settling on soluble trace gas distributions, Tellus, Ser. B Chem. Phys. Meteorol., 50B, 263-289, 1998.

Lelieveld, J. and Crutzen, P. J.: Influences of cloud photochemical processes on tropospheric ozone, Nature, 343, 227-233, 1990.

Lelieveld, J. and Crutzen, P. J.: The role of clouds in tropospheric photochemistry, J. Atmos. Chem., 12, 229-267, 1991.

Li, J., Chen, X., Wang, Z., Du, H., Yang, W., Sun, Y., Hu, B., Li, J., Wang, W., Wang, T., Fu, P., and Huang, H.: Radiative and heterogeneous chemical effects of aerosols on ozone and inorganic aerosols over East Asia, Sci. Total Environ., 622-623, 13271342, 2018

Li, K., Jacob, D. J., Liao, H., Shen, L., Zhang, Q., and Bates, K. H.: Anthropogenic drivers of 2013-2017 trends in summer surface ozone in China, P. Natl. Acad. Sci. USA, 116, 422-427, 2019.

Liao, H. and Seinfeld, J. H.: Global impacts of gas-phase chemistryaerosol interactions on direct radiative forcing by anthropogenic aerosols and ozone, J. Geophys. Res.-Atmos., 110, D18208, https://doi.org/10.1029/2005JD005907, 2005.

Lin, J.-T., Liu, Z., Zhang, Q., Liu, H., Mao, J., and Zhuang, G.: Modeling uncertainties for tropospheric nitrogen dioxide columns affecting satellite-based inverse modeling of nitrogen oxides emissions, Atmos. Chem. Phys., 12, 12255-12275, https://doi.org/10.5194/acp-12-12255-2012, 2012.

Liu, Y. and Wang, T.: Worsening urban ozone pollution in China from 2013 to 2017 - Part 2: The effects of emission changes and implications for multi-pollutant control, Atmos.
Chem. Phys., 20, 6323-6337, https://doi.org/10.5194/acp-206323-2020, 2020.

Logan, J. A., Prather, M. J., Wofsy, S. C., and McElroy, M. B.: Tropospheric chemistry: a global perspective, J. Geophys. Res., 86, 7210-7254, 1981.

Loukhovitskaya, E., Bedjanian, Y., Morozov, I., and Le Bras, G.: Laboratory study of the interaction of $\mathrm{HO} 2$ radicals with the $\mathrm{NaCl}, \mathrm{NaBr}, \mathrm{MgCl}_{2} \cdot 6 \mathrm{H}_{2} \mathrm{O}$ and sea salt surfaces, Phys. Chem. Chem. Phys., 11, 7896-7905, 2009.

Lowe, D., Archer-Nicholls, S., Morgan, W., Allan, J., Utembe, S., Ouyang, B., Aruffo, E., Le Breton, M., Zaveri, R. A., Di Carlo, P., Percival, C., Coe, H., Jones, R., and McFiggans, G.: WRF-Chem model predictions of the regional impacts of $\mathrm{N} 2 \mathrm{O} 5$ heterogeneous processes on night-time chemistry over north-western Europe, Atmos. Chem. Phys., 15, 1385-1409, https://doi.org/10.5194/acp-15-1385-2015, 2015.

Macintyre, H. L. and Evans, M. J.: Sensitivity of a global model to the uptake of $\mathrm{N}_{2} \mathrm{O}_{5}$ by tropospheric aerosol, Atmos. Chem. Phys., 10, 7409-7414, https://doi.org/10.5194/acp10-7409-2010, 2010.

Macintyre, H. L. and Evans, M. J.: Parameterisation and impact of aerosol uptake of $\mathrm{HO}_{2}$ on a global tropospheric model, Atmos. Chem. Phys., 11, 10965-10974, https://doi.org/10.5194/acp-1110965-2011, 2011.

Mao, J., Fan, S., Jacob, D. J., and Travis, K. R.: Radical loss in the atmosphere from $\mathrm{Cu}-\mathrm{Fe}$ redox coupling in aerosols, Atmos. Chem. Phys., 13, 509-519, https://doi.org/10.5194/acp-13-5092013, 2013.

Martin, R. V., Jacob, D. J., Yantosca, R. M., Chin, M., and Ginoux, P.: Global and regional decreases in tropospheric oxidants from photochemical effects of aerosols, J. Geophys. Res.-Atmos., 108, 4097, https://doi.org/10.1029/2002JD002622, 2003.

McFarquhar, G. M. and Heymsfield, A. J.: Microphysical characteristics of three anvils sampled during the Central Equatorial Pacific Experiment, J. Atmos. Sci., 53, 2401-2423, 1996.

Monks, P. S., Archibald, A. T., Colette, A., Cooper, O., Coyle, M., Derwent, R., Fowler, D., Granier, C., Law, K. S., Mills, G. E., Stevenson, D. S., Tarasova, O., Thouret, V., von Schneidemesser, E., Sommariva, R., Wild, O., and Williams, M. L.: Tropospheric ozone and its precursors from the urban to the global scale from air quality to short-lived climate forcer, Atmos. Chem. Phys., 15, 8889-8973, https://doi.org/10.5194/acp-15-8889-2015, 2015.

Morgenstern, O., Hegglin, M. I., Rozanov, E., O’Connor, F. M., Abraham, N. L., Akiyoshi, H., Archibald, A. T., Bekki, S., Butchart, N., Chipperfield, M. P., Deushi, M., Dhomse, S. S., Garcia, R. R., Hardiman, S. C., Horowitz, L. W., Jöckel, P., Josse, B., Kinnison, D., Lin, M., Mancini, E., Manyin, M. E., Marchand, M., Marécal, V., Michou, M., Oman, L. D., Pitari, G., Plummer, D. A., Revell, L. E., Saint-Martin, D., Schofield, R., Stenke, A., Stone, K., Sudo, K., Tanaka, T. Y., Tilmes, S., Yamashita, Y., Yoshida, K., and Zeng, G.: Review of the global models used within phase 1 of the Chemistry-Climate Model Initiative (CCMI), Geosci. Model Dev., 10, 639-671, https://doi.org/10.5194/gmd-10-639-2017, 2017.

Morita, A., Kanaya, Y., and Francisco, J. S.: Uptake of the $\mathrm{HO}_{2}$ radical by water: Molecular dynamcs calculations and their implications for atmospheric modeling, J. Geophys. Res.-Atmos. 109, D09201, https://doi.org/10.1029/2003JD004240, 2004. 
National Research Council: Rethinking the Ozone Problem in Urban and Regional Air Pollution, The National Academies Press, Washington, D.C., 1991.

Osthoff, H. D., Sommariva, R., Baynard, T., Pettersson, A., Williams, E. J., Lerner, B. M., Roberts, J. M., Stark, H., Goldan, P. D., Kuster, W. C., Bates, T. S., Coffman, D., Ravishankara, A. R., and Brown, S. S.: Observation of daytime $\mathrm{N}_{2} \mathrm{O}_{5}$ in the marine boundary layer during New England Air Quality Study - Intercontinental Transport and Chemical Transformation 2004, J. Geophys. Res.-Atmos., 111, D23S14, https://doi.org/10.1029/2006JD007593, 2006.

Platt, U. F., Winer, A. M., Biermann, H. W., Atkinson, R., and Pitts, J. N.: Measurement of Nitrate Radical Concentrations in Continental Air, Environ. Sci. Technol., 18, 365-369, 1984.

Qin, M., Zhongming, C., Hengqing, S., Huan, L., Huihui, W., and Yin, W.: Impacts of heterogeneous reactions to atmospheric peroxides: Observations and budget analysis study, Atmos. Environ., 183, 144-153, 2018.

Qu, Y., Chen, Y., Liu, X., Zhang, J., Guo, Y., and An, J.: Seasonal effects of additional HONO sources and the heterogeneous reactions of $\mathrm{N}_{2} \mathrm{O}_{5}$ on nitrate in the North China Plain, Sci. Total Environ., 690, 97-107, 2019.

Richard, W. P.: Chemistry of Atmosphere, Oxford University Press, USA, 2000.

Riemer, N., Vogel, H., Vogel, B., Schell, B., Ackermann, I., Kessler, C., and Hass, H.: Impact of the heterogeneous hydrolysis of $\mathrm{N}_{2} \mathrm{O}_{5}$ on chemistry and nitrate aerosol formation in the lower troposphere under photosmog conditions, J. Geophys. Res., 108, 4144, https://doi.org/10.1029/2002JD002436, 2003.

Riemer, N., Vogel, H., Vogel, B., Anttila, T., Kiendler-Scharr, A., and Mentel, T. F.: Relative importance of organic coatings for the heterogeneous hydrolysis of $\mathrm{N}_{2} \mathrm{O}_{5}$ during summer in Europe, J. Geophys. Res., 114, D17307, https://doi.org/10.1029/2008JD011369, 2009.

Saathoff, H., Naumann, K.-H., Riemer, N., Kamm, S., Mohler, O., Schurath, U., Vogel, H., and Vogel, B.: The loss of $\mathrm{NO}_{2}, \mathrm{HNO}_{3}$, $\mathrm{NO}_{3} / \mathrm{N}_{2} \mathrm{O}_{5}$, and $\mathrm{HO}_{2} / \mathrm{HOONO}_{2}$ on soot aerosol: A chamber and modeling study, Geophys. Res. Lett., 28, 1957-1960, 2001.

Salisbury, G., Rickard, A. R., Monks, P. S., Allan, B. J., Bauguitte, S., Penkett, S. A., Carslaw, N., Lewis, A. C., Creasey, D. J., Heard, D. E., Jacobs, P. J., and Lee, J. D.: Production of peroxy radicals at night via reactions of ozone and the nitrate radical in the marine boundary layer, J. Geophys. Res.-Atmos., 106, 12669-12687, 2001.

Schwartz, S. E.: Mass-Transport Considerations Pertinent to Aqueous Phase Reactions of Gases in Liquid-Water Clouds, in: Chemistry of Multiphase Atmospheric Systems, Springer, Berlin Heidelberg, 415-471, 1986.

Sekiya, T., Miyazaki, K., Ogochi, K., Sudo, K., and Takigawa, M.: Global high-resolution simulations of tropospheric nitrogen dioxide using CHASER V4.0, Geosci. Model Dev., 11, 959-988, https://doi.org/10.5194/gmd-11-959-2018, 2018.

Shepson, P. B., Mackay, E., and Muthuramu, K.: Henry's law constants and removal processes for several atmospheric $\beta$-hydroxy alkyl nitrates, Environ. Sci. Technol., 30, 3618-3623, 1996.

Sommariva, R., Bloss, W. J., Brough, N., Carslaw, N., Flynn, M., Haggerstone, A.-L., Heard, D. E., Hopkins, J. R., Lee, J. D., Lewis, A. C., McFiggans, G., Monks, P. S., Penkett, S. A., Pilling, M. J., Plane, J. M. C., Read, K. A., Saiz-Lopez,
A., Rickard, A. R., and Williams, P. I.: $\mathrm{OH}$ and $\mathrm{HO}_{2}$ chemistry during NAMBLEX: roles of oxygenates, halogen oxides and heterogeneous uptake, Atmos. Chem. Phys., 6, 1135-1153, https://doi.org/10.5194/acp-6-1135-2006, 2006.

Stadtler, S., Simpson, D., Schröder, S., Taraborrelli, D., Bott, A., and Schultz, M.: Ozone impacts of gas-aerosol uptake in global chemistry transport models, Atmos. Chem. Phys., 18, 31473171, https://doi.org/10.5194/acp-18-3147-2018, 2018.

Sudo, K. and Akimoto, H.: Global source attribution of tropospheric ozone: Long-range transport from various source regions, J. Geophys. Res.-Atmos., 112, D12302, https://doi.org/10.1029/2006JD007992, 2007.

Sudo, K., Takahashi, M., Kurokawa, J. I., and Akimoto, H.: CHASER: A global chemical model of the troposphere 1. Model description, J. Geophys. Res.-Atmos., 107, ACH 7-1-ACH 7-20, 2002.

Takemura, T., Okamoto, H., Maruyama, Y., Numaguti, A., Higurashi, A., and Nakajima, T.: Global three-dimensional simulation of aerosol optical thickness distribution of various origins, J. Geophys. Res., 105, 17853-17873, 2000.

Taketani, F., Kanaya, Y., and Akimoto, H.: Kinetics of heterogeneous reactions of $\mathrm{HO}_{2}$ radical at ambient concentration levels with $\left(\mathrm{NH}_{4}\right)_{2} \mathrm{SO}_{4}$ and $\mathrm{NaCl}$ aerosol particles, J. Phys. Chem. A, 112, 2370-2377, 2008.

Taketani, F., Kanaya, Y., and Akimoto, H.: Heterogeneous loss of $\mathrm{HO}_{2}$ by $\mathrm{KCl}$, synthetic sea salt, and natural seawater aerosol particles, Atmos. Environ., 43, 1660-1665, 2009.

Taketani, F., Kanaya, Y., Pochanart, P., Liu, Y., Li, J., Okuzawa, K., Kawamura, K., Wang, Z., and Akimoto, H.: Measurement of overall uptake coefficients for $\mathrm{HO}_{2}$ radicals by aerosol particles sampled from ambient air at Mts. Tai and Mang (China), Atmos. Chem. Phys., 12, 11907-11916, https://doi.org/10.5194/acp-1211907-2012, 2012.

Thornton, J. A., Jaeglé, L., and McNeill, V. F.: Assessing known pathways for $\mathrm{HO}_{2}$ loss in aqueous atmospheric aerosols: Regional and global impacts on tropospheric oxidants. J. Geophys. Res.-Atmos., 113, D05303, https://doi.org/10.1029/2007JD009236, 2008.

Tie, X., Brasseur, G., Emmons, L., Horowitz, L., and Kinnison, D.: Effects of aerosols on tropospheric oxidants: A global model study, J. Geophys. Res.-Atmos., 106, 22931-22964, 2001.

Villalta, P. W., Lovejoy, E. R., and Hanson, D. R.: Reaction probability of peroxyacetyl radical on aqueous surfaces, Geophys. Res. Lett., 23, 1765-1768, 1996.

Wang, H., Lu, K., Guo, S., Wu, Z., Shang, D., Tan, Z., Wang, Y., Le Breton, M., Lou, S., Tang, M., Wu, Y., Zhu, W., Zheng, J., Zeng, L., Hallquist, M., Hu, M., and Zhang, Y.: Efficient $\mathrm{N}_{2} \mathrm{O}_{5}$ uptake and $\mathrm{NO}_{3}$ oxidation in the outflow of urban Beijing, Atmos. Chem. Phys., 18, 9705-9721, https://doi.org/10.5194/acp18-9705-2018, 2018.

Wang, Z., Wang, W., Tham, Y. J., Li, Q., Wang, H., Wen, L., Wang, $\mathrm{X}$., and Wang, T.: Fast heterogeneous $\mathrm{N}_{2} \mathrm{O}_{5}$ uptake and $\mathrm{ClNO}_{2}$ production in power plant and industrial plumes observed in the nocturnal residual layer over the North China Plain, Atmos. Chem. Phys., 17, 12361-12378, https://doi.org/10.5194/acp-1712361-2017, 2017.

Watanabe, S., Hajima, T., Sudo, K., Nagashima, T., Takemura, T., Okajima, H., Nozawa, T., Kawase, H., Abe, M., Yokohata, T., Ise, T., Sato, H., Kato, E., Takata, K., Emori, S., and Kawamiya, 
M.: MIROC-ESM 2010: model description and basic results of CMIP5-20c3m experiments, Geosci. Model Dev., 4, 845-872, https://doi.org/10.5194/gmd-4-845-2011, 2011.

Xia, M., Wang, W., Wang, Z., Gao, J., Li, H., Liang, Y., Yu, C., Zhang, Y., Wang, P., Zhang, Y., Bi, F., Cheng, X., and Wang, T.: Heterogeneous Uptake of $\mathrm{N}_{2} \mathrm{O}_{5}$ in Sand Dust and Urban Aerosols Observed during the Dry Season in Beijing, Atmosphere, 10, 204, https://doi.org/10.3390/atmos10040204, 2019.
Zheng, B., Tong, D., Li, M., Liu, F., Hong, C., Geng, G., Li, H., Li, X., Peng, L., Qi, J., Yan, L., Zhang, Y., Zhao, H., Zheng, Y., He, K., and Zhang, Q.: Trends in China's anthropogenic emissions since 2010 as the consequence of clean air actions, Atmos. Chem. Phys., 18, 14095-14111, https://doi.org/10.5194/acp-18-140952018, 2018. 